\title{
Energy restriction in childhood, physical activity and risk of breast, prostate and colon cancer
}

Citation for published version (APA):

Dirx, M. J. M. (2002). Energy restriction in childhood, physical activity and risk of breast, prostate and colon cancer. [Doctoral Thesis, Maastricht University]. UM. https://doi.org/10.26481/dis.20020222md

Document status and date:

Published: 01/01/2002

DOI:

10.26481/dis.20020222md

Document Version:

Publisher's PDF, also known as Version of record

\section{Please check the document version of this publication:}

- A submitted manuscript is the version of the article upon submission and before peer-review. There can be important differences between the submitted version and the official published version of record.

People interested in the research are advised to contact the author for the final version of the publication, or visit the DOI to the publisher's website.

- The final author version and the galley proof are versions of the publication after peer review.

- The final published version features the final layout of the paper including the volume, issue and page numbers.

Link to publication

\footnotetext{
General rights rights.

- You may freely distribute the URL identifying the publication in the public portal. please follow below link for the End User Agreement:

www.umlib.nl/taverne-license

Take down policy

If you believe that this document breaches copyright please contact us at:

repository@maastrichtuniversity.nl

providing details and we will investigate your claim.
}

Copyright and moral rights for the publications made accessible in the public portal are retained by the authors and/or other copyright owners and it is a condition of accessing publications that users recognise and abide by the legal requirements associated with these

- Users may download and print one copy of any publication from the public portal for the purpose of private study or research.

- You may not further distribute the material or use it for any profit-making activity or commercial gain

If the publication is distributed under the terms of Article $25 \mathrm{fa}$ of the Dutch Copyright Act, indicated by the "Taverne" license above, 


\title{
Energy restriction in childhood,
} physical activity and risk of breast, prostate and colon cancer

\author{
Miranda Dirx
}


๑ Dirx, Maria Josephina Mathea

Energy restriction in childhood, physical activity and risk of breast, prostate and colon cancer.

Thesis Maastricht University. - with summary in Dutch

ISBN: $90-9015426-4$

Subject headings: early energy restriction/physical activity/energy balance/breast/prostate/colon/cohort studies/epidemiology

Lay-out: Miranda Dirx, UM Epidemiologie, Maastricht

Omslagfoto: Rijksinstituut voor Oorlogsdocumentatie (RIOD)

Production: Datawyse, Maastricht 


\title{
Energy restriction in childhood, physical activity and risk of breast, prostate and colon cancer
}

\author{
PROEFSCHRIFT \\ ter verkrijging van de graad van doctor \\ aan de Universiteit Maastricht, \\ op gezag van de Rector Magnificus, \\ Prof. dr. A.C. Nieuwenhuijzen Kruseman, \\ volgens het besluit van het College van Decanen, \\ in het openbaar te verdedigen op \\ vrijdag 22 februari 2002 om 14.00 uur
}

door

Maria Josephina Mathea Dirx 


\section{Promotor:}

Prof.dr.ir. P.A. van den Brandt

\section{Co-promotores:}

Dr.ir. R.A. Bausch-Goldbohm (TNO-Voeding, Zeist)

Dr. L.H. Lumey (Columbia University, New York)

\section{Beoordelingscommissie:}

Prof.dr. H. Kuipers (voorzitter)

Prof.dr. M.F. von Meyenfeldt

Prof.dr.ir J.C. Seidell (Rijksinstituut voor Volksgezondheid en Milieu, Bilthoven)

Prof.dr. A.L.M. Verbeek (Katholieke Universiteit Nijmegen)

Prof.dr. K.R. Westerterp

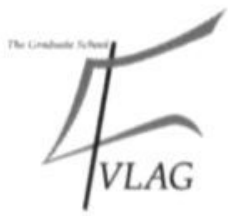

\section{nutrim \\ itutiti}

The study presented in this thesis was performed at the Nutrition and Toxicology Research Institute Maastricht (NUTRIM) which participates in the Graduate School VLAG (Food Technology. Agrobiotechnology. Nutrition and Health Sciences), accredited by the Royal Netherlands Academy of Arts and Sciences.

De druk van dit proefschrift kwam mede tot stand dankzij financiele steun van NOC"NSF, Stichting Nationaal Fonds tegen Kanker.

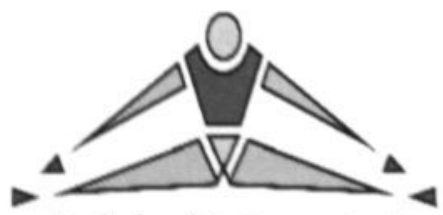

Nederland in Beweing! 


\section{Contents}

Chapter

page

1. Introduction 7

2. Energy restriction and the risk of spontaneous mammary tumors in mice: a meta-analysis (submitted)

3. Diet in adolescence and the risk of breast cancer: results of the Netherlands Cohort Study (Cancer Causes and Control 1999: 10: 189-199)

4. Energy restriction in childhood and adolescence and the risk of prostate cancer: results of the Netherlands Cohort Study (American Joumal of Epidemiology 2001; 154: 530-7)

5. Energy restriction early in life and colon cancer risk: results of the Netherlands Cohort Study after 7.3 years of follow-up (submitted)

6. Baseline recreational physical activity, history of sports participation and post-menopausal breast cancer risk in the Netherlands Cohort Study (Cancer 2001; 92:1638-49)

7. General Discussion

Summary

Samenvatting

Dankwoord

Curriculum Vitae 


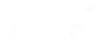

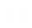

taranana

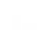

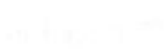

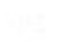

(2)

1 


\section{Introduction}


conoter 1 
In 1995. The Netherlands celebrated the 50th anniversary of the liberation after World War II. At that moment, a research proposal was funded on energy restriction in childhood and adolescence and the risk of breast cancer. This project concentrated on women who were exposed to the Dutch Famine in 1944-45, the War years (1940-44) and the Economic Depression years $(1932-40)$ and their breast cancer risk later in life. The hypothesis relating energy restriction to the risk of breast cancer is supported by longstanding results from animal experiments documenting a reduced risk of breast cancer in rodents on an energy-restricted dietary regimen [1]. And, having worked for four years as a teacher at the Department of Epidemiology at the Maastricht University, I had the opportunity to participate in this PhD-project. This research project utilized the unique setting in the Netherlands, a Western population where a substantial part of the population experienced a severe famine during World War II (1944-45). The Dutch famine can be considered as a unique natural 'experiment of history' to test the hypothesis that energy restriction early in life may be protective for cancer risk later in life.

\section{Evidence from animal experiments and human studies}

Since Rabagliatti [2] concluded in 1904 that "overfeeding is the predisposing cause of cancer", restriction of total energy intake has been shown over decades of research to be one of the most powerful nutritional interventions capable of lowering cancer rates in laboratory animals [3-6]. Although lifelong dietary restriction has had the greatest impact, reduced food consumption during early development also effectively inhibits tumorigenesis [7, 8]. Most studies have tested energy restriction imposed early in life. Energy restriction started in mid adulthood retards cancer and might possible retards ageing. Energy restriction without malnutrition in mice and rats reduces the incidence of spontaneous and chemically induced tumors and delays their appearance while increasing maximum life span [6, 9, 10]. Energy restriction without malnutrition means energy intake restriction without essential nutrient deficiency. In animal research, the essential nutrients (fat, protein and carbohydrates) are provided in balanced amounts while restricting calorie intake to a range $30-70 \%$ below the ad libitum level [6].
In this thesis, the early energy restriction hypothesis has been investigated with respect to three sites, namely breast, prostate and colon cancer. We have focused on these three cancer sites for several reasons. From rodent experiments energy restriction showed a protective effect regarding these three sites Furthermore, breast cancer is the most frequent cancer in women, prostate cancer is the second most commonly diagnosed cancer in males after lung cancer and colon cancer is the fourth most common cancer worldwide [11, 12] Furthermore, it seems as if breast, colon and prostate cancer have some possible risk factors in common which are related to, or show an interaction with early energy intake.

Rodent models for breast cancer provide extensive data on effects of dietary fat and calories [13-15], energy balance, body weight gain, and physical activity on mammary tumor development [16-18]. It has been shown that energy restriction decreased mammary carcinogenesis in several murine models. whether spontaneous, transplanted or chemically induced tumors [19-22]. Energy restriction appeared to counteract the promoting effect of fat and seems effective whatever the proportion of fat in the diet is $[20,23]$. A study by Gillette et al. [18] analyzed the effect of energy restriction and physical activity in a rat model of chemically induced mammary carcinogenesis. Only energy restriction inhibited mammary tumor development. The unrestricted exercised rats lost weight but the tumor incidence was as high as in the sedentary unrestricted rats. Thus. the results of the animal studies show that the protective effect on mammary carcinogenesis depend largely on energy restriction per se, and not on low intakes of fat, carbohydrates or other nutrients.

Studies of dietary influences on carcinogenesis in the prostate await development of satisfactory animal models [24, 25]. However, animal studies have been conducted on the effect of a high fat diet on prostate cancer. Kondo et al. [26] investigated the effect on prostatic carcinogenesis of two-generation exposure to a high-fat diet using $\mathrm{ACl} / \mathrm{Seg}$ rats, a strain with high incidence of spontaneous prostate cancer. A high-fat diet ( $20 \%$ corn oil) or a low-fat diet $(5 \%$ corn oil) was given to mother rats during pregnancy and the newborn male rats were fed the same diets for 60 or 100 weeks after 
weaning. There was a significant increase of atypic hyperplasia in the high-fat diet group. These results showed that feeding a high-fat diet before conception and from the beginning of life had a marked promotional effect on the early stage of prostate carcinogenesis in rats. Mukherjee et al. [27] compared ad libitum fed rats with rats whose energy intake was restricted by $30 \%$ using three different methods. i.e., total diet restriction, carbohydrate restriction or fat restriction. They concluded that energy restriction reduces prostate tumor growth by inhibiting tumor angionesis. Furthermore, dietary fat and carbohydrates did not influence prostate tumor growth when energy intake was reduced.

In male and female rodents, studies have shown that chemically induced adenocarcinoma of the colon are strongly inhibited in energy-restricted rodents [28, 29], but enhancement has not been as consistently demonstrable as in the mammary gland. Kumar et al. [30] have documented a dose-dependent effect of calories on induced colon carcinogenesis in male F344 rats. Kritchevsky's study demonstrated that the tumor-reducing effect of energy restriction dominates even if the fat intake increases during energy restriction [31]. Albanes et al [32] conducted a study to examine the effect of early energy restriction on the total number of colonic cells and the total number of dividing cells in the colon. The food-restricted animals were shorter, had smaller colons with fewer cells and the total number of dividing cells was reduced. Another study by Steinbach [33] was conducted to investigate the effect of energy restriction on colonic cell proliferation in carcinogen-treated rats, an intermediate marker of colon cancer risk. They concluded that energy restriction reduced the colonic cell proliferation.

\section{Biological mechanisms}

The way(s) by which energy restriction impedes cancers remain unclear, but possibilities include less cellular oxidative damage, retarded immunologic ageing, hormonal changes, less energy available for cell proliferation, reduced exposure to dietary carcinogens and promoters, enhanced DNA repair, and less carcinogen activation [34-37]. Candidate mechanisms also include greater exposure to mitogenic factors such as growth hormone, insulin, insulin-like growth factor, and sex steroids that could result from accelerated maturation mediated by the hypothalamic-pituitary axis [38-43].

Recently. Thompson et al. [44] stated that energy restriction exerts its effect by altering one or more aspects of cell cycle regulation. In their experiments, they used a short-term animal model for mammary carcinogenesis. It was observed that energy restriction inhibited cell proliferation and increased cell death due to apoptosis. It was hypothesized that energy restriction inhibits carcinogenesis, at least in part, by delaying cell cycle progression. There are also indications that corticosteroids, which are produced in increased amounts in response to energy restriction, may by involved in mediating this effect [44].

With respect to colon tumor carcinogenesis the mechanism of insulin resistance is often mentioned. Insulin resistance is a condition in which higher levels of insulin are needed to normalize plasma glucose. The mechanism begins with the excess dietary energy provided by an energy rich diet. This excess energy elevates the intravascular levels of insulin and energy substrates. This stimulates cell-signaling pathways to increase the proliferation. The effects are widespread throughout the colon and elsewhere in the body $[38,39,41]$

In humans, a lot of research has been conducted on diet and cancer risk. However, the relation between energy restriction and cancer risk is not so often investigated. Especially fat intake has been investigated extensively and has been related to breast, prostate and colon prostate cancer. The studies that have evaluated nutrients have failed to find a specific effect of energy intake over dietary fat and above the effect of other nutrients such as carbohydrates or proteins. Case-control studies often showed a positive association between fat intake and breast, prostate and colon cancer risk [45-56]. Results from prospective cohort studies were not as consistent and often showed no association [52, 57-66].

With respect to energy restriction early in life and subsequent cancer risk only a few studies have been conducted although suggestions have been stated that early life exposures (such as early energy intake) might play an important role in tumor carcinogenesis $[67,68]$ 


\section{The Netherlands Cohort Study}

The Netherlands Cohort Study on diet and cancer (NLCS) provided a unique opportunity to study the relation between early energy restriction and subsequent cancer risk. This study started in 1986, when a cohort of 58.279 men and 62.573 women, aged 55-69 years, was recruited from 204 municpal population registries in the Netherlands [69]. The baseline questionnaire was mailed to the participants in 1986 and information was collected about the nutritional habits of the cohort and various life style factors (smoking, physical activity), medical history, anthropometry, occupation, education. and reproductive history. The cohort is being followed up for cancer incidence by using annual computerized record linkage of the cohort to the nine regional cancer registries and PALGA, a national database of pathology records. For data processing and analysis, the case-cohort approach is being used: the cases are enumerated for the entire cohort, while the person-years at risk accumulating in the cohort are estimated from a random sample (subcohort). This subcohort of 3500 subjects (1688 men, 1812 women) was sampled from the entire cohort immediately after the baseline measurement.

With the unique nutritional situation experienced by this cohort during World War II in mind, the NLCS also collected information on the food situation during childhood and adolescence of the cohort members. In the baseline questionnaire, information was collected about their residence during the Hunger winter (1944$45)$, their residence during the War years (194044 ) and if their father was employed during the Economic Depression years (1932-40). Residence history and father's employment status were used as proxy measures for the energy restriction to which the participants of the cohort were exposed during their childhood and adolescence. The cohort members were born between 1916 and 1931. In World War II, the cohort members were nine years and older. In the following paragraph the food situation will be described during the years 1932-1945.

\section{Food restriction during the period 1932-1945 Economic Depression (1932-40)}

During 1930-1939 the Great Depression also affected the Netherlands. A high number of people were unemployed during this period, varying from 10 to 13 percent (CBS 1947). Several nutritional surveys were conducted to get insight into the nutritional status of the unemployed [70-73]. The results showed that in the food pattern of the unemployed families there was little variation and that the amount of calories was sufficient, but not at the same level as the employed people. Employed persons, like laborers, peasant proprietors and white-collar workers had in this period a mean daily intake of 3500 calories. The energy providing nutrients for the employed persons had the following contribution to the amount of total calories: 45 energy $\%$ carbohydrates, 40 energy $\%$ fat and 15 energy $\%$ of protein [74].

The government undertook some actions to help the unemployed families to improve their nutritional status (e.g. distribution of school milk). From the surveys, it was concluded that there was enough food available during this period although the fat intake in the Economic Depression years was less compared to the present consumption of energy $\%$ fat $(30 \%$ vs. $40 \%$ ) [75].

War years (1940-44)

During the War period the food supply was based on the food rationing system. In 1937 the Government Office for the Food Supply in Time of War had already begun preparing in view of the possibility that the Netherlands might be neutral, isolated or occupied; plans were made to adjust agricultural production for each contingency and to introduce a system of rationing. The government started with the food rationing in October 1939. Sugar was the first food product that was only available by ration cards. All the food products were distributed among the whole Dutch population by way of ration cards. The Dutch population was divided in certain groups. These groups received differend amountsof rations related to their work. performance and age (Pols committee 1953) [76].

Consumers of 20 years or older, doing no heavy work, were at first allowed about 3000 calories per day. As early as 1940, this level decreased but stabilized during the years 1941-1943 at about 1700 calories a day. Virtually all foods were rationed from April 1941 onwards. During 1943-1944 the nutritional status of the Dutch population deteriorated $[76,77]$. The level of the rations declined further because of the bad 
harvest in 1943 and because people could get less food products, in particular in the cities. Many persons received some extra supplies by using the Central Kitchens and through illegal transport of food products [76, 78]. In 1944, the average allowance was lowered to 1600 calories, an average maintained with difficulty until September 1944. A few persons got some extra food through their own supply or they bought some products from the farmers. Many persons bought some extra food products on the black market. In the rural areas there was still enough food available during these four years. The food supply situation in the cities deteriorated much faster than in the rural areas.

\section{The Dutch Famine 1944-45}

In the Netherlands, the food production areas were mainly concentrated in the Northeastern and Southern part of the country during the War period. In the Western part of the country, a quarter of the Dutch population lived in seven large cities that were dependent on the food production areas for food supplies.

In the autumn of 1944 the Dutch government-inexile in London asked local resistance groups to help the allied offensive by sabotage activities to hinder the German army. On September 17. 1944 a general transportation strike began in the Netherlands against the Germans at the request of the Dutch government. In reprisal the German occupying forces imposed an embargo on all transport and food supplies to the West [78]. The food storages from the Northeast and the South could not be transported to the Western part of the country. The strike held for the entire period until liberation in May 1945. During this period, the so-called Hunger winter, little or no food was transported into the major cities in the Western part of the country. As a result the rations declined further in the Western region and in November 1944 the rations for a normal manual worker dropped to 1000 calories. The only way of transport was by boat but after the frost set in (December 23rd 1944) shipping was impossible because of the frozen canals [78]. In January and February 1945 the rations declined further until 450-500 calories a day for a normal consumer with no heavy labor. In February 1945 the rations were $15 \mathrm{~g}$ protein, $4 \mathrm{~g}$ fat and $100 \mathrm{~g}$ carbohydrates a day. Thus, the allocated rations were very inadequate with regard to the caloric value and the relative contribution of the several nutrients, especially fat, was very low. The situation in the Hunger winter was much worse in Western cities compared to the rural areas in the Western part of the country [79, 80]. By the end of April 1945 the food situation in the Western part of the country was considered hopeless. The available ration stocks were sufficient for only a few more days, without any prospect of new supplies.

The differences in food availability in the Netherlands comparing the Western part to the rest of the country were very clear in the Hunger winter. In the Northeastern part of the country there was no famine because it was a production area. The southern part of the Netherlands had already been liberated in September 1944. Compared to the rest of the country the amount of calories was very low in the Western part of the country during 1944-45 [81]. The exact rations are different in the different publications about the rationing system during the Hunger winter 1944-45, ranging from 450 to 900 calories [78, 82].

The Dutch Famine led in a short time to severe consequences to public health, which can be distinguished in short and long-term effects. Short-term effects concerned an increase in the number of cases of tuberculosis and an increase in infant mortality. The infant mortality rose by 50 percent to 80 per 1,000 live births in 1945 . Hunger edema was seen daily in the practice of the general practitioner $[79,80]$. Five percent of the total population of the Western region was in a serious state of under nutrition at the end of the war.

The long-term consequences of the Dutch Famine are related to reproductive outcomes of women who gave birth during and after the Hunger winter and were exposed to the famine. These consequences refer to lower birth weight, malformations and perinatal mortality of the newborn and also to the medical and psychological situation of infants born during the famine [83-85]. Several studies determined whether prenatal exposure to severe famine was associated with an increased risk of affective disorders [81, 86, 87]. The results showed an increased risk of psychoses and schizophrenia among persons exposed prenatal to famine. Recently, studies have been conducted that showed positive associations between prenatal exposure to the Dutch famine and obesity risk in later life, glucose tolerance risk and risk of cardiovascular disease [88, 89]. These finding have recently been critically reviewed [90]. 


\section{Energy restriction as a component of energy balance}

Energy balance results from the interaction between energy intake and energy expenses. Food (including alcohol) provides the energy intake, while basal metabolism, thermogenesis and physical activities are responsible for the expenses [91]. An unfavorable energy balance as a whole (i.e., physically inactive, a high energy intake and a high body mass index (BMI)) may be an important risk factor for certain cancers. In Western societies, energy imbalance is characterized by obesity and sedentary life styles and is associated with increased morbidity and mortality from all causes of cancer. This concept may equally well apply to breast, prostate and colon cancer. The interaction between energy restriction, physical activity and BMI may explain part of the observed inconsistencies between studies on physical activity and these cancers [92-96]

Physical activity itself has been associated with a lower risk of breast, prostate and colon cancer risk. Most of the case-control studies on recreational physical activity and breast cancer [97-102] have reported an inverse association. The cohort studies on physical activity and breast cancer risk showed inconclusive results. Three cohort studies reported that recreational exercise reduced the risk of developing breast cancer [103-105]. No association was reported in three other cohort studies [106-108].

Case-control studies on physical activity and prostate cancer risk showed inconsistent results. The studies that showed a protective effect had risk reduction ranging from 20-70\% [109-114]. Others found no protection or an elevated risk in individuals who engaged in the highest level of activity [53, 115]. Seven cohort studies showed reduction in prostate risks ranging from $10-80 \%$, comparing the highest vs. lowest level of physical activity [106, 116-120].

Studies on the relation between occupational and/or leisure time physical activity and colon cancer in both men and women showed a consistent inverse relation. Subjects in the highest category of physical activity appear to have a 40 to 50 percent reduction in risk of colon cancer, compared to the least active group [95, 121]. Cohort studies are less consistent in showing a decreased risk of colon cancer with higher physical activity [122-125]. Limited data exist on the interaction between physical activities, energy intake and body size with respect to colon cancer. In a large case control study, the greatest risk for colon cancer was found in subjects with the most unfavourable energy balance, defined by physical inactivity, high-energy intakes and a large BMI. In physically active subjects however. a high-energy intake and a large BMI did not result in a significant increase of colon cancer risk (Slattery, 1997).

The results also seem to vary according to subtypes of these cancers. Furthermore, it is still not clear for breast, prostate and colon cancer what type, level and duration of physical activity are required to afford protection. A positive energy balance during development may led to a higher subsequent risk of malignancy not only through increased cumulative cell proliferation but also by expanding organ specific stem cell populations [126]

A review of studies on the influence of physical activity or exercise on the incidence of mammary-gland carcinogenesis in rats concluded that there is consistent evidence that exercise reduces tumor incidence by more than $50 \%$ and increases tumor latency [17]. From studies in rats on the effects of energy balance on mammary gland tumorigenesis, using either exercise to increase energy expenditure or diet restriction to reduce intake, it has been reported that adrenal corticosteroid responses to exercise or diet restriction, rather than energy balance per se are responsible for reducing tumorigenesis [18, 127]. Differences in physical activity represent the biggest source of variability in energy requirements, both within and between individuals, and thereby influence the net available energy.

\section{Outline of the thesis}

The main topic of this thesis is the relation between energy restriction in childhood and adolescence and the risk of breast, prostate and colon cancer later in life. Results of a metaanalysis on energy restriction and the risk of spontaneous mammary tumors in mice are described first (chapter 2). Thereafter, our findings of the epidemiological studies regarding possible associations between exposure to energy restriction in childhood and adolescence and incidence of three different cancer sites (breast, prostate and colon cancer) are presented (chapter 3, 4 and 5). In chapter 6. another component of energy balance, namely 
physical activity, is studied in relation to breast cancer risk.

Finally, the results of the different studies are discussed in chapter 7 and implications for further research will be stated.

\section{References}

1. Albanes D: Caloric intake, body weight, and cancer: a review. Nutr Cancer 1987: $9: 199-217$

2. Rabagliatti A: Air, food and exercises, an essay on the predisposing causes of disease, 3rd ed. London: Bailliere. Tindall and Cox, 1904

3. Rous $P$. The influence of diet on transplanted and spontaneous mouse tumors. J Exp Med 1914, 20 433-351

4. Tannenbaum A: The genesis and growth of tumors. effects of a high fat diet. Cancer Research 1942: 2 468-75

5. Tannenbaum A: The dependence of tumor formation on the composition of the calorie restricted diet as well as on the degree of restriction. Cancer Research 1945a, 5(11) 616-25

6. Weindruch R. Walford RL. The retardation of aging and disease by dietary restriction. Springfield Charis C. Thomas. 1988 (Weindruch R, Walford RL, eds 7. Engelman RW, Day NK, Good RA: Calorie intake during mammary development influences cancer risk: lasting inhibition of $\mathrm{C} 3 \mathrm{H} / \mathrm{HeOu}$ mammary tumorigenesis by peripubertal calorie restriction. Cancer Reserach 1994; 53: 5724-30.

8. Silverman J, Powers J, Stromberg P. Pultz JA, Kent S: Effects on $\mathrm{C} 3 \mathrm{H}$ mouse mammary cancer of changing from a high fat to a low fat diet before, at, or after puberty. Cancer Res 1989; 49(14): 3857-60.

9. Weindruch R, Albanes D, Kritchevsky D. The role of calories and caloric restriction in carcinogenesis. Hematology oncology clinics of North America 1991; 5(1): $79-89$

10. Albanes D Total calories, body weight, and tumor incidence in mice. Cancer Research 1987: 47: 19871992

11. Fund WCR: Food, nutrition and the prevention of cancer: a global perspective: American Institute for Cancer Research, 1997

12. Visser O, Coebergh JWW. Schouten LJ, Van Dijck JAAM Incidence of cancer in the Netherlands, 1995 Utrecht Vereniging van Integrale Kankercentra, 1998

13. Tannenbaum A. The dependence of tumor formation on the degree of caloric restriction. Cancer Research 1945b, 5(11): 609-15

14. Sarkar NH, Fernandes G. Telang NT. Kourides IA, Good RA Low-calorie diet prevents the development of mammary tumors in $\mathrm{C} 3 \mathrm{H}$ mice and reduces circulating prolactin level, murine mammary tumor virus expression, and proliferation of mammary alveolar cells. Proc Natl Acad Sci. 1982; 79: 7758-62. 15. Engelman RW, Day NK, Chen RF, et al: Calorie consumption level influences development of $\mathrm{C} 3 \mathrm{H} / \mathrm{Ou}$ breast adenocarcinoma with indifference to calorie source. Proc Soc Experimen Biol Med 1990; 193 : 23 30.

16. Thompson HJ, Ronan AM, Ritacco KA, Tagliaferro AR, Meeker LD: Effect of exercise on the induction of mammary carcinogenesis. Cancer Research 1988, 48: 2720-3

17. Thompson $\mathrm{HJ}$ : Effects of physical activity and exercise on experimentally-induced mammary carcinogenesis. Breast Cancer Res Treat 1997; 46(2-

3): $135-41$

18. Gillette CA, Zhu Z, Westerlind KC, Melby CL. Wolfe P. Thompson $\mathrm{HJ}$ : Energy availability and mammary carcinogenesis: effects of calorie restriction and exercise. Carcinogenesis 1997; 18(6): 1183-8.

19. Tannenbaum $A$. The initiation and growth of tumors. Am J Cancer 1940; 38: 335-350

20 Kritchevsky D, Weich CB, Klurfeld DM: Response of mammary tumors to caloric restriction for different time periods during the promotion phase. Nutrition and cancer 1989, 12(3): 259-69

21. Weisch CW. House JL, Herr BL. Eliasberg SJ, Weisch MA Enhancement of mammary carcinogenesis by high levels of dietary fat: a phenomenon dependent on ad libitum feeding [see comments] J Nati Cancer Inst 1990, 82(20): 1615-20. 22. Welsch CW Interrelationship between dietary lipids and calories and experimental mammary gland tumorigenesis. Cancer 1994; $74: 1055-1062$.

23. Pariza MW Dietary fat, calorie restriction, ad libitum feeding. and cancer risk. Nutr Rev 1987: 45(1): $1-7$

24. Rose DP: Dietary fatty acids and prevention of hormone-responsive cancer. Proc Soc Exp Biol Med 1997a; 216(2): 224-33.

25. Rose DP: Effects of dietary fatty acids on breast and prostate cancers: evidence from in vitro experiments and animal studies. Am J Clin Nutr 1997d; 66(6 Suppl): 1513s-1522s

26. Kondo $\mathrm{Y}$, Homma $\mathrm{Y}$, Aso $\mathrm{Y}$, Kakizoe $\mathrm{T}$ : Promotional effect of two-generation exposure to a high-fat diet on prostate carcinogenesis in ACI/Seg rats. Cancer Res 1994; 54(23): 6129-32.

27. Mukherjee P, Sotnikov AV, Mangian HJ, Zhou JR, Visek WJ. Clinton SK: Energy intake and prostate tumor growth, angiogenesis, and vascular endothelial growth factor expression [see comments] J Natl Cancer Inst 1999; 91(6): 512-23

28. Kritchevsky D Colorectal cancer: the role of dietary fat and caloric restriction. Mutat Res 1993; 290(1): 63-70

29. Newberne PM. Nauss KM: Dietary fat and colon cancer; variable results in animal models. In: Ip C, Birt DF. Rogers $A E$, et al., eds. Dietary fat and cancer. New York: Liss, $1986,311-330$

30. Kumar SP, Roy SJ. Tokumo K, Reddy BS. Effect of different levels of calorie restriction on azoxymethane-induced colon carcinogenesis in male F344 rats Cancer research 1990: 50(18): 5761-6

31. Kritchevsky D Influence of caloric restriction and exercise on tumorigenesis in rats. Proceedings of the 
Society for Experimental Biology and Medicine 1990; 193(1): $35-8$

32. Albanes D, Salbe AD, Levander OA, Taylor PR, Nixon DW. Winick M: The effect of early caloric restriction on colonic cellular growth in rats. Nutr Cancer 1990: 13(1-2): 73-80.

33. Steinbach G, Kumar SP. Reddy BS, Lipkin M. Holt PR. Effects of caloric restriction and dietary fat on epithelial cell proliferation in rat colon. Cancer research 1993; 53(12): 2745-9

34. Weindruch $R$. Effect of caloric restriction on ageassociated cancers. Experimental gerontology 1992 : 27(5-6): 575-81

35. Ross RK. Henderson BE: Do diet and androgens alter prostatecancer risk via a common etiologic pathway? JNCI 1994: 86: 252-4 (editorial)

36. Ross $\mathrm{MH}$, Bras $\mathrm{G}$ : Lasting influence of early caloric restriction on prevalence of neoplasmsm in the rat J Natl Cancer Inst 1971; 47(5): 1095-1103.

37. Waard de F. Trichopoulos D: A unifying concept of the etiology of breast cancer. Int J Cancer 1988; 41: 666-669

38. Giovannucci $\mathrm{E}$ : Insulin and colon cancer. Cancer causes and control 1995, 6(2): 164-79

39. Bruce WR. Wolever TMS, Giacca A: Mechanisms linking diet and colorectal cancer: the possible role of insulin resistance. Nutr Cancer 2000; 37: 19-26.

40. Bruce WR, Giacca A, Medline A: Possible mechanisms relating diet and risk of colon cancer. Cancer Epidem Biomarkers Prevention 2000; 9: 1271-1279.

41. McKeown-Eyssen G: Epidemiology of colerectal cancer revisited: are serum triglycerides and/or plasma glucose associated with risk? Cancer Epidemiol Biom Prev 1994; 3: 687-95.

42. Ballard-Barbash R, Forman MR, Kipnis V: Dietary fat, serum estrogen levels and breast cancer risk: a multifaceted story. J Natl Cancer Inst 1999; 91: 492-4. 43. Barrett Connor E, Garland C, McPhillips JB, Khaw KT, Wingard DL: A prospective, population-based study of androstenedione, estrogens, and prostatic cancer. Cancer Res 1990; 50(1): 169-73.

44. Thompson HJ, Jiang W. Zhu Z: Mechanisms by which energy restriction inhibits carcinogenesis. Advances in experimental medicine and biology 1999 ; 470: 77-84.

45. Carroll KK: Dietary fat and breast cancer. Lipids 1992; $27(10): 793-7$

46. Katsouyanni K. Trichopoulou A, Stuver S, et al: The association of fat and other macronutrients with breast cancer: a case-control study from Greece. Br J Cancer 1994; 70(3): 537-41.

47. Potischman N. Swanson CA, Coates RJ, et al: Dietary relationships with early onset (under age 45) breast cancer in a case-control study in the United States: influence of chemotherapy treatment. Cancer Causes Control 1997: 8(5): 713-21.

48. Rohan TE, McMichael AJ, Baghurst PA: A population-based case-control study of diet and breast cancer in Australia. Am J Epidemiol 1988; 128(3): 478-89.
49. Veer van T P. Kolb CM, Verhoef $P$, et al: Dietary fiber, beta-carotene and breast cancer results from a case-control study. Int J Cancer 1990; 45(5): 825-8

50. Slattery ML. Caan BJ, Potter JD, et al: Dietary energy sources and colon cancer risk. Am J Epidemiol 1997; 145(3): 199-210.

51. Franceschi S, La Vecchia C, Russo A. et al: Macronutrient intake and risk of colorectal cancer in Italy. Int J Cancer 1998; 76(3): 321-4

52. Giovannucci E, Goldin B. The role of fat, fatty acids. and total energy intake in the etiology of human colon cancer. Am J Clin Nutr 1997, 66(6 Suppl): 1564s-1571s

53. West DW. Slattery ML. Robison LM. French TK. Mahoney AW Adult dietary intake and prostate cancer risk in Utah a case-control study with special emphasis on aggressive tumors. Cancer Causes Control 1991: 2(2): 85-94

54. Andersson SO, Baron J., Bergstrom R. Lindgren C. Wolk A. Adami HO Lifestyle factors and prostate cancer risk a case-control study in Sweden. Cancer Epidemiol Biomarkers Prev 1996, 5(7) :509-513

55. Tzonou A, Signorello LB, Lagiou P. Wuu J. Trichopoulos D. Trichopoulou A. Diet and cancer of the prostate: a case-control study in Greece Int J Cancer 1999: 80(5) 704-8

56. Rohan TE, Howe GR, Burch JD, Jain M Dietary factors and risk of prostate cancer a case-control study in Ontario. Canada. Cancer Causes Control 1995; 6(2): 145-54.

57. Santiago E, Gonzalez MJ, Matos MI, Perez CM: Dietary fat and breast cancer a brief update on current knowledge. P R Health Sci J 1998, 17(3): 273-9.

58. Clavel Chapelon F, Niravong M, Joseph RR: Diet and breast cancer review of the epidemiologic literature. Cancer Detect Prev 1997: 21(5): 426-40.

59. Willett WC: Fat, energy and breast cancer. J Nutr 1997; 127(5 Suppl): 921s-923s

60. Hunter DJ, Spiegelman D, Adami HO, et al: Cohort studies of fat intake and the risk of breast cancer - a pooled analysis [see comments]. N Engl J Med 1996; 334(6): 356-61

61. Van den Brandt PA, Van 't Veer P. Goldbohm RA, et al: A prospective cohort study on dietary fat and the risk of postmenopausal breast cancer. Cancer Res 1993: 53(1): 75-82.

62. Schuurman AG, Van den Brandt PA, Dorant E, Brants HAM, Goldbohm RA: Associations of energy and fat intake with prostate carcinoma risk. Results from the Netherlands Cohort Study. Cancer 1999, 86 : 1019-1027.

63. Giovannucci E, Rimm EB, Colditz GA, et al: A prospective study of dietary fat and risk of prostate cancer. J Natl Cancer Inst 1993; 85(19): 1571-1579. 64. Veierod MB, Laake P. Thelle DS: Dietary fat intake and risk of prostate cancer: a prospective study of 25,708 Norwegian men. Int J Cancer 1997; 73(5): $634-8$

65. Giacosa A, Franceschi S, La Vecchia C. Favero A. Andreatta R Energy intake, overweight, physical 
exercise and colorectal cancer risk. European journal of cancer prevention 1999: 8 Suppl 1: S53-60.

66. Goldbohm RA, Van den Brandt PA, Van 't Veer P. et al: A prospective cohort study on the relation between meat consumption and the risk of colon cancer. Cancer Res 1994: 54(3): 718-23

67. Colditz GA. Frazier AL: Models of breast cancer show that risk is set by events of early life: preventions efforts must shift focus. Cancer, Epidemiology, biomarkers \& prevention 1995; 4 : 567 .

71

68. Albanes D Height, early energy intake and cancer BMJ 1998, 317: 1331-2

69. Van den Brandt PA, Goldbohm RA, Van 't Veer P. Volovics A. Hermus, R.J.J., Sturmans F: A large scale prospective cohort study on diet and cancer in the Netherlands J Clin Epidemiol 1990; 19 . 285-95

70. Ten Bokkel Huinink SA. De voeding van de gezonde en zieke werkloozen; 1936

71. Tromp MH De voeding in het gezin van den werklooze. Ned T Geneesk 1934. 78 . 5388-99

72 Kastein GW De voeding van 343 werkloozengezinnen in Rotterdam en Schiedam in de wintermaanden van 1934-1935. Ned T Geneesk 1935, 79 .5583-7

73. Eijkel C Voeding. gezondheid en financiele toestand van 700 werkloozen gezinnen, deel I en II. The Hague: Algemene Landsdrukkerij, 1940.

74. Reith JF, Gorter A: De Nederlandse voedingsenquetes. Voeding 1948; 9: 81-105

75. Moss $\mathrm{NH}$, Mayer J. Food and nutrition in health and disease. New York: New York Academy of Sciences, 1977

76. Dols MJL. Van Arcken AJM De voedselvoorziening in Nederland tijdens en onmiddelijk na den tweeden wereldoorlog 1940-1945. Voeding 1946; $6: 193-207$

77. Breunis J: The food supply. Ann Am Acad Pol Soc Sci 1946; $245 ; 87-92$

78. Trienekens GMT: Between Us and starvation (Tussen ons volk en de honger, de voedselvoorziening 1940-1945). Wageningen

Agriculter University: 1985

79. Burger GCE. Sandstead HR. Drummond J Starvation in Western Holland: 1945 . Lancet 1945; ii: 282-3

80. Burger GCE, Drummond JC, Sandstead HR Malnutrition and starvation in Western Netherlands. September 1944-July 1945. The Hague: The hague General State Printing Office, 1948

81. Stein Z, Susser M, Saenger G, Marolla F: Famine and human development, the Dutch Hunger winter of 1944-1945 New York: Oxford University Press. 1975 82. Neumann $\mathrm{H}$ De samenstelling van de rantsoenen in West-Nederland van augustus 1944 tot en met april 1945. Voeding 1945; $6: 78-83$

83. Lumey LH: Decreased birthweights in infants after maternal in utero exposure to the Dutch famine of 1944-1945. Paediatr Perinat Epidemiol 1992: 6(2): 240-53
84. Lumey LH, Ravelli AC. Wiessing LG, Koppe JG, Treffers PE, Stein ZA: The Dutch famine birth cohort study: design, validation of exposure, and selected characteristics of subjects after 43 years follow-up. Paediatr Perinat Epidemiol 1993: 7(4): 354-67.

85. Lumey LH, Stein AD, Ravelli AC: Timing of prenatal starvation in women and birth weight in their first and second born offspring: the Dutch Famine Birth Cohort study. Eur J Obstet Gynecol Reprod Biol 1995: 61(1): 23-30

86. Brown AS. Susser ES, Lin SP. Neugebauer R. Gorman JM: Increased risk of affective disorders in males after second trimester prenatal exposure to the Dutch Hunger winter of 1944-45. Br J Psychiatry 1995: $166: 601-606$

87. Susser ES, Lin SP. Schizophrenia after prenatoal exposure to the Dutch Hunger Winter of 1944-45 Arch Gen Psychiatry 1992: 49: 983-988.

88. Ravelli ACJ: Prenatal exposure to the Dutch famine and clucose tolerance and obesity at age 50 University of Amsterdam: 1999

89. Roseboom TJ Prenatal exposure to the Dutch famine and health later in life. University of Amsterdam; 2000

90. An overstretched hypothesis? Lancet. Feb 2001: 357(9254): 405

91. Gerber M, Corpet D: Energy balance and cancers. Eur J Cancer Prev 1999; 8: 77-89.

92. Slattery ML, Potter J, Caan B, et al: Energy balance and colon cancer--beyond physical activity Cancer Res 1997: 57(1): 75-80

93. Shoff SM, Newcomb PA, Ytentham-Dietz A, et al. Early life physical activity and postmenopausal breast cancer: effect of body size and weight change. Cancer Epidemiol Biomarkers Prev 2000; 9: 591-5.

94. McTiernan A: Associations between energy balance and body mass index and risk of breast carcinoma in women from diverse racial and ethnic backgrounds in the U. Cancer 2000; 88(5 Suppl): 1248-55

95. McTiernan A, Ulrich C, Slate S, Potter J: Physical activity and cancer etiology: associations and mechanisms. Cancer Causes Control 1998: 9: 487 509

96. Hoffman Goetz L, Apter D, Demark Wahnefried W. Goran MI, McTiernan A. Reichman ME: Possible mechanisms mediating an association between physical activity and breast cancer. Cancer 1998; 83(3 Suppl): $621-8$

97. Bernstein L, Henderson BE, Hanisch R, Sullivan Halley J. Ross RK: Physical exercise and reduced risk of breast cancer in young women [see comments]. J Natl Cancer Inst 1994: 86(18): 1403-8.

98. D'Avanzo B. Nanni O. LaVecchia C. et al Physical activity and breast cancer risk. Cancer Epidemiol Biomarkers Prev 1996; $5: 155-60$

99. Friedenreich CM, Rohan TE Physical activity and risk of breast cancer. Eur J Cancer Prev 1995; 4(2) 145-51.

100. McTiernan A, Stanford JL. Weiss NS, Daling JR, Voigt LF Occurrence of breast cancer in relation to 
recreational exercise in women age 50-64 years. Epidemiology 1996, 7(6): 598-604

101. Mittendorf R, Longnecker MP, Newcomb PA, et al: Strenuous physical activity in young adulthood and risk of breast cancer (United States). Cancer Causes Control 1995; 6(4): 347-53.

102. Taioli E. Barone J, Wynder EL: A case-control study on breast cancer and body mass. The American Health Foundation-Division of Epidemiology Eur J Cancer 1995; 31a(5): 723-8

103 Chen $\mathrm{CL}$. White E, Malone KE, Daling JR: Leisure-time physical activity in relation to breast cancer among young women (Washington, United States). Cancer Causes Control 1997; 8(1): 77-84 104 Frisch RE, Wyshak G. Albright NL, et al: Lower prevalence of breast cancer and cancers of the reproductive system among former college athietes compared to non-athletes. Br.J Cancer 1985. 52: 88591

105. Thune I: Physical activity and energy balance. modifiable lifestyle factors for breast cancer? Irish Medical Journal 1997; 90 : 168-70

106 Albanes D, Blair A, Taylor PR. Physical activity and risk of cancer in the NHANES I population. Am J Public Health 1989; 79(6): 744-50

107. Paffenbarger RS, Hyde RT, Wing AL: Physical activity and incidence of cancer in diverse populations: a preliminary report. Am.J.Clin. Nutr. $1987 ; 45: 312-7$.

108. Rockhill B. Willett WC, Hunter DJ, et al. Physical activity and breast cancer risk in a cohort of young women [see comments]. J Natl Cancer Inst 1998; 90(15): 1155-60.

109. Andersson SO, Baron J, Wolk A, Lindgren C, Bergstrom R, Adami HO: Early life risk factors for prostate cancer: a population-based case-control study in Sweden. Cancer Epidemiol Biomarkers Prev 1995; 4(3): 187-92

110. Brownson RC, Chang JC, Davis JR, C.A. S Physical activity on the job and cancer in Missoure Am.J. Public Health 1991; 81: 639-642.

111. Dosemeci M, Hayes RB, Vetter R, et al. Occupational physical activity, socioeconomic status, and risks of 15 cancer sites in Turkey. Cancer Causes Control 1993; 4(4): 313-21

112. Hsing AW, McLaughlin JK, Zheng W, Gao YT, Blot WJ: Occupation, physical activity, and risk of prostate cancer in Shanghai, People's Republic of China. Cancer Causes Control 1994; 5(2): 136-40.

113. Le Marchand L, Kolonel LN. Yoshizawa CN Lifetime occupational physical activity and prostate cancer risk. Am J Epidemiol 1991; 133(2): 103-11.

114. Whittemore AS, Kolonel LN, Wu AH, et al. Prostate cancer in relation to diet, physical activity, and body size in blacks, whites, and Asians in the United States and Canada [see comments]. J Natl Cancer Inst 1995: 87(9): 652-61.

115. Ilic M, Vlajinac $\mathrm{H}$, Marinkovic J: Case-control study of risk factors for prostate cancer. $\mathrm{Br} \mathrm{J}$ Cancer 1996, 74(10): 1682-6.
116. Lee IM. Paffenbarger RS, Hsieh CC: Physical activity and risk of prostatic cancer among college alumni. Am. J.Epidemiol 1992; 135: 169-79.

117. Oliveria SA, Kohl HW, III, Trichopoulos D, Blair SN: The association between cardiorespiratory fitness and prostate cancer. Med Sci Sports Exerc 1996; 28(1): $97-104$

118. Paffenbarger RS. Jr., Lee IM, Wing AL: The influence of physical activity on the incidence of sitespecific cancers in college alumni. Adv Exp Med Biol 1992: $322: 7-15$.

119. Steenland K. Nowlin S, Palu S: Cancer incidence in the National Health and Nutrition Survey I. Follow-up data diabetes, cholesterol, pulse and physical activity. Cancer Epidemiol Biomarkers Prev 1995. 4(8) 807-11

120. Thune I. Lund E Physical activity and the risk of prostate and testicular cancer a cohort study of 53.000 Norwegian men. Cancer Causes Control 1994: 5(6): 549-56

121. Colditz GA, Coakley E: Weight, weight gain, activity, and major illnesses: the Nurses' Health Study. Int J Sports Med 1997; 18 Suppl 3: S162-70.

122. Lee IM. Manson JE, Ajani U. Paffenbarger RS. Jr. Hennekens CH. Buring JE: Physical activity and risk of colon cancer the Physicians' Health Study (United States). Cancer Causes Control 1997; 8(4) 568-74

123. Bostick RM, Potter JD, Kushi LH, et al: Sugar, meat, and fat intake, and non-dietary risk factors for colon cancer incidence in lowas women (United States). CCC 1994; 8: 649-67

124. Giovannucci E, Ascherio A, Rimm EB, Colditz GA. Stampfer MJ. Willett WC Physical activity, obesity, and risk for colon cancer and adenoma in men. Ann Intern Med 1995; 122(5): 327-34

125. Martinez ME, Giovannucci E, Spiegelman D, Hunter DJ, Willett WC, Colditz GA: Leisure-time physical activity, body size, and colon cancer in women. Nurses' Health Study Research Group. J Natl Cancer Inst 1997; 89(13): 948-55

126. Albanes $D$, Winick $M$ : Are cell number and cell proliferation risk factors for cancer? J Natl Cancer Inst 1988: 80(10): $772-774$

127. Zhu Z, Haegele AD. Thompson HJ: Effect of caloric restriction on pre-malignant and malignant stages of mammary carcinogenesis. Carcinogenesis 1997; 18(5): 1007-12. 



\section{Energy restriction and the risk of spontaneous mammary tumors in mice: a meta-analysis}

Miranda JM Dirx ${ }^{1}$

Maurice PA Zeegers ${ }^{1}$

Pieter C Dagnelie ${ }^{1}$

Ton van den Bogaard ${ }^{2}$

Piet $A$ van den Brandt ${ }^{1}$

\section{Affiliations}

${ }^{1}$ Maastricht University, Department of Epidemiology, Maastricht, The Netherlands

${ }^{2}$ Maastricht University, Centralized Experimental Animal Facilities, Maastricht, The Netherlands 


\section{Abstract}

Energy restriction has been shown to be one of the most effective ways of reducing the incidence of mammary tumors in rodents. This meta-analysis was aimed at providing a systematic review of the literature regarding the effect of energy restriction on spontaneous mammary tumors in mice and at providing a more precise pooled (summary) estimates of the risk of mammary tumors. This study made use of a sensitivity analysis to get insight in potential heterogeneity between the animal studies. A literature search was conducted with the following terms to identify relevant articles: animal studies, mammary tumors, fat restricted, dietary carbohydrates, energy restriction, calorie restriction. A criteria list for the assessment of quality items (i.e., study characteristics) in animal experiments was developed which was intended to quantitatively assess potential factors underlying heterogeneous results of different animal experiments. Incidence figures were used to calculate the risk difference. The pooled risk difference was calculated by random effects meta regression analysis.

A total of fourteen animal experiments were included in this meta-analysis. Publication bias could not be identified. The pooled risk difference for the 14 studies was -0.55 with a narrow $95 \%$ confidence interval $(-0.69 ;-0.41)$, implicating that the energy-restricted animal groups developed $55 \%$ less mammary tumors than the control groups. No heterogeneity could be detected between the studies based on study characteristics including age of mice at start of intervention, duration of intervention, allocation of the mice, use of ad libitum control group, fertility of the mice, and the type of energyproviding nutrient (fat, carbohydrate or protein).

This meta-analysis confirms that energy restriction in itself consistently protects against the development of mammary tumor in mice, irrespective of the type of restricted nutrient or other study characteristics.

(Submitted for publication) 


\section{Introduction}

Breast cancer is one of the main causes of death in women nowadays (1). It is important to understand more about the etiology and possibilities for prevention of breast cancer. The hypothesis that high fat intake will increase the risk of breast cancer has often been examined in human studies. Although epidemiological studies in humans suggested that diet (energy and fat) is related to the incidence of breast cancer (2-5), the results are not consistent (5). A pooled analysis of the results of several cohort studies yielded no evidence of a positive association between total dietary fat intake and the risk of breast cancer (5).

To clarify the role of dietary factors in the etiology of breast cancer, much research has been conducted in rodents, especially regarding the effect of dietary fat-intake and energy (i.e. caloric) restriction on breast cancer risk. Energy restriction has been suggested a very effective way of reducing the incidence of mammary tumors in rodents $(6,7)$. In contrast with the human studies, these results appeared to be consistent between different studies. Suggestions have been made that calorie intake may reduce carcinogenic risk by influencing hormones, cytokines, growth factors, rates of cellular proliferation and levels of immunological responsiveness (8). Nevertheless, the precise mechanism by which caloric restriction decreases the incidence of mammary tumors in mice is still unknown.

Several investigators have discussed the effect of different levels of total fat intake and different levels of total energy intake (9-12). However, no clear conclusions are available on whether the level of calorie intake modifies the effect of fat intake on tumor incidence.

Energy restriction in experimental animal studies can be achieved in several ways. Sources of energy are nutrients such as fat, carbohydrates and protein. In some animal studies energy restriction was achieved by reducing the amount of fat $(13,14)$, in other studies by reducing the amount of carbohydrates $(10,11,15,16)$. In more recent studies a combination of several energy providing nutrients was used to achieve energy restriction $(17,18)$.

The purpose of this study was to systematically review the animal literature on energy restriction and mammary tumors and to provide precise quantitative pooled (summary) estimates of the risk of mammary tumors, by means of a metaanalysis. The purpose of a meta-analysis is to combine results from different studies in an attempt to identify consistent patterns and sources of disagreement among those results (19). The technique of meta-analysis is mostly used for human randomized clinical trials (RCT's). It allows evaluating the influence of the type of nutrient restricted, the age of mice at the start of the experiment and the duration of the intervention period on the association between energy restriction and the development of mammary tumors. The present meta-analysis had an emphasis on type of energy restriction and duration of intervention period. Also, a sensitivity analysis can be performed in order to get insight in causes of possible heterogeneity in results between the studies. Furthermore, we evaluated changes in summary estimates according to study methodology. The age at which the energy restriction took place had our special interest because the hypothesis has been put forward that energy restriction early in life may affect breast cancer risk $(20,21)$.

\section{Materials and Methods}

\section{Literature search}

A literature search was conducted using the computerized databases MEDLINE and Current Contents. We restricted this systematic review to experiments with mice and spontaneous mammary tumors because of the comparability of this animal model to the human situation and the comparability between the studies.

The following terms were used to identify relevant articles: animal studies, mammary tumors, fat restricted, dietary carbohydrates, energy restriction, calorie restriction. The computerized search covered the years 1966 to 1999. Furthermore, references cited in published original and review articles were examined. For inclusion in this analysis, studies had to meet the following criteria. The study had to be a randomized trial with mice and spontaneously occurring mammary tumors (i.e. no induced tumors). Secondly, sufficient information had to be available in the report to determine the degree of energy restriction and to estimate risk differences for mammary breast tumors when comparing groups. The incidence of mammary tumors and the number of mice per 
dietary group had to be reported. Excluded were studies with animal groups who were fed an isocaloric diet. This review had no limitation on language.

\section{Data collection}

A criteria list for the assessment of quality items (i.e. study characteristics) in animal experiments was developed. This list was intended to quantitatively assess potential factors of heterogeneity in results between the animal experiments. The list calls for aspects of the studies such as general information on mouse strain, age at start of the study and virginal status. Intervention information (quantity and duration of energy restriction, type of diet, individual vs. group caging) and the number of mice in the experimental and control group were also assessed. The criteria list also assessed whether or not the effect measurement was blinded and if the studies made use of an ad libitum fed control group.

All publications eligible for reviewing were blinded regarding author(s), journal, publication year, acknowledgments and affiliations. They were distributed to three independent reviewers who assessed the studies using the criteria list (MJMD, MPAZ, PCD). In case of any discrepancies between the three reviewers consensus was reached in subsequent meetings. If more than one animal experiment was described in one publication, they were considered as separate studies $(10,11,13,14)$.

Mammary tumors in the experiments were detected by palpation or autopsy. Incidence rates were based on the intervention period, because none of the studies had a follow-up period after the end of the intervention. Based on the starting numbers of mice in each study, the number of incident cases in each group and the degree of energy restriction, two-way contingency tables were constructed for each study. The animal group with the highest degree of energy restriction was compared with the animal group that was fed ad libitum or with the group with the highest intake of calories. Not all the experiments used an ad libitum control group. In studies with more than two restricted animal groups the two groups with the highest contrast were compared. Data were extracted from the experiments in order to construct the tables. The tables were used to calculate the risk difference (incidence in the experimental group minus the incidence in the control group,
$\left.\left(I_{0}-I_{0}\right)\right)$ and its corresponding variance. The risk difference has a range from -1.00 to +1.00 and is dimensionless (19). A risk difference of -0.3 ($30 \%$ ) means that in the energy restricted group $30 \%$ less mammary tumors were developed compared to the control group.

In one study, the contingency table showed two cells with zero (no mice with incident tumors), which would yield a variance of zero. Since the inverse of the variance was used as weight (22), the mean variance of the studies was utilized instead for this specific study (14). Mortality rates were not available for each individual study and could therefore not be used in this meta-analysis.

\section{Determinant}

The primary determinant studied in this review was the degree of energy restriction in the studies. Because of the small number of studies $(n=14)$, energy restriction was divided into three approximately equivalent categories (s $33 \%$ energy restriction, $34-40 \%$ energy restriction or $>40 \%$ energy restriction). However, the distribution of this variable is skewed because 5 studies had an energy restriction equal to the cut-off value of $40 \%$. Furthermore, the type of restricted nutrient was also evaluated (carbohydrates, fat or protein restricted).

\section{Statistical analysis}

To detect publication bias we explored asymmetry in funnel plots, i.e., plots of effect estimates against their estimated precision, and we measured the degree of asymmetry using Egger's unweighted regression asymmetry test $(23,24)$. The pooled (summary) risk difference was calculated by random effects meta regression analysis using the STATA statistical software package $(22,25,26)$. To account for both sources of variation (between and within studies) we used random effects meta regression analysis to combine the results from the primary studies. The random effect approach provides some allowance for heterogeneity in studies beyond sampling error. To explore possible reasons for the observed heterogeneity in results between different studies, sensitivity analyses were performed on the following study characteristics: age of mice at the start of the intervention ( $<1-5$ weeks old, 6-9.5 weeks old and $>9.5$ weeks old), duration of intervention period ( $\leq 56.6$ weeks, $57-71.5$ weeks and intervention period longer than 71.5 weeks). The cut-off points of these study 
characteristics were based on tertiles. Allocation of the mice (individually caged or two or more mice in one cage) and the state of fertility of the animals at the start of the experiment (virgin or not) were also tested in sensitivity analyses to explore their influence on the association between energy restriction and mammary cancer.

\section{Results}

Based on the literature search, 16 articles were identified reporting animal experiments with mice on energy restriction and development of spontaneous mammary tumors of which six studies reporting isocaloric diets. The latter studies were excluded. In four articles more than one animal experiment was described; these were considered as separate studies. Thus, a total number of fourteen animal experiments were included in this meta-analysis.

In table 1 characteristics of the different studies are summarized $(10,11,13-17,27-29)$. All studies were published between 1942 and 1994 The mean energy restriction in the fourteen included studies was $37 \%$ (range 23\%-50\%) and mean age of the mice at the start of the experiments was 9.6 weeks (range 3-23 weeks). The mean duration of the experiments was 72.6 weeks (range 38-126.5 weeks). All experiments stopped after they stopped the intervention. The mean number of mice per study was 66 (range 20-144 mice). None of the reports mentioned whether the effect measurement was blinded. Most of the mice in the energy-restricted groups in the studies were individually caged. The incidence of mammary tumors in the control groups ranged from $37 \%$ to $100 \%$. Mice strains used in these experiments varied between DBA, $\mathrm{C} 3 \mathrm{H}, \mathrm{C} 3 \mathrm{H} / \mathrm{Bi}, \mathrm{C} 3 \mathrm{H} / \mathrm{Ou}$ and $\mathrm{RIII} / \mathrm{Sa}$.

Risk differences were below zero in all individual studies except one (10), with values ranging from -1.0 to 0.13 . The pooled risk difference (pooled RD) for the 14 studies was -0.55 $(95 \% \mathrm{Cl}-0.69 ;-0.41)$, implicating that the energy-restricted animal groups developed $55 \%$ less mammary tumors than the control groups. Figure 1 shows the different risk differences for the individual studies and the pooled (summary) risk difference. We could not identify publication bias, either visually or in terms of statistical significance (Egger's test $p>0.8$ ).
To explore the influence of study characteristics on outcome estimates, heterogeneity between the different studies was evaluated. Figure 2 shows the relationship between energy restriction and spontaneous mammary tumors by age of the mice at start of intervention, duration of the intervention, housing (individual or not) of the mice, use of an ad libitum control group and fertility of the mice. The pooled risk differences for energy restriction and mammary tumors were $-0.57(95 \% \mathrm{Cl}-0.79 ;-0.35)$ for mice aged 1.5 weeks, $-0.54(95 \% \mathrm{Cl}-0.70$; 0.38 ) for mice aged 6-10 weeks, and -0.51 $(95 \% \mathrm{Cl}-0.76 ;-0.26)$ for mice aged over 10 weeks at the start of the study.

In experiments with a short intervention period, the greatest reduction in development of mammary tumors was seen. For studies with a short duration of intervention ( $\leq 56.5$ weeks) the pooled risk difference was $-0.65(95 \% \mathrm{Cl}-0.87$; $-0.42)$ and $-0.56(95 \% \mathrm{Cl}-0.71 ;-0.41)$ for studies with a median duration of intervention period (57-71.5 weeks). For studies with a long intervention period (over 71.5 weeks) the pooled risk difference was $-0.47(95 \% \mathrm{Cl} ;-0.69 ;-0.25)$. For studies using individual caging the pooled risk difference was $-0.61(95 \% \mathrm{Cl}-0.77 ;-0.45)$. For studies using an ad libitum control group the pooled risk difference was $-0.56(95 \% \mathrm{Cl}-0.72$; -0.40 ). For studies that did not use an ad libitum control group the pooled risk difference was $-0.49(95 \% \mathrm{Cl}-0.79 ;-0.19)$. No difference was seen in pooled RD between studies using virgin mice or not. Studies that used virgin mice the pooled risk difference was $-0.55(95 \% \mathrm{Cl}-0.72$; -0.39 ) and for studies that used no virgin mice the pooled risk difference was $-0.53 \quad(95 \% \mathrm{Cl}$ $-0.83 ;-0.23$ ) (figure 2). None of the above mentioned results were significantly different between the subgroups ( $p$-values of interaction $>0.20$ ). In figure 3 , results according to different dietary exposure characteristics are presented. For studies with $\leq 33 \%$ energy restriction the pooled risk difference was $-0.50(95 \% \mathrm{Cl}-0.72$; -0.28 ). 
Table 1 Characteristics of mice studies on calorie restriction and spontaneous mammary tumors, ordered by publication year.

\begin{tabular}{|c|c|c|c|c|c|c|}
\hline Author & Year & Mice strain & $\begin{array}{l}\text { of mice } \\
\text { eeks) }\end{array}$ & $\begin{array}{l}\text { Intervention period } \\
\text { (in weeks) }\end{array}$ & $\begin{array}{l}\text { Degree of restriction } \\
\text { (\%), (source) }\end{array}$ & $\begin{array}{l}\text { Total number } \\
\text { of mice in stuc }\end{array}$ \\
\hline Visscher et al. & 1942 & $\mathrm{C} 3 \mathrm{H}$, virgin & 4.5 & 67 & $33 \%\left(\mathrm{fat}+\mathrm{CHO}^{2}\right)$ & 95 \\
\hline Tannenbaum & $1945 a^{\prime}$ & DBA, virgin & 9.5 & 126.5 & $23 \% \quad(\mathrm{CHO})$ & 94 \\
\hline Tannenbaum & $1945 a^{2}$ & $\mathrm{C} 3 \mathrm{H}$, virgin & 10 & 54 & $33 \%$ (CHO+protein) & 58 \\
\hline Tannenbaum & $1945 b^{1}$ & $\mathrm{DBA}$, virgin & 10 & 90 & $35 \% \quad(\mathrm{CHO})$ & 98 \\
\hline Tannenbaum & $1945 b^{2}$ & DBA & 23 & 113 & $33 \% \quad(\mathrm{CHO})$ & 50 \\
\hline Sarkar et al. & 1982 & $\mathrm{C} 3 \mathrm{H}$, virgin & 5 & 107 & $50 \%$ (protein) & 144 \\
\hline Shao et al. & $1990^{\prime}$ & $\mathrm{C} 3 \mathrm{H} / \mathrm{Bi}$ & 20 & 56.5 & $40 \%(\mathrm{CHO})$ & 25 \\
\hline Shao et al. & $1990^{2}$ & $\mathrm{C} 3 \mathrm{H} / \mathrm{Bi}$ & 20 & 56.5 & $40 \%$ (fat) & 30 \\
\hline \multirow[t]{2}{*}{ Koizumi et al. } & 1990 & (C3H/SHN) F1-hybrid & 3 & 64 & $50 \%(\mathrm{CHO})$ & 65 \\
\hline & \multicolumn{3}{|c|}{ (C3H/He male*SHN female), virgin } & & & \\
\hline Engelman et al. 1990 & \multicolumn{2}{|c|}{$\mathrm{C} 3 \mathrm{H} / \mathrm{HeOu}$, virgin } & 4 & 72 & $32 \% \quad(\mathrm{CHO})$ & 48 \\
\hline Engelman et al. $1991^{1}$ & \multicolumn{2}{|c|}{$\mathrm{C} 3 \mathrm{H} / \mathrm{Ou}$, virgin } & 7 & 54 & $40 \%$ (CHO+protein) & 53 \\
\hline Engelman et al. $1991^{2}$ & \multicolumn{2}{|c|}{$\mathrm{C} 3 \mathrm{H} / \mathrm{Ou}$, virgin } & 7 & 54 & $40 \% \quad$ (fat) & 46 \\
\hline Engelman et al. 1994 & \multicolumn{2}{|c|}{$\mathrm{C} 3 \mathrm{H} / \mathrm{Ou}$, virgin } & 6 & 38 & $40 \% \quad(\mathrm{CHO})$ & 20 \\
\hline Li et al. 1994 & \multicolumn{2}{|c|}{ RIII/Sa, virgin } & 5 & 72 & $37.5 \%(\mathrm{CHO})$ & 103 \\
\hline
\end{tabular}

1 and $^{2}$ : one article describing two independent animal experiments

${ }^{2} \mathrm{CHO}$ : carbohydrate

${ }^{3} 30 \%$ restriction means that animals received $70 \%$ of amount eaten by ad libitum group 
Author

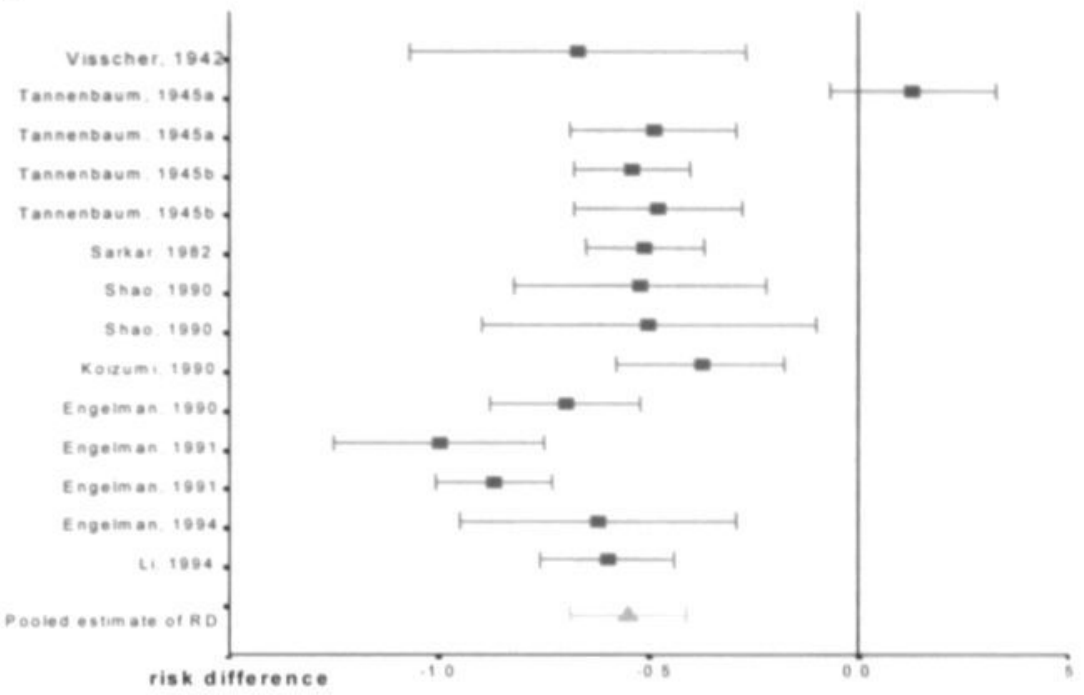

Figure 1

Difference in incidence of mammary tumors (risk difference) for energy restricted groups relative to ad libitum (or highest amount of calories) fed groups, and $95 \%$ confidence intervals for each study separately and pooled risk difference (pooled RD)

(solid line indicates no effect, a risk difference of -0.55 means that the energy restricted group has $55 \%$ less mammary tumors developed compared to the control (non-restricted) group).

\section{Study characteristics}

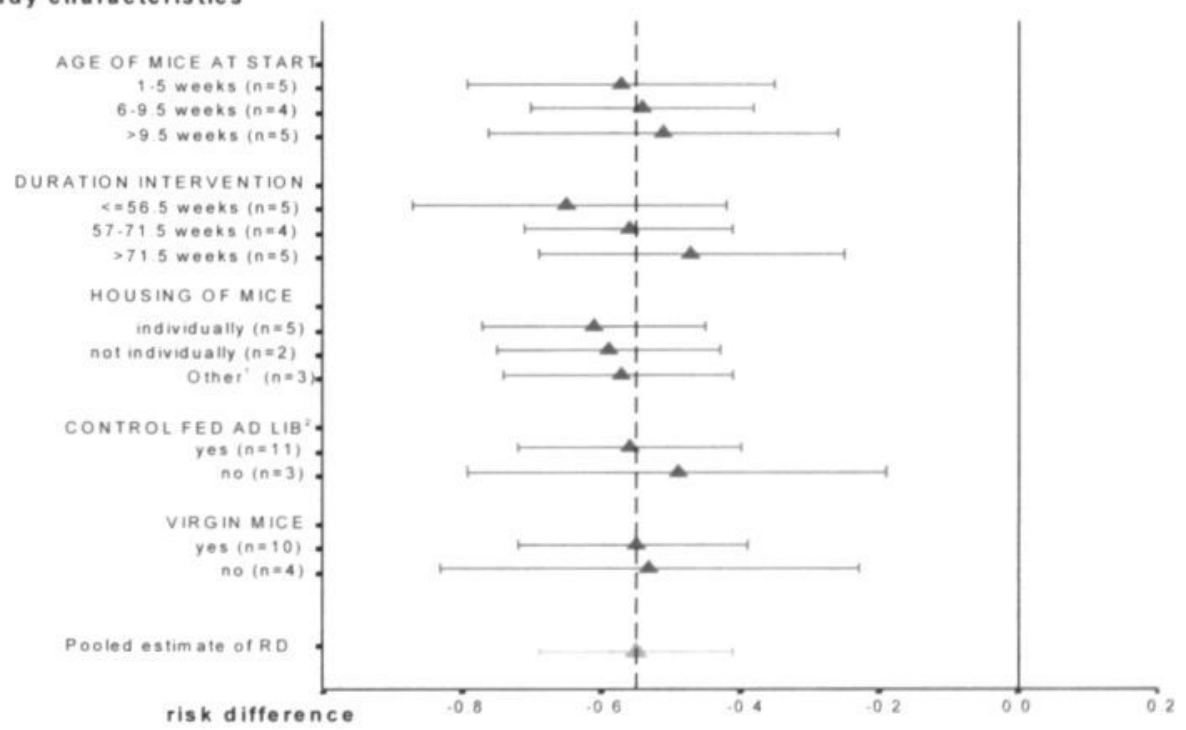

Figure 2 Summary risk differences for energy restricted groups vs. ad libitum (or highest amount of calories) and $95 \%$ confidence intervals of mammary tumors for pooled studies with different study characteristics

1 other housing. the experimental (restricted) group is individually caged and the control group is not individually caged, 2 ad lib means 'ad libitum' 
For studies with an energy restriction between $34-40 \%$ the pooled risk difference was -0.56 $(95 \% \mathrm{Cl}-0.70 ;-0.41)$. For studies with the highest degree of energy restriction $(>40 \%)$ the pooled risk difference was $-0.62(95 \% \mathrm{Cl}-0.91 ;-0.33)$. This means that in studies with more than $40 \%$ energy restriction, $62 \%$ fewer animals in the intervention groups developed mammary tumors than in the control groups. For carbohydraterestricted studies, the pooled risk difference was $-0.52(95 \% \mathrm{Cl}-0.68 ;-0.36)$, and for studies that did not restrict the carbohydrates the pooled risk difference was $-0.64(95 \% \mathrm{Cl}-0.93 ;-0.35)$. Fatrestricted studies showed a pooled risk difference of $-0.71(95 \% \mathrm{Cl}-1.04 ;-0.39)$ and non-fat restricted studies $-0.51(95 \% \mathrm{Cl}-0.66$; -0.36 ). Studies with and without protein restriction showed a pooled risk difference of $-0.57(95 \% \mathrm{Cl}-0.86 ;-0.27)$ and $-0.55(95 \% \mathrm{Cl}$ $-0.75 ;-0.35)$, respectively. None of the interactions were significant ( $p$-values $>0.30$ ).

\section{Discussion}

We performed a meta-analysis of 14 animal experiments reporting on energy restriction and the incidence of spontaneous mammary tumors mice. Energy restricted animal groups showed a statistically significant lower incidence of spontaneous mammary tumors compared to the non-restricted groups (control groups), with a pooled risk difference of -0.55 . All individual studies, except one (10), showed a negative risk difference. The results of this systematic review show that energy restriction protects against the development of mammary tumors in mice and support earlier studies. An energy restriction of more than $40 \%$ shows an apparently greater preventive effect (pooled RD -0.62) than $33 \%$ energy restriction or less (pooled RD -0.50 ), but the difference was not statistically significant. The type of nutrient which was restricted (fat, carbohydrates or protein) seemed not to have an important influence on the pooled risk difference, although fat-restricted studies showed a pooled RD of -0.71 (again not statistically significant). These results are in accordance with the narrative review of Albanes (6). The only study, which showed a positive risk difference of 0.13 , was the study with the longest duration of intervention period, namely 126.5 weeks (almost 2.5 years) and the lowest degree of energy restriction (23\%).
Because of heterogeneity of the studies with regard to animal strain, duration of the intervention period, age of mice and housing. we assumed that the true effect of dietary restriction varied between the studies in addition to the usual sampling variation in the estimates. In order to account for both sources of variation, we used random effects meta regression analysis to combine the results from the primary studies. The random effect approach provides some allowance for heterogeneity in studies beyond sampling error. Results showed that pooled risk differences were independent of the age of the mice, housing of mice, fertility of mice, the use or non-use of an ad libitum control group and the duration of intervention period. No heterogeneity could be detected between the studies based on study characteristics although a longer duration of intervention period tended to be associated with a smaller risk difference. A possible explanation could be the fact that almost every mouse of the strains used in these experiments may finally develop a mammary tumor, provided the observation period is long enough. In experiments used in this metaanalysis, the incidence in the control groups varied between $37 \%$ and $100 \%$. In comparison, lifetime cumulative incidence of breast cancer among women varies between $8 \%-15 \%$ worldwide (1). Therefore, strains with lower incidence would be needed to achieve a situation, which more closely resembles the human situation.

It has been suggested that the age at which animals are exposed to energy restriction may be an important factor in the development of mammary tumors. Early restriction will permanently stunt growth and reduce total cell numbers in all organs. Exposure to undernutrition in the prepubertal years leads to a decrease in cell division and a reduction in the total number of dividing cells (mitosis). It was hypothesized that when feeding the animals an energy-restricted diet from birth till weaning age and ad libitum after weaning, the deficiency in the number of cells will not completely be corrected, although the reduction in cell volume will generally recover $(30,31)$. When energy restriction occurs later in life, it will affect the rate of mitosis in the regenerating tissue (32). Cell division can be interrupted by malnutrition at any time. When the rate of cell division is very high, the cellular DNA is subject to frequent damage. The effects of energy restriction therfore might 


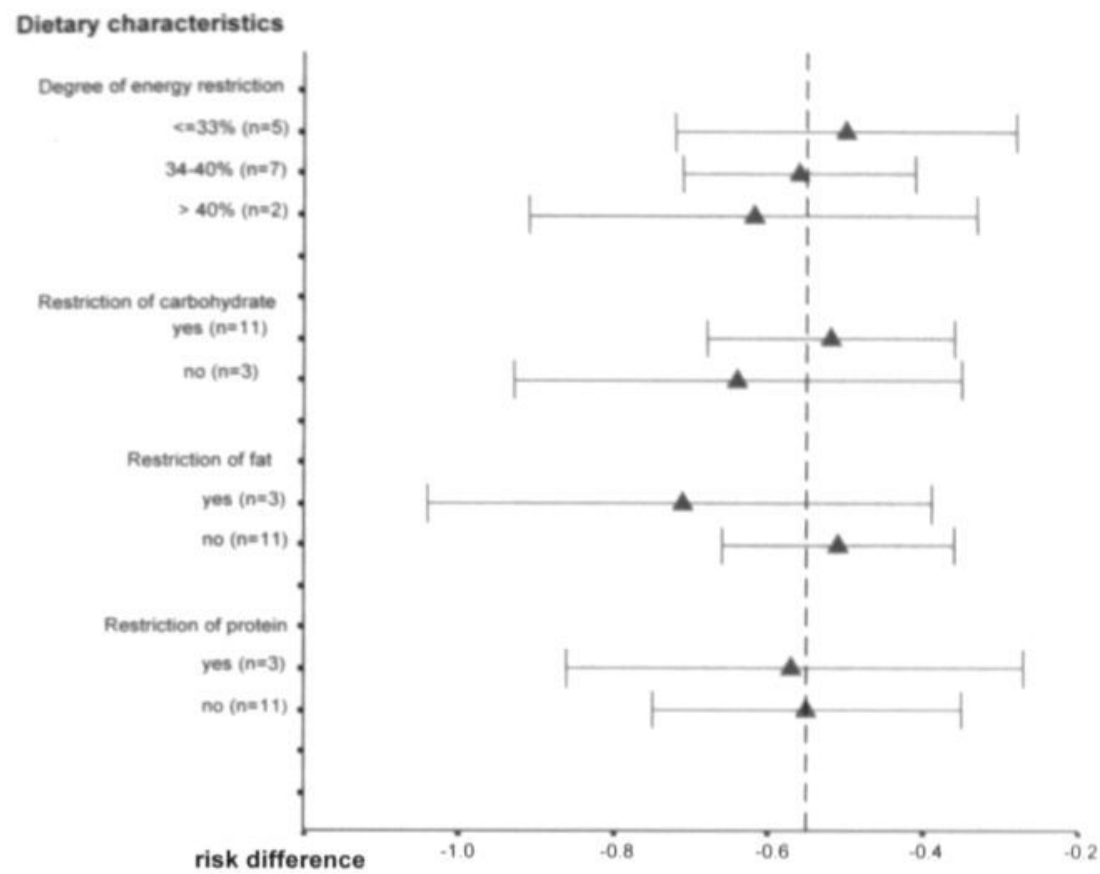

\section{Figure 3}

Summary risk difference for energy restricted groups vs. ad libitum (or highest degree of calories) and $95 \%$ confidence interval of mammary tumors for studies by different dietary characteristics (dashed line refers to pooled estimate of risk difference for all the studies)

depend on the timing of the restriction. In this meta-analysis, we could not detect an effect by the age of mice. Silverman (33) also concluded that the age of puberty in itself does not act as a risk factor for mammary carcinogenesis in animal experiments if a high fat/high calorie diet was fed throughout the period. Another point of discussion is the duration of intervention period, which differs considerably between the various studies. In our meta-analysis the duration of the intervention period did not significantly influence the association between energy restriction and mammary tumor risk. However, the results suggest that studies with a long intervention period reported a lower pooled risk difference. The shortest duration of intervention period was 38 weeks. It would be interesting to see whether shorter experiments would show the same results.

Given the strong and consistent effect of energy restriction on cancer prevention in experimental animals, it is clearly possible that the balance between energy consumption, retention and expenditure, perhaps in combination with frequency and length of fasting periods between meals, represents an underlying and central link in the relationship between diet, nutrition and cancer in Western society (34). Future dietary cohort studies and intervention trials are needed to get insight into the effects of energy and/or fat restriction on human breast cancer development.

In conclusion, this meta-analysis confirms that energy restriction in itself consistently protects against the development of mammary tumor in mice, irrespective of the type of restricted nutrient and/or other study characteristics. No significant heterogeneity in results between the animal studies was detected in this metaanalysis.

\section{References}

1. Fund. W C R Food, nutrition and the prevention of cancer: a global perspective: American Institute for Cancer Research, 1997

2 Kelsey, J. L. Gammon, M D. and John, E M Reproductive factors and breast cancer. Epiderniol Rev 15 36-47, 1993 
3. Howe, G R. Hirohata, T. Hislop, T. G. Iscovich, J. M. Yuan, J M. Katsouyanni, K., Lubin, F., Marubini, E., Modan, B. Rohan. T. and et al Dietary factors and risk of breast cancer combined analysis of 12 case-control studies. J Nati Cancer inst 82 561-9. 1990

4 Graham, S. Zielezny, M. Marshall, J. Priore, R. Freudenheim. J., Brasure. J. Haughey. B. Nasca. P., and Zdeb. M. Diet in the epidemiology of postmenopausal breast cancer in the New York State Cohort, Am J Epidemiol. 136 1327-37. 1992

5 Hunter. D J Spiegeiman. D. Adami. H O Beeson, L. van den Brandt. P. A. Folsom, A R. Fraser, G. E Goldbohm. R A. Graham. S. Howe, G R and et al Cohort studies of fat intake and the risk of breast cancer-a pooled analysis [see comments]. N Engl J Med 334 . 35661. 1996

6. Albanes. D Total calories. body weight, and tumor incidence in mice. Cancer Research 47 1987-1992. 1987

7. Freedman, L S, Clifford. C. and Messina, M Analysis of dietary fat, calories body weight. and the development of mammary tumors in rats and mice a review. Cancer Res $50 \quad 5710-9.1990$

8. Weindruch, $R$ and Walford. R L The retardation of aging and disease by dietary restriction. Springfield Charis C Thomas. 1988

9 Kritchevsky. D and Klurfeld. D M Influence of caloric intake on experimental carcinogenesis a review. Adv Exp Med Biol. 206 55-68. 1986

10 Tannenbaum. A The dependence of tumor formation on the composition of the calorie restricted diet as well as on the degree of restriction. Cancer Research. 5 . 616-25. 1945 a

11. Tannenbaum. A. The dependence of tumor formation on the degree of caloric restriction, Cancer Research. 5: 609. 15. $1945 \mathrm{~b}$

12. Ip. C Fat and essential fatty acid in mammary carcinogenesis. Am J Clin Nutr 45 218-24, 1987.

13. Shao, R, Dao, M L. Day, N K and Good, R A Dietary manipulation of mammary tumor development in adult $\mathrm{C} 3 \mathrm{H} / \mathrm{Bi}$ mice. Proc Soc Experimen Biol Med. 193: 3137. 1990

14 Engeiman, R W . Fukaura, Y. Hamada, N., Good, R. A. and Day. $N$ K . Dietary restriciton permits normal parturition and lactation but suppresses mouse mammary tumor virus proviral transcription even after mammry involution, Cancer Research 51, 5123-8, 1991

15 Sarkar, N. H. Fernandes, G. Telang. N T. Kourides, I A. and Good. R A Low-calorie diet prevents the development of mammary tumors in $\mathrm{C} 3 \mathrm{H}$ mice and reduces circulating

prolactin level, murine mammary tumor virus expression. and proliferation of mammary alveolar cells. Proc. Natl Acad Sci 79 7758-62, 1982

16. Engelman. R W. Day. N K and Good. R A Calorie intake dunng mammary development influences cancer risk. lasting inhibition of $\mathrm{C} 3 \mathrm{H} / \mathrm{HeOu}$ mammary tumongenesis by peripubertal calorie restriction, Cancer Reserach $53 \quad 5724$. 30. 1994

17 Li. H W . Zhao W. and Sarkar, N H Dietary regulation of mammary tumorigenesis in RIII/Sa mice investigation of a possible mechanism. Cancer Lettres. 79 199-211. 1994

18 Kritchevsky. D. Calonc restriction and experimental mammary carcinogenesis. Breast Cancer Res Treat 46 $161.7,1997$

19. Rothman, K J and Greenland, S Modern epidemiology Philadeiphia Lippencott-Raven publishers. 1998

20 . Trethi, S. Haldorsen. T and Ottestad. L. The effect of pre-morbid height and weight on the survival of breast cancer patients. Br J Cancer 62 299-303, 1990
21. Waard de, F. On the nutritional etiology of breast cancer. Adv Exp Med Biol. 348 : 119-22. 1993

22. Newton, H. J. Stata Technical Bulletin (STB-37-STB-42) College Station. Texas. 1998

23. Egger, M., Davey Smith, G. Schneider, M. and Minder. C. Bias in meta-analysis detected by a simple, graphical test. BMJ 315: 629-634, 1997

24. Steichen, T. J. Egger. M. and Sterne, J. Tests for publication bias in meta-analysis. Vol STB-44: sbe 19.1, 1998

25. Stata. Statistical, and Software Release 6.0 [Program] College Station, Texas. Stata Corporation, 1999

26 Sharp. S J. Meta-analysis regression. Vol. STB-42 sbe 23. 1998

27 Visscher, M B. Ball, Z B. Barnes. R. H and Sivertsen. 1. The influence of caloric restriction upon the incidence of spontaneous mammary carcinoma in mice, Surgery. 11:4855. 1942

28 Koizumi, A., Wada, Y., Tsukada, M. Kamiyama, S. and Weindruch. $R$ Effects of energy restriction on mouse mammary tumor virus mRNA levels in mammary glands and uterus and on uterin endometrial hyuperplasia and pituitary histology in C3H/SHN F1 mice. J Nutr. 120 1401-11, 1990 29. Engeiman, R. W. Day, N K. Chen, R F. Tomita, Y Baver-Sardina. I Dao. M L and Good. R A Calorie consumption level influences development of $\mathrm{C} 3 \mathrm{H} / \mathrm{O}$ u breast adenocarcinoma with indifference to calone source. Proc Soc Experimen Biol Med 193. 23-30, 1990

30 Ross. M H and Bras. G. Lasting influence of early calonc restriction on prevalence of neoplasmsm in the rat. $J$ Natl Cancer inst 47: 1095-1103, 1971

31. Albanes, D. and Winick, M Are cell number and cell proliferation risk factors for cancer? J Natl Cancer Inst. 80 . $772-774,1988$

32. Winick, M. and Noble, A. Cellular response in rats during malnutrition at various ages. J Nutrition. 89, 300-6, 1966.

33 Silverman. J. Powers, J., Stromberg. P.. Pultz, J. A. and Kent. S. Effects on $\mathrm{C} 3 \mathrm{H}$ mouse mammary cancer of changing from a high fat to a low fat diet before, at. or after puberty. Cancer Res. 49:3857-60, 1989

34. Pariza, M. W. Fat, calories, and mammary carcinogenesis: net energy effects. Am J Clin Nutr. 45: 2613. 1987 


\section{Diet in adolescence and the risk of breast cancer:}

\section{results of the Netherlands Cohort Study.}

Miranda J.M. Dirx ${ }^{1}$

Piet $A$. van den Brandt ${ }^{1}$

R. Alexandra Goldbohm ${ }^{2}$

L.H. Lumey ${ }^{3}$

\section{Affiliations}

${ }^{1}$ Maastricht University, Department of Epidemiology, Maastricht, The Netherlands

${ }^{2}$ TNO Nutrition and Food Research Institute, Department of Nutritional Epidemiology, Zeist, The Netherlands

${ }^{3}$ The Joseph L. Mailman School of Public Health, Columbia University, Division of Epidemiology, New York, NY10032 USA 


\section{Abstract}

In The Netherlands, part of the population experienced food restriction and severe famine during World War II. The purpose of this study was to study the effects of severe undernutrition during adolescence on the risk of breast cancer later in life.

We examined the hypothesis in the Netherlands Cohort Study on diet and cancer (NLCS), among 62,573 women aged 55-69 years. Baseline information on diet and other risk factors was collected with a questionnaire in 1986. Information was collected on residence in the Hunger winter (19441945) and War years (1940-1944) and father's employment status in 1932-1940 as indicators of exposure. After 6.3 years of follow-up 1009 incident breast cases were available for analysis.

In multivariate case-cohort analysis residents of the Western part of the country in 1944-1945 had an increased breast cancer risk (Western city $R R=1.1,95 \% \mathrm{Cl} 0.9-1.4$, Western rural area $\mathrm{RR}=1.5,95 \% \mathrm{Cl}$ 1.1-1.9). For the War years (1940-1944) we found no association between breast cancer risk and urban vs rural residence. Women whose fathers were unemployed during the Depression years (1932-1940) had a nonsignificant decrease in breast cancer risk ( $R R=0.9,95 \% \mathrm{Cl} 0.7-1.2)$. Exposure to energy restriction during the adolescent growth spurt or during the period between menarche and birth of the first child did not change the RRs substantially.

We found no clear evidence in this study for the hypothesis that energy restriction in adolescence leads to a decreased breast cancer risk.

(MJM Dirx, PA van den Brandt, RA Bausch, LH Lumey. Diet in adolescence and the risk of breast cancer: results of the Netherlands Cohort Study. Cancer Causes and Control 1999; 10: 189-199) 


\section{Introduction}

Among women in The Netherlands breast cancer is the most frequent cancer accounting for almost one third of all the cancer cases [1]. The hypothesis relating energy restriction to the risk of breast cancer is supported by longstanding results from rodent experiments documenting a reduced risk of breast cancer in animals on an energy-restricted dietary regimen. Potential mechanisms for an effect of energy [2] restriction early in life on decreased breast cancer risk can be summarized as follows: energy restriction in childhood and adolescence leads to a later age at menarche which leads to a decrease in breast cancer risk. Energy restriction in childhood and adolescence may also lead to a decrease in attained height. Attained height can act as an intermediate factor or as an independent risk factor for breast cancer. De Waard and Trichopoulos hypothesized that besides age at menarche and height, an energy-rich diet during childhood and adolescence could be an independent risk factor for breast cancer [3]. As a consequence of a high fat/high energy diet in childhood, breast development might be stimulated resulting in an increased susceptibility for initiating hits which lead to cells with more malignant potential.

Many studies have been conducted on the relationship between diet and breast cancer, but only few concentrated on diet in adolescence. To investigate early dietary exposures in relation to later cancer risk, proxy measures are generally needed, as no individual data are available on diet early in life. Hislop et al. conducted a case-control study to examine the relationship between childhood and current eating practices and the risk of breast cancer [4]. No elevated risks of breast cancer for the childhood consumption of foods with high fat content were found, except possibly for animal fat. Results of an ecological study in Norway showed that one or more environmental factors influenced the risk of breast cancer during World War II. The authors suggested that important factors to consider were a decrease in fat and milk consumption, an increase in fish and fresh vegetables, and an increase in physical activity level [5].

In The Netherlands, a substantial part of the population experienced a severe famine during World War II, the so called Hunger winter (winter of 1944-1945), especially in the Western part of the country. This unique setting provided the opportunity to study the effects of severe undernutrition during adolescence on the risk of breast cancer later in life [6-8]. In addition, a period of chronically impaired nutrition existed in The Netherlands during the earlier years of World War II (1940-1944) and the Depression in the 1930's. As a consequence of the poor availability of food products in the cities nutritional differences developed between cities and rural areas during the war years $[9,10]$. The available amount of calories was greater in the rural areas. Also, the ratio between the dietary nutrients was different for cities and rural areas. In the cities carbohydrates contributed more to the total amount of energy (70 energy $\%$ ) compared to the rural areas (65 energy $\%)$. The contribution of fat was less in the cities compared to the rural areas (10 energy $\%$ vs. 15 energy $\%$ ).

During the Economic Depression a large proportion of people were unemployed. Several surveys showed that in the food pattern of the unemployed families there was little variation and the energy intake was not at the same level as for the employed people [11-13]. The total amount of energy available for unemployed families compared to employed families was 3000 vs 3400 calories [14]. The daily menu of the unemployed people was very sober, consisting of boiled potatoes and some fat. Also the bread meals underwent changes, no longer including cheese, meat and confectionary. The energy restriction in these three periods. Economic Depression, the War years and the Hunger winter are subject of investigation in this study.

We examined the association between diet in adolescence and breast cancer risk in the Netherlands Cohort Study (NLCS) on diet and cancer. Women who were passing their pubertal years during the Economic Depression, the War and the Hunger winter were included in this prospective cohort study. There are biological reasons to believe that the period between the beginning of breast development at puberty and the first full term pregnancy is a particular sensitive period in a woman's life regarding the development of breast cancer [15]. Russo et al. have proposed, on the basis of experiments in rats, that the full cellular differentiation of the mammary gland during a full-term pregnancy protects against the subsequent development of 
breast cancer. Therefore, the period between menarche and first full-term pregnancy might be critical for the initiation of breast carcinogenesis [16, 17]. In this study we focused on the interaction with the age at which dietary restriction took place, with particular attention to those women who were exposed between menarche and delivery of their first child.

\section{Materials and methods}

The Netherlands Cohort Study started in September 1986 when 62,573 women 55 to 69 years were enrolled in the cohort. Baseline exposure data were collected by means of a self-administered questionnaire. The questionnaire referred to dietary habits and potential confounders such as reproductive history, smoking habits, education and family history of cancer. Also included were questions about the residences of the cohort members during their entire life, including the residence in the war years and the winter of 1944-1945 and the fathers' employment status during the Economic Depression. A detailed description of the cohort study design has been reported elsewhere [18]. After the baseline exposure measurement, a subcohort was randomly sampled from the cohort and followed up biennially for vital status information. Incident cancer cases occurring in the entire cohort have been identified by record linkage to cancer registries and a national pathology register (PALGA). The method of record linkage has been described previously [19].

The collected data from subcohort and breast cancer cases were key-entered twice by a research assistant who was blinded with respect to subcohort/case status in order to minimize observer bias in coding and interpretation of the data. The present analysis is restricted to cancer incidence in the 6.3-year follow-up from September 1986 to December 1992. Completeness of cancer follow-up was estimated to exceed 96 percent [20]. After these 6.3 years of follow-up, 1009 breast cancer cases were available for analysis, after exclusion of prevalent cancer cases and cases with in situ breast carcinoma. Prevalent cancer cases other than skin cancer were also excluded from the subcohort, after which 1,716 women remained. For data analysis the case-cohort approach was used in which cases are derived from the entire cohort, while the person years at risk are estimated from the subcohort.

\section{Assessment of energy restriction}

The exposure variables have to adequately represent the energy restriction of the women in the cohort for the Economic Depression years (1932-1940), the War years (1940-1944) and the Hunger winter (1944-1945). Individual food intake data of the women in these periods were not available; we therefore used proxy variables for the energy restriction in each of these periods. For the Economic Depression years (1932-1940), the occupation of the father was the best available proxy variable for energy restriction. Contemporary studies observed that having an unemployed father indicated that the family had less energy to consume and less variation in their food pattern compared to families with an employed father [11-13]. The exposure variable for the Economic Depression years was dichotomous: women whose father had $\mathbf{a}$ job and women whose father had no job. For the other two periods, the War period (19401944) and the Hunger winter (1944-1945), the city of residence during these periods was used to approximate the exposure for energy restriction. Living in a city in 1942 (midpoint year 1940-1944) with more than 40,000 inhabitants was considered as an indicator for energy restriction in the War period because of the documented nutritional differences between a city and a rural area [9, 10]. This exposure variable was dichotomous, women living in a city in 1942 or women living in a rural area in 1942.

With respect to the Hunger winter, three categories were defined, women who lived in a Western city, women who lived in a Western rural area and women who lived in a NonWestern part of The Netherlands. Living in a Western city in 1944-1945 was considered as an indicator for severe energy restriction. The definition of a famine city (>40,000 inhabitants) is based upon the definition of a famine city according to the study of Stein et al [21]

In addition, the timing of exposure was of interest. Two periods can be distinguished in a woman's life in which energy restriction can have great influence on the development of the breast cells:

1. the 'adolescent growth spurt', in which the menarche occurs [22] and in which enlargement of the breasts is starting. If less energy is available during the growth spurt the enlargement of the breasts will take place in a 
slower rate and the breasts may be less susceptible for initiation hits. The adolescent growth spurt in this study was defined as 2 years before the reported age at menarche until 1 year after the reported age at menarche.

2. the time span between menarche and birth of the first child, referred to as the sensitive period During the first pregnancy the breast tissue differentiation is completed and until that moment the breast tissue is constantly sensitive to change and cell dividing activities. If less energy is available for these cell dividing activities the breast tissue may be less susceptible to carcinogenic exposures.

The women in the adolescent growth spurt or sensitive period in the three exposure periods were defined. Since the exposure periods are age-dependent and of varying duration it was decided to restrict the relevant time span in the long exposure periods 1932-1940 and 19401944 to the years in which the food situation was worst. For the Economic Depression period we selected the years 1933-34 because the literature regarding the Economic Depression showed a very poor food situation in the first years of the Economic Depression [14, 23] and some improvement in the later years [11]. Thus, only women with the adolescent growth spurt or sensitive period in 1933-34 were included in the subgroup. For the War period we selected the years 1942-43 because the food situation deteriorated progressively during the World War II years and the years $1942-43$ represent the worst years of the pre-famine period [10].

\section{Data analysis}

The distributions of the exposure variables were compared between the breast cancer cases and the female subcohort members. The associations between exposure variables and covariates were also studied in the subcohort. For the continuous covariates age, age at menarche, age at menopause, height, Quetelet index, alcohol intake and energy intake, mean values of these variables were compared between the exposure categories. Statistical significance of these associations was tested by t-tests and analysis of variance. Chi-square tests were conducted to test associations between exposure categories and the following categorical covariates: history of benign breast disease, familial breast cancer, parity, age at first birth and educational level. Age-adjusted analyses rate ratios (RR) were computed for the covariates for breast cancer [24, 25]. Covariates associated with breast cancer itself or with any of the exposure variables were considered as potential confounders. The effects of the risk factors were in the anticipated direction. A history of benign breast disease, a family history of breast cancer, age at menopause, height. alcohol intake, age at first birth, parity, age at menarche, education and energy intake were considered as confounders. The same confounders for breast cancer had already been investigated in the NLCS-cohort in previous analyses concerning dietary fat and breast cancer risk [26]

\section{Results}

In table 1 the overall means of various continuous variables and distributions of various categorical variables in relation to the exposure categories among subcohort women are presented

For the Hunger winter period alcohol intake and energy intake during the year preceding the baseline measurement, age at first birth, parity and education were different between the three exposure categories. Women who lived in a Western city in 1944-1945 had the highest level of alcohol intake in 1986 and the lowest level of energy intake in 1986 compared to women who lived in the Western rural area or in some other parts of The Netherlands in the winter of 1944 1945. Furthermore, women who lived in a Western city during the Hunger winter had the youngest age at menarche (mean, 13.6 years) and the lowest Quetelet index at baseline compared to women living in other parts of The Netherlands in 1944-1945. For women who were still at risk for their menarche at the start of the famine, the women living in a Western city had the oldest age at menarche (mean, 15.8 years)(data not shown). For the remaining war years (1940-1944), mean age at menopause and alcohol intake were significantly different between the exposure categories. Alcohol intake was significantly higher for women who had lived in a city in 1942 . Women who had lived in a rural area in 1942 were taller (mean, 165.3 $\mathrm{cm}$ ) compared to women who had lived in a city in 1942 (mean, $164.9 \mathrm{~cm}$ ). Furthermore, the women who had lived in a city in 1942 had fewer children and a higher educational level compared to women living in a rural area in 1942 
Table 1 Means, standard deviations (s d.) of selected continuous variables and distribution of selected categorical variables by food restriction exposure category in female subcohort members. Netherlands Cohort Study 1986-1992

\begin{tabular}{|c|c|c|c|c|c|c|c|c|c|}
\hline \multirow{4}{*}{$\begin{array}{ll}\text { Characteristics } & \begin{array}{l}\text { Subcohort } \\
\text { Cases }\end{array} \\
\end{array}$} & \multicolumn{9}{|c|}{ Exposure categones } \\
\hline & \multicolumn{5}{|l|}{$1944-45$} & \multicolumn{2}{|l|}{$1940-44$} & \multicolumn{2}{|l|}{$1932-40$} \\
\hline & $\begin{array}{l}\text { Non-West } \\
n=900 \\
n=500 \\
\text { mean (s.d.) }\end{array}$ & \multicolumn{2}{|c|}{$\begin{array}{l}\text { Western rural area } \\
n=239 \\
n=167 \\
\text { mean (s d.) }\end{array}$} & \multicolumn{2}{|c|}{$\begin{array}{l}\text { Western city } \\
n=454 \\
n=275 \\
\text { mean (s.d.) }\end{array}$} & $\begin{array}{l}\text { Rural area in } 42 \\
n=597 \\
n=350 \\
\text { mean (s d) }\end{array}$ & $\begin{array}{l}\text { Cify in } 42 \\
n=624 \\
n=371 \\
\text { mean (s.d) }\end{array}$ & $\begin{array}{l}\text { Father a job } \\
n=1419 \\
n=856 \\
\text { mean (s.d) }\end{array}$ & $\begin{array}{l}\text { Father no job } \\
n=184 \\
n=103 \\
\text { mean (s.d.) }\end{array}$ \\
\hline & $614 \quad(4.3)$ & 61.3 & (4.1) & 61.7 & $(44)$ & $(42)$ & (4.4) & $(42)$ & $62.1^{\circ} \quad(4.4)$ \\
\hline Age at menarche & 138 (1.7) & 13.7 & $(1.8)$ & 13.6 & $(19)$ & $137 \quad(17)$ & $(18)$ & $(1.7)$ & $13.9^{\circ} \quad(2.1)$ \\
\hline Age at menopause & $48.8 \quad(4.4)$ & 48.8 & $(44)$ & 48.7 & $(4.7)$ & $492 \quad(41)$ & $486^{6}$ & (4.4) & $480^{\circ} \quad(47)$ \\
\hline Height $(\mathrm{cm})$ in 1986 & 165.4 (6.3) & 165.1 & (6.1) & 1652 & $(5.9)$ & $1653 \quad 61)$ & 1649 & 1652 & $1639^{\circ}$ \\
\hline Weight $(\mathrm{kg})$ in 1986 & $687(0.4)$ & 69.7 & $(10.6)$ & 682 & $(100)$ & $692 \quad(10.3)$ & $(10.3)$ & 685 (10.1) & (110) \\
\hline Quetelet Index $\left(\mathrm{kg} / \mathrm{m}^{2}\right)$ in 1986 & $252(36)$ & 25.5 & (3.6) & 25.0 & $(34)$ & $25.3 \quad(3.5)$ & $(3.5)$ & (3.5) & $(3.8)$ \\
\hline Alcohol (g/day) in 1986 & $53 \quad(92)$ & 53 & $(82)$ & $69^{\circ}$ & $(10.8)$ & $47 \quad 80)$ & $63^{\circ}(102)$ & (98) & $44^{\circ}$ \\
\hline \multirow[t]{2}{*}{ Energy intake (kcal/day) in 1986} & $1692.1(435.8)$ & 1682.7 & $(433.8)$ & $1623.4^{\circ}$ & $(388.3)$ & $16830(4375)$ & $16400 \quad(398.0)$ & $1676.4(421.7)$ & $1591.3(430.6)$ \\
\hline & $\%$ & & $\%$ & & $\%$ & $\%$ & $\%$ & $\%$ & $\%$ \\
\hline \multicolumn{10}{|l|}{ Parity } \\
\hline nulliparous & 176 & & 18.3 & & 18.8 & 146 & 172 & 18.2 & 138 \\
\hline 1 child & 70 & & 6.1 & & 11.4 & 75 & 94 & 8.4 & 8.8 \\
\hline 2 children & 21.6 & & 243 & & 240 & 205 & 237 & 222 & 222 \\
\hline 23 children & 53.8 & & 51.3 & & 45.8 & 57.4 & 49.7 & 51.3 & 55.2 \\
\hline \multicolumn{10}{|l|}{ Age at first birth } \\
\hline nulliparous & 175 & & 18.0 & & $186^{\prime}$ & 146 & 170 & 18.0 & 13.8 \\
\hline $17.19 \mathrm{yr}$ & 1.3 & & 1.7 & & 20 & 0.7 & 1.9 & 1.3 & 22 \\
\hline $20-24 \mathrm{yr}$ & 191 & & 22.7 & & 251 & 210 & 228 & 196 & 337 \\
\hline $25-29 \mathrm{yr}$ & 413 & & 399 & & 39.9 & 445 & 397 & 422 & 343 \\
\hline $230 \mathrm{yr}$ & 20.8 & & 17.7 & & 14.4 & 19.2 & 18.6 & 18.9 & 16.0 \\
\hline \multicolumn{10}{|l|}{ Level of education } \\
\hline low & 629 & & 637 & & $479^{\circ}$ & 720 & $493^{\circ}$ & 54.9 & $758^{\circ}$ \\
\hline medium & 301 & & 27.4 & & 416 & 229 & 414 & 358 & 214 \\
\hline high & 70 & & 89 & & 105 & 51 & 93 & 9.3 & 28 \\
\hline
\end{tabular}

due to missing values numbers may not add up till 1716 and 1009

p p<0.01 (ANOVA). " $p<0.001$ (ANOVA)

$p<0.05$ (t-test). $p<0.005$ (t-test)

$p<0.001$ ( $x 2$-test), $p<0.005$ ( ( $x 2$-test) 
For exposure during the Economic Depression, baseline age, age at menarche, age at menopause, height, alcohol intake and energy intake were significantly different between the two exposure categories. Women whose father did not have a job during the Economic Depression had a later age at menarche and an earlier age at menopause compared to women whose father had a job in this period. The women whose father had no job were also shorter and had a lower alcohol intake and energy intake in 1986 compared to women whose father had a job during the Economic Depression (table 1). Women whose father was unemployed during the Economic Depression were considerably less educated compared to women whose father had a job during the Depression.

In table 2 the results of the age-adjusted and multivariate analyses of exposure in the three periods and breast cancer risk are presented. The age-adjusted analyses show that there are differences in RRs for the three periods. For the Hunger winter, a small increase in risk was seen for women who were then living in the Western rural area, compared to the reference category of women living in Non-Western parts of The Netherlands (RR=1.3, 95\% $\mathrm{Cl}: 1.0-1.6)$. Living in a Western city during the Hunger winter period showed a small increase in risk $(\mathrm{RR}=1.1,95 \% \mathrm{Cl}$ $0.9-1.3)$, which was not statistically significant. For exposure during the remaining War period there was no difference in RR between women living in a rural area and women living in a city in 1942 (RR=1.0, 95\% Cl: 0.9-1.2). With respect to the Economic Depression years, the analysis shows a small, nonsignificant decrease in risk for women whose father was unemployed ( $R R=0.9,95 \% \mathrm{Cl}: 0.7-1.2)$.

The associations between the risk of breast cancer and energy restriction were further evaluated in a multivariate model with adjustment for age, age at menopause, benign breast disease, maternal breast cancer, breast cancer in sister(s), age at first birth, parity, alcohol intake, energy intake and education. Age at menarche and height were not included in the model. The rate ratios were slightly changed compared to the age-adjusted analysis, as is shown in table 2, but the multivariate adjusted RRs showed the same trend as in the age-adjusted analyses. There was again no difference in breast cancer risk for women living in a city in 1942 compared to women living in a rural area in 1942. For women living in a Western rural area during the Hunger winter 1944-1945 the analysis showed a significant increase in breast cancer risk compared to women who lived in Non-Western parts of The Netherlands (RR $=1.5,95 \% \mathrm{Cl}: 1.1$. 1.9). Women whose father was unemployed during the Economic Depression years showed a decrease in breast cancer risk ( $R R=0.9$, $95 \% \mathrm{Cl}: 0.7-1.2)$ in multivariate analysis. although not significantly.

Age at menarche and height are two variables that might play a role in the possible biological explanations of our hypothesis. We conducted a multivariate analysis where additional correction was included for these two variables. This adjustment did not alter the RRs appreciably. but they were closer to 1 (see table 3). suggesting that each of these two variables might act as intermediate variables. In further analyses these two variables were not included in the multivariate model.

Additional comparisons with other reference categories were made in multivariate analyses. A comparison was made between the Western cities and cities in other parts of The Netherlands and a comparison between the Western rural area and rural area in other parts of The Netherlands. By using different reference categories the RRs did not change substantially (data not show). We conducted several subgroup analyses to evaluate possible effects of the timing of energy restriction. As a consequence of the small number of cases in the subgroups "exposure before growth spurt in the Hunger winter" and "exposure before sensitive period in the War years", some multivariate models did not converge. For these subgroups we only conducted an age-adjusted analysis. Exposure to energy restriction during the adolescent growth spurt (table 4) shows for women living in a Western city an increased risk ( $R R=1.2,95 \% \mathrm{Cl} 0.8-2.0$ ) compared to women living in Non-Western parts of The Netherlands. For women living in the Western rural area a significantly increased risk $(R R=1.8,95 \% \mathrm{Cl} 1.0$ 3.2) was seen compared to women living in Non-Western parts of The Netherlands during the Hunger winter, but the number of cases is very small and the $95 \%$ confidence interval is accordingly large. 
Table 2 Age-adjusted relative rates and multivariate relative rates of breast cancer, according to food restriction exposure in three time periods, 1944-45 1940-44 and 1932-40, Netherlands Cohort Study 1986-1992

\begin{tabular}{|c|c|c|c|c|c|c|}
\hline \multirow[b]{2}{*}{ Exposure } & \multicolumn{3}{|c|}{ Age-adjusted } & \multicolumn{3}{|c|}{ Multivariate } \\
\hline & $\begin{array}{l}\text { Cases } \\
\text { cohort }\end{array}$ & $\mathrm{RR}^{\prime}$ & $95 \% \mathrm{Cl}$ & $\begin{array}{l}\text { Cases } \\
\text { Cohort }\end{array}$ & $\mathrm{RR}^{2}$ & $95 \% \mathrm{Cl}$ \\
\hline \multicolumn{7}{|c|}{ Hunger winter 1944-1945 } \\
\hline Non-West & 500 & $1.0^{\mathrm{a}}$ & & 418 & $1.0^{\mathrm{a}}$ & \\
\hline Western rural area & 167 & 1.3 & $1.01-1.55$ & 144 & 1.5 & $1.13-1.87$ \\
\hline Western city & 275 & 1.1 & $0.91-1.31$ & 239 & 1.1 & $0.91-1.38$ \\
\hline \multicolumn{7}{|l|}{ War Years 1940-1944 } \\
\hline Rural area in 1942 & 350 & $1.0^{\mathrm{a}}$ & & 295 & $1.0^{\mathrm{a}}$ & \\
\hline City in 1942 & 371 & 1.0 & $0.85-1.21$ & 323 & 1.0 & $0.79-1.21$ \\
\hline \multicolumn{7}{|c|}{ Economic Depression 1932-1940 } \\
\hline Father had a job & 856 & $1.0^{\mathrm{a}}$ & & 733 & $1.0^{\mathrm{a}}$ & \\
\hline Father had no job & 103 & 0.9 & $0.72-1.19$ & 83 & 0.9 & $0.68-1.22$ \\
\hline
\end{tabular}

\footnotetext{
"Reference category

Age in three categories: 55-59 yr, 60-64 yr, 65-69 yr.

${ }^{2}$ Relative rate after adjustment for age, age at menopause, parity, age at first birth, maternal breast cancer, breast cancer in sister(s), benign breast disease, alcohol use, energy consumption, education, without age at menarche and height.
}

Table 3 Multivariate relative rates of breast cancer, according to food restriction exposure in three time periods, 1944-45, 1940-44 and 1932-40 with age at menarche and height added to the model, Netherlands Cohort Study 1986-1992

\begin{tabular}{|c|c|c|c|c|c|c|}
\hline \multirow[b]{2}{*}{ Exposure } & \multicolumn{2}{|c|}{ Model I' } & \multicolumn{2}{|c|}{ Model II } & \multicolumn{2}{|c|}{ Model III ${ }^{3}$} \\
\hline & $R R$ & $95 \% \mathrm{Cl}$ & RR & $95 \% \mathrm{Cl}$ & RR & $95 \% \mathrm{Cl}$ \\
\hline
\end{tabular}

\section{Hunger winter 1944-1945}

\begin{tabular}{lllllll} 
Non-West & $1.0^{\mathrm{a}}$ & \multicolumn{3}{c}{$1.0^{\mathrm{a}}$} & & $1.0^{\mathrm{a}}$ \\
Western rural area & 1.4 & $1.10-1.81$ & 1.4 & $1.09-1.79$ & 1.3 & $1.02-1.72$ \\
Western city & 1.1 & $0.89-1.34$ & 1.1 & $0.90-1.34$ & 1.1 & $0.91-1.40$
\end{tabular}

War Years 1940-1944

Rural area in 1942

City in 1942

\begin{tabular}{|c|c|c|}
\hline $1.0^{\mathrm{a}}$ & $1.0^{\mathrm{a}}$ & \\
\hline $0.79-1.21$ & 1.0 & $0.80-1.23$ \\
\hline
\end{tabular}

\section{Economic Depression 1932-1940}

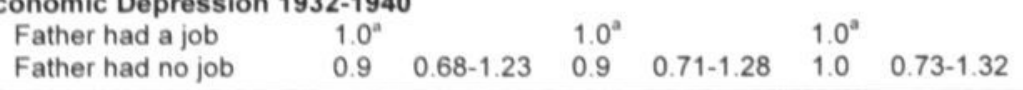

Reference category

Model I adjustment for: age, age at menopause, parity. age at first birth, maternal breast cancer. breast cancer in sister(s), benign breast disease, alcohol use, energy consumption, education and age at menarche

2 Model II adjustment for the variables named in model I without age at menarche but with height.

3 Model III adjustment for the variables named in model I with height 
During the war years there was no difference in risk between women living in a city during their adolescent growth spurt and women living in a rural area. The RR for the women whose father had no job in 1933-34 and who were in their growth spurt at that time showed a decrease in breast cancer risk ( $R R=0.8,95 \% \mathrm{Cl} 0.5-1.4)$ which was not statistically significant (table 4). Again the number of cases is quite small.

The subgroups of women exposed after the growth spurt showed the same pattern as the group exposed during the growth spurt. Except the subgroups of women exposed before the growth spurt showed a different pattern. A decrease in risk is seen for women living in a Western city before their growth spurt ( $R R=0.3$. $95 \% \mathrm{Cl} 0.03-2.0$ ); however, the number of cases is very small. Also the women living in a city in 1942 before their growth spurt have a decreased risk ( $R R=0.5,95 \% \mathrm{Cl} 0.2-1.3)$ (see table 4).

Exposure during the sensitive period between the menarche and birth of first child showed the same pattern with breast cancer risk as exposure during adolescent growth spurt (see table 4). The RR for the exposure category Western city was nonsignificantly increased ( $R R=1.1,95 \% \mathrm{Cl} 0.9-1.4$ ). The RR for women living in the Western rural area was again significantly elevated $(R R=1.4,95 \% \mathrm{Cl} 1.1-1.9)$ compared to the exposure category living in other parts of The Netherlands. There was no difference in breast cancer risk between women living in a city or rural area during the war years and who were passing their sensitive period in the war years. Also with respect to the Economic Depression years no clear association was found between exposure during the sensitive period and breast cancer risk (RR=0.9, $95 \% \mathrm{Cl}: 0.5-1.7$ ). The subgroups exposed before and after the sensitive period also showed the same pattern as the subgroup exposed during the sensitive period (table 5). Only for the Hunger winter period there is a negative association ( $R R=0.7,95 \% \mathrm{Cl} 0.3-1.6)$ for the exposure living in a Western city in 19441945 before the sensitive period, although not significant. With respect to the war years, living in a city in 1942 showed for the subgroup exposure before the sensitive period a decrease in $\mathrm{RR}$ ( $\mathrm{RR}=0.7,95 \% \mathrm{Cl} 0.3-1.7$ ) but the number of cases is again very small. A small, nonsignificant negative association with living in a city in 1942 (RR=0.9, $95 \% \mathrm{Cl} 0.5-1.6)$ was found for the subgroup exposure after the sensitive period

Women whose father was unemployed during the Economic Depression years showed a negative association with exposure before the sensitive period, although not significant ( $R R=0.9,95 \% \mathrm{Cl}$ 0.6-1.3). In 1933-34 no woman in the cohort had already delivered her first child, thus no women were exposed after their sensitive period at that time.

Possibly not the food situation was the most important factor (because for everybody the food situation deteriorated during the War) but being in the adolescent growth spurt during these years could be the most important factor. Therefore, we also conducted a multivariate analysis for the War years in which exposure was defined as a combination of the residence in 1942 and being in the adolescent growth spurt in 1942. The subgroup of women who lived in a city in 1942 during their adolescent growth spurt showed a borderline significant decrease in breast cancer risk $(R R=0.7,95 \% \mathrm{Cl}$ 0.5-1.0) compared to all women who were before or after their adolescent growth spurt irrespective of their residence in 1942 (data not shown).

\section{Discussion}

This prospective cohort study found no clear evidence that energy restriction during adolescence decreased the risk of breast cancer, also after controlling for potential confounders. Compared to residents in the North and South of the country who served as controls with almost no exposure to energy restriction, for those living in the presumably food-restricted regions such as Western cities the results showed an increased breast cancer risk $(R R=1.1)$ and for those living in a Western rural area in 1944-1945 also $(R R=1.5)$. With respect to the war period (1940-1944) no differences in breast cancer risk were found for women who lived in a city (food restricted area) in 1942 vs women who lived in a rural area. Having an unemployed father during the Economic Depression years 1932-1940 was associated with a small, but not significant, decrease in breast cancer risk $(R R=0.9)$. Several alternative explanations for the results will be discussed. The potential for selection bias in the NICS is low considering the high completeness of cancer follow-up. 
Table 4 Relative rate of breast cancer for women exposed to energy restriction before, during and after their adolescent growth spurt ( $2 \mathrm{yr}<$ menarche< $1 \mathrm{yr}$ ) and their sensitive period (menarche1 st child) in the time-period 1944-45, 1942-43 en 1933-34. Netherlands Cohort Study 19861992

\begin{tabular}{|c|c|c|c|c|c|c|c|c|c|}
\hline \multirow[b]{2}{*}{ Exposure } & \multicolumn{3}{|c|}{ Before growth spurt } & \multicolumn{3}{|c|}{ During growth spurt } & \multicolumn{3}{|c|}{ After growth spurt } \\
\hline & \multicolumn{2}{|c|}{ Cases RR } & \multirow[t]{2}{*}{$95 \% \mathrm{Cl}$} & \multirow[t]{2}{*}{ Cases } & \multirow[t]{2}{*}{$\mathrm{RR}^{*}$} & \multirow[t]{2}{*}{$95 \% \mathrm{Cl}$} & \multirow[t]{2}{*}{ Cases } & \multicolumn{2}{|c|}{ s RR $95 \% \mathrm{Cl}$} \\
\hline \multicolumn{5}{|c|}{ Hunger winter 1944-1945 } & & & & & \\
\hline Non-West & 8 & $1.0^{a t}$ & & 102 & $1.0^{\circ}$ & & 332 & $1.0^{\circ}$ & \\
\hline Western rural area & 3 & 1.4 & $0.22-9.51$ & 32 & 1.8 & $1.01-3.15$ & 112 & 1.3 & $0.99-1.77$ \\
\hline Western city & 2 & 0.3 & $0.03-2.04$ & 60 & 1.2 & $0.77-1.99$ & 182 & 1.1 & $0.87-1.41$ \\
\hline \multicolumn{10}{|l|}{ War years 1942-1943 } \\
\hline Rural area in 1942 & 23 & $1.0^{\circ}$ & & 81 & $1.0^{\circ}$ & & 190 & $1.0^{\mathrm{a}}$ & \\
\hline City in 1942 & 33 & 0.5 & $0.22-1.34$ & 74 & 1.0 & $0.65-1.52$ & 215 & 1.0 & $0.75-1.28$ \\
\hline \multicolumn{10}{|c|}{ Economic Depression 1933-1934 } \\
\hline Father had a job & 463 & $1.0^{\circ}$ & & 226 & $1.0^{\circ}$ & & 40 & $1.0^{2}$ & \\
\hline \multirow[t]{2}{*}{ Father had no job } & 54 & 1.1 & $0.74-1.56$ & 24 & 0.8 & $0.45-1.39$ & 5 & 0.7 & $0.15-3.13$ \\
\hline & \multicolumn{3}{|c|}{ Before sensitive period } & \multicolumn{3}{|c|}{ During sensitive period } & \multicolumn{3}{|c|}{ After sensitive period } \\
\hline $\begin{array}{l}\text { Hunger winter } 1944-45 \\
\text { Non-West }\end{array}$ & 32 & $1.0^{\circ}$ & & 354 & $1.0^{\circ}$ & & 64 & $1.0^{\circ}$ & \\
\hline Western rural area & 12 & 2.9 & $1.04-8.03$ & 123 & 1.4 & $1.07-1.86$ & 19 & 1.7 & $0.85-3.37$ \\
\hline Western city & 22 & 0.7 & $0.26-1.61$ & 190 & 1.1 & $0.90-1.43$ & 48 & 1.1 & $0.62-1.79$ \\
\hline \multicolumn{10}{|l|}{ War years $1942-1943$} \\
\hline Rural area in 1942 & 18 & $1.0^{\text {at }}$ & & 241 & $1.0^{\circ}$ & & 43 & $1.0^{\mathrm{a}}$ & \\
\hline City in 1942 & 14 & 0.7 & $0.28-1.73$ & 250 & 1.0 & $0.76-1.22$ & 62 & 0.9 & $0.52-1.56$ \\
\hline \multicolumn{7}{|c|}{ Economic Depression 1933-1934 } & \multirow{3}{*}{\multicolumn{3}{|c|}{$\begin{array}{l}\text { no women who were } \\
\text { after their sensitive- } \\
\text { period in } 1933-34\end{array}$}} \\
\hline Father had a job & 585 & $1.0^{\mathrm{a}}$ & & 144 & $1.0^{\mathrm{a}}$ & & & & \\
\hline Father had no job & 64 & 0.9 & $0.61-1.27$ & 19 & 0.9 & $0.49-1.70$ & & & \\
\hline
\end{tabular}

\footnotetext{
- Relative rate after adjustment for: age, age at menopause, parity, age at first birth, maternal breast cancer. breast cancer in sister(s), benign breast disease, alcohol use, energy consumption, education

Reference category

${ }^{t}$ Only age-adjusted
}

Also, there were no reasons to assume that residual confounding was still present because all major risk factors for breast cancer were measured and controlled for in multivariate analyses. Differential recall of major events such as age at first birth, parity, age at menarche and residence during the Hunger winter seems unlikely. A factor that could have influenced the results is misclassification of food restriction exposure. Three proxy measures of energy restriction were used in this study: the fathers employment status of the women during the Economic Depression years, residence during the World War II (1940-1944), and residence during the Hunger winter (1944-1945). Whereas surveys showed that energy intake was associated with fathers' employment status in
1932-1940 [12, 13], that the food supply in the cities deteriorated much faster than in the rural area during 1940-1944 $[9,10]$ and that starvation in the West in 1944-1945 was mostly confined to Western cities [6-8], we are aware that these ecological measures are only a proxy measure of individual exposures. Other studies used the same proxy measure for energy restriction in the Hunger winter. These studies found relations between living in a Western city and perinatal mortality of the newborn, lower birth weight and delay in the onset of menarche. These studies had a more complete exposition available in their study population compared to the population of the NLCS-cohort. Most of the women in the NLCS-cohort had already passed their menarche. The severe energy restriction during the hunger winter, could therefore no 
longer affect the age of menarche of these women.

Also long term effects have been reported on the birth weight of offspring of women who themselves were conceived during the famine period. These results indicate that the residence in 1944-1945 is a good predictor for energy restriction and is likely to be a valid measure [21, 27-32].

In our study, we asked only the female subcohort members, during follow-up if they really had experienced hunger during the winter of $1944-1945$. Our results showed that $75 \%$ of the women living in a Western city reported that they experienced hunger during the winter of 1944-1945 of whom 35\% experienced severe hunger. Of the women who reported severe hunger during the Hunger winter $80 \%$ lived in a Western city during this winter. These results also indicated that the proxy measure for energy restriction in the Hunger winter is reasonably adequate. In our study the period of severe energy restriction was relatively short in the Hunger winter (only 7 months of severe deprivation, i.e. less than $40 \%$ of normal energyintake) [7]. The short duration of energy restriction could be a possible explanation for not finding an effect on breast cancer risk. Nevertheless, the famine had an effect on reproductive factors of women who gave birth during and after the Hunger winter and were exposed to the famine $[29,31,32]$. A delay in the birth of the first child is seen in the NLCS although the number of births is very small and this effect is seen in the whole country.

With respect to the War years (1940-1944) no association was found between living in a city and breast cancer risk. During World War II the food situation leveled off for everybody, for people living in city as well as for people living in rural areas[33]. Therefore the contrast in energy intake between the exposure categories was probably not sufficient to detect an effect of energy restriction. In addition we defined exposure as a combination of residence in 1942 and being in the adolescent growth spurt. For women who lived in a city in 1942 and being in their adolescent growth spurt a borderline significant decrease in breast cancer risk was seen $(R R=0.7)$. This definition of exposure suggests that energy restriction has more impact on women being in the adolescent growth spurt than on women only living in a city in 1942. Possibly, the adolescent growth spurt is a more important factor than residence in 1942.

Another possible explanation of our findings could be the opposite effects of energy restriction on selected breast cancer risk factors. Energy restriction may delay age at menarche. which may lead to a decrease in breast cancer risk. In our study a delay in age at menarche is seen for women who were still at risk for their menarche at the beginning of the Hunger winter (mean age of menarche 15 years). This effect was seen in the whole country and not only for the Western region. However, due to energy restriction and social circumstances during the Hunger winter, a delay in the birth of first child could also occur, which may lead to an increase in breast cancer risk. These opposite effects of energy restriction early in life could have resulted in no overall effect on breast cancer risk later in life.

Height is a risk factor for breast cancer in the NLCS-cohort [34]. Energy restriction early in life may negatively affect attained height, which might itself lead to a reduction in breast cancer risk [35-38]. Our data show that the variable adult height is associated with the exposure in the Economic Depression years. Women whose father was unemployed during the Economic Depression are significantly shorter than women whose father had a job during this period (table 1). Therefore, the longer period of relatively minor food deprivation during the Economic Depression years could have had an effect on adult height and, consequently, on breast cancer risk. Adult height was not associated with exposure in the War years and the Hunger winter

The cohort could have been too old at the time of exposure. During exposure in the Hunger winter no women were under 13 years of age The influence of energy restriction might play a role earlier in life than around the age of menarche. The results of the subgroup analyses point in this direction. Subgroups in which exposure before growth spurt and sensitive period was analyzed, showed a decrease in breast cancer risk for women living in a Western city in 1944-1945, living in a city in 1942 and having an unemployed father during the Economic Depression years (only for exposure before the sensitive period), although the number of women in the subgroups was very small. These analyses should be repeated when 
follow-up data is available for later years with a larger number of cases.

Another explanation for the elevated breast cancer risk in the Western rural area could be the choice of the reference category. For various reasons, the Western part of The Netherlands may not be directly comparable to the other parts of The Netherlands. Specifically, because of historical migration patterns, there may be region-specific breast cancer risks. In the NLCS, the Western rural area did not differ from the Western cities or other parts of The Netherlands in breast cancer risk factors (see table 1 and 2). However, whereas the Western Netherlands was exposed to severe food and fuel shortages during the winter of 1944-1945, the overall reproductive casualty rates (stillbirths plus infant mortality) were no worse in the West, and for most of the time, considerably lower than in the North and South of the country $[6,8]$. As an explanation for this paradox selective migration of the heslthiest and hest fed women towards the West has been postulated [39]. It is possible that this has led to regional baseline differences in breast cancer risk.

We made an additional comparison with different reference categories for the Hunger winter period 1944-1945. When the multivariate analysis was limited to the Western region, the RR for the women who lived in a Western city is decreased ( $R R=0.7$ ), compared to women who lived in the Western rural area.

In conclusion, we found no strong support for the hypothesis that energy restriction in the defined periods of adolescence leads to a decrease in breast cancer risk in adults living in The Netherlands. In future studies the effects on breast cancer risk should be explored among populations who experienced energy restriction for a longer period of time, especially before menarche.

\section{References}

1 de Winter GW. Coebergh JWW, van Leeuwen FE Schouten LJ Incidence of cancer in the Netherlands. 1989 Utrecht Netherlands Cancer Registry, 1989

2. Albanes D Caloric intake, body weight, and cancer a review Nutr Cancer 1987.9 199-217

3 Waard de F. Trichopoulos D A unifying concept of the etiology of breast cancer Int J Cancer 1988, 41 666-669

4. Hislop TG, Coldman AJ. Elwood JM. Brauer G, Kan L Childhood and recent eating patterns and risk of breast cancer Cancer Detect Prev 1986, 9(1-2) 47-58

5. Treth S. Gaard M. Lifestyle changes during adolescence and risk of breast cancer an ecologic study of the effect of
World War II in Nonway. Cancer Causes Control 1996, 7(5): $507-12$

6. Burger GCE, Drummond JC, Sandstead HR Appendices to mainutrition and starvation in Western Netherlands, September 1944- July 1945 (Part II). The Hague. The Hague General Sate Printing Office, 1948

7. Burger GCE, Sandstead HR, Drummond J: Starvation in Western Holland: 1945 . Lancet 1945; ii: 282-3.

8. Burger GCE. Drummond JC. Sandstead HR. Malnutrition and starvation in Western Netherlands. September 1944July 1945. The Hague. The hague General State Printing Office, 1948

9. Breunis J. The food supply Ann Am Acad Pol Soc Sci 1946, $245,87.92$

10. Dols MJL, Van Arcken AJM. De voedselvoorziening in Nederland tijens en onmiddelijk na den tweeden wereldoorlog 1940-1945. Voeding 1946, 6 : 193-207

11. Eljkel C Voeding. gezondheid en financiele toestand van 700 werkloozen gezinnen. deel I en II. The Hague. Algemene Landsdrukkerij. 1940.

12. Tromp MH De voeding in het gezin van den werklooze Ned T Geneesk 1934; 78 :5388-99

13. Kastein GW. De voeding van 343 werkloozengezinnen in Rotterdam en Schiedam in de wintermaanden van 19341935 Ned T Geneesk 1935, 79 . 5583-7

14 den Hartog AP [Unemployed people and their nutrition in the depression years 1930-1939] Werkiozen en hun voeding in de jaren 1930-1939 Voeding 1983, 44 . 92-8

15. Moolgavkar SH The multistage theory of carcinogenesis and the age distribution of cancer in man. J Nati Cancer Inst $1978,61(1)$ 49-52

10. Russo J. Ousieisur Dh, Tuyers Ac, Nubsu ws, Womiryo SR, van Zwieten MJ. Biology disease, comparative study of huyman and rat mammary tumorigenesis. Lab Invest 1990 . 3. $244-79$

17 Russo J. Tay LK, Russo IH Differentiation of the mammary gland and susceptibility to carcinogenesis. Breast Cancer Res Trat 1982, 2. 5-73

18. Van den Brandt PA, Goldbohm RA, Van 't Veer P. Volovics A, Hermus, R J J. Sturmans F: A large scale prospective cohort study on diet and cancer in the Netherlands J Clin Epidemiol 1990; $19: 285-95$

19. Van den Brandt PA. Schouten LJ, Goldbohm RA. Dorant E. Hunen PMH Development of a record linkage protocol for use in the Dutch cancer registry for epidemiological research Int J Epidemiol 1990; $19: 553-8$

20. Goldbohm RA, Van den Brandt PA, Dorant E Estimation of the coverage of Dutch municipalities by cancer registries and PALGA based on hospital discharge data. Tijdschr Soc Gezondheidsz 1994: 72: 80-4

21. Stein Z, Susser M, Saenger G, Marolla F: Famine and human development, the Dutch Hunger winter of 1944-1945 New York: Oxford University Press, 1975.

22. Marshall WA. Tanner JM Puberty. 2nd, ed New York: Plenum Press, 1986. (Falkner F, Tanner JM, eds. Human growth, a comprehensive treatise)

23 Banning C. Den Hartog C. Nutrition and dietary habits in the various provinces of the Netherlands Nutrition and Dietary 1936, $5: 560-3$

24 Volovics A. Van den Brandt PA Methods for the analyses of case-cohort studies Biom J 1997, 39 195-214.

25 Self SG. Prentice RL Asymptotic distribution theory and efficiency results for case-cohort studies Ann Statistics $1988,16.64-81$

26 Van den Brandt PA, Van T Veer P. Goldbohm RA, et al A prospective cohort study on dietary fat and the risk of postmenopausal breast cancer. Cancer Res 1993, 53(1): 75 . 82

27. Van Noord PA. Kaaks R. The effect of wartime conditions and the 1944-45 'Dutch famine' on recalled menarcheal age in participants of the DOM breast cancer screening project Ann Hum Biol 1991, 18(1) 57-70

28 Lumey LH Decreased birthweights in infants after maternal in utero exposure to the Dutch famine of 1944 1945 Paediatr Perinat Epidemioi 1992, 6(2) 240-53 
29. Lumey LH, Ravelli AC. Wiessing LG, Koppe JG, Treffers PE, Stein ZA. The Dutch famine birth cohort study design validation of exposure, and selected characteristics of subjects after 43 years follow-up. Paediatr Perinat Epidemiol 1993: 7(4): 354-67.

30 Lumey LH. Stein $A D$ : In utero exposure to famine and subsequent fertility. The Dutch Famine Birth Cohort Study. Am J Public Health 1997; 87(12): $1962-6$.

31. Lumey $L$. Stein $A D$ Offspring birth weights after maternal intrauterine undernutrition: a comparison within sibships. Am J. Epidemiology 1997; 146(10): 810-9

32. Susser M, Stein Z. Timing in prenatal nutrition a reprise of the Dutch famine study. Nutrition reviews 1994, 52(3): 84 . 94.

33. Trienekens GMT: Between Us and starvation (Tussen ons volk en de honger, de voedselvoorziening 1940-1945), Wageningen Agriculter University: 1985.

34 Van den Brandt PA. Dirx M.M. Ronckers CM. Van den Hoogen P. Goldbohm A. Height, weight, weight change and postmenopausal breast cancer risk the Netherlands Cohort Study. Cancer Causes Control 1997; 8. 39-47.

35. Vatten LJ. Kvikstad A. Nymoen EH: Incidence and mortality of breast cancer related to body height and living conditions during childhood and adolescence. Eur J Cancer 1992, 28(1): 128-31

36. Willett WC. Nutritional epidemiology In. Rothman K.J. Greenland S. eds. Modern epidemiology. Philadelphia. Lippincot-Raven, 1998; 623-42

37. Brinton LA. Swanson CA. Height and weight at various ages and risk of breast cancer. Ann Epidemiol 1992; 2(5): $597-609$.

38. Le Marchand L. Kolonel LN, Earle ME, Mi MP: Body size at different periods of life and breast cancer risk. Am J Epidemiol 1988, 128(1): 137-52.

39. Hart N. Famine, maternal nutrition and infant mortality a re-examination of the Dutch hunger winter. Population Studies 1993:47: 27-46. 



\section{Energy restriction in childhood and adolescence and risk of prostate cancer: results from the Netherlands Cohort Study.}

Miranda J.M. Dirx $x^{1}$

Piet $A$. van den Brandt ${ }^{1}$

R. Alexandra Goldbohm ${ }^{2}$

L.H. Lumey ${ }^{3}$

Affiliations

Maastricht University, Department of Epidemiology, Maastricht, The Netherlands

2 TNO Nutrition and Food Research Institute, Department of Nutritional Epidemiology, Zeist. The Netherlands

${ }^{3}$ The Joseph L. Mailman School of Public Health, Columbia University, Division of Epidemiology, New York, NY10032 USA 


\section{Abstract}

This study investigated the association between prostate cancer risk and energy restriction during childhood. The authors examined the hypothesis among 58,279 men aged 55-69 years enrolled in the Netherlands Cohort Study on diet and cancer (NLCS). Information on diet and risk factors was collected by questionnaire in 1986. Additional information was collected on residence during the Hunger winter (1944-1945), the World War II years (1940-1944) and father's employment status during the economic depression of 1932-1940, used as indicators of exposure. A case-cohort approach was used. After 7.3 years of follow-up (through December 1993), 903 prostate cancer cases were available for analysis. Analyses were carried out for all prostate cancer cases.

The prostate cancer rate ratio for men who had lived in a western Netherlands city in 1944-1945 was 1.15 (95\% confidence interval $(\mathrm{Cl}) 0.80,1.31)$, and the rate ratio for men who had lived in a western rural area in 1944-1945 was 1.30 (95\% Cl 0.97, 1.73). Residence during the war years (1940-1944) and father's employment in 1932-1940 showed no relation to prostate cancer risk. In subgroup analyses in which exposure before, during, and after the adolescent growth spurt was evaluated, the same pattern as that of the overall data was shown.

The authors found no evidence for the hypothesis that energy restriction early in life decreases prostate cancer risk later in life.

(Dirx MJM, van den Brandt PA, Goldbohm RA, Lumey LH. Energy restriction in childhood and adolescence and the risk of prostate cancer: results of the Netherlands Cohort Study. American Joumal of Epidemiology 2001; 154 : 530-7 


\section{Introduction}

Prostate cancer is the second most commonly diagnosed cancer in males after lung cancer. The age-standardized incidence rate in the Netherlands in 1994 was 87.2 per 100,000 males. In addition, the number of newly diagnosed patients with prostate cancer has recently increased considerably [1]

The role of dietary risk factors in the development of prostate cancer is not clear. Ross and Henderson [2] stated that diet could alter steroid hormone profiles and thereby modify prostate cancer risk throughout life. Their model suggests that diet-regulated hormonal influences first exert an effect in utero. Ross and Henderson speculated that high testosterone levels during pregnancy might contribute to high rates of prostate cancer in male offspring. A high-fat diet during childhood could also contribute to early puberty and to a prolonged exposure to testosterone. It has been hypothesized that exposure to a high-fat diet during adolescence may initiate tumor development. Diamandis et al (1996) speculated that in early life, especially around puberty. when there is an abrupt and massive increase of steroid hormone production by the testes, prostate cells might undergo malignant transformation and start to proliferate [3-5].

Several studies have evaluated the relation between diet and prostate cancer, but only a few have concentrated on diet in adolescence. Slattery et al. (1990) conducted a case-control study of prostate cancer in which reported foodconsumption patterns for the adolescent and adult years were assessed. Men who had had a diet high in saturated fatty acids as adolescents were not at increased risk of developing prostate cancer [6]. Another study evaluated the relation of dietary and lifestyle characteristics to subsequent prostatic cancer risk in a cohort of 14,000 Seventh-day Adventist men. In that study, exposure to a vegetarian diet during childhood was not associated with prostate cancer risk later in life [7]. Results of a casecontrol study carried out in Sweden showed no clear association between dietary habits during childhood and adolescence and prostate cancer risk [8]. To investigate the relation between early dietary exposures and later cancer risk, proxy measures are generally needed, because no individual data on diet early in life are available.

In the Netherlands, a substantial portion of the population experienced severe famine in World War II, during the so-called Hunger winter of 1944-1945. The famine especially affected the western part of the country. This unique setting has provided researches with an opportunity to study the effects of severe undernutrition during adolescence on risk of prostate cancer later in life [9-11]. In addition, a period of chronically impaired nutrition existed in the Netherlands during the earlier years of World War II (19401944) and the Economic Depression of the 1930 s. As a consequence of the poor availability of food products in the cities. nutritional differences developed between residents of cities and residents of rural areas during the war years [12, 13]. During the Economic Depression a large proportion of people were unemployed. Several surveys showed that there was little variation in the food patterns of unemployed families and that their energy intake was not at the same level as the intake of employed people [14-17]. The energy restriction during these three periods. Economic Depression, the War years and the Hunger winter was the subject of investigation in this study

We examined the association between diet in childhood and adolescence and prostate cancer risk in the Netherlands Cohort Study (NLCS) on diet and cancer. Men who had been in their pubertal years during the Economic Depression. the War years and the Hunger winter were included in this prospective cohort study. We also examined interactions with the age at which dietary restriction had taken place.

\section{Materials and methods}

The Netherlands Cohort Study started in September 1986 when 58,279 men aged 55- 69 years were enrolled in the cohort. The total cohort comprises the 120,852 subjects who completed the baseline questionnaire, which was sent to 31940,439 persons (response rate $=35.5$ percent). Subjects originated from 204 municipal population registries throughout the country. Baseline exposure data were collected by means of a self-administered questionnaire. The questionnaire referred to dietary habits and potentially confounding 
dietary habits and potentially confounding factors such as physical activity, anthropometric measurements, smoking, education, and family history of cancer. Also included were questions about residences of the cohort members, including residence in the winter of 1944-1945 and father's employment status during the Economic Depression. A detailed description of the cohort study design has been reported elsewhere [18]. After the baseline exposure measurement, a subcohort was randomly sampled from the cohort and was followed biennially by questionnaire for information on vital status information, drug use, and occurrence of other diseases. Incident cancer cases occurring in the entire cohort were identified through record linkage to cancer registries and a national pathology register (PALGA). The method of record linkage has been described previously [19].

In order to minimize potential observer bias in coding and data interpretation, data from the subcohort and from prostate cancer cases were key-entered twice by research assistants who were blinded with respect to subcohort/case status. The present analysis was restricted to cancer incidence during the 7.3-year follow-up period from September 1986 to December 1993. Completeness of cancer follow-up exceeded 96 $\%$ [20]. After these 7.3 years of follow-up, 903 prostate cancer cases were available for analysis, after exclusion of prevalent cases. Prevalent cases of cancers other than skin cancer were also excluded from the subcohort, after which 1,630 men remained for analysis. Data analysis used the case-cohort approach, in which cases are derived from the entire cohort, while person-years at risk are estimated from the subcohort.

\section{Assessment of energy restriction}

The exposure variables had to adequately represent the energy restriction experienced by the men in the cohort during the Economic Depression years (1932-1940), the War years (1940-1944) and the Hunger winter (19441945). Data on the men's intake of individual food during these periods were not available; therefore, we used proxy variables for the energy restriction incurred during each of these periods. For the Economic Depression years (1932-1940), the occupation of the subject's father was the best available proxy variable. Having an unemployed father was taken to indicate that the amount of calories available was sufficient but the variation in the subject's food pattern was limited. The exposure variable for the Economic Depression years was dichotomous: men whose father had had a job during most of the period and men whose father had had no job during that period. For the War period (1940-1944) and the Hunger winter (1944-1945), the city of residence during the period was taken to approximate exposure to energy restriction. Living in a city with more than 40,000 inhabitants in 1942 (midpoint year 19401944) was considered an indicator for energy restriction during the war because of the documented nutritional differences between cities and rural areas [13]. This exposure variable was dichotomous, (living in a city in 1942 vs. living in a rural area in 1942).

With respect to the Hunger winter, three categories were defined: men who had lived in a Western city, men who had lived in a Western rural area and men who had lived in a NonWestern part of the Netherlands. Living in a western city in 1944-1945 was considered an indicator for severe energy restriction. The definition of a famine city (>40,000 inhabitants) was based on the definition used in the study by Stein et al [21].

In addition, the timing of exposure was considered. During the adolescent growth spurt of boys, energy restriction may have a considerable impact on later cancer risk. If less energy is available during the growth spurt, cell division may be slowed, making cells less susceptible for carcinogenic factors [2]. Adolescent growth spurt, as used in this study, was taken to occur between the ages of 12 and 15 years [22]. For men who had been in the adolescent growth spurt, the three exposure periods were defined more specifically. Since the exposure periods were age-dependent and of varying durations, we decided to restrict the relevant time span in the long exposure periods, 1932-1940 and 1940-1944 to the years in which the food situation was worst. For the Economic Depression period, we selected the years 19331934 because the literature on the Economic Depression showed a very poor food situation in the early years and some improvement in the later years. Thus, only men with an adolescent growth spurt in 1933-1934 were included in that subgroup. The age range was 2-11 years for men who had been exposed in the Economic 
Depression years before their adolescent growth spurt. For the World War II period, we selected the years 1942-1943 because the food situation deteriorated progressively during the war and the years 1942-1943 represented the worst years of the pre-famine period. The men who had been exposed in the war years before their adolescent growth spurt were all 11 years old at that time.

\section{Data analysis}

The data distributions of exposure variables for the prostate cancer cases and the male subcohort members were compared. Associations between exposure variables and covariates were also studied in the subcohort. For the continuous covariates age, height, Quetelet index [23], and intake of energy and Bcryptoxanthin [24] at baseline, mean values were compared between the exposure categories. The statistical significance of these associations was tested by t-tests and analysis of variance. Chi-squared tests were also conducted for associations between exposure categories and categorical covariates. Covariates associated with prostate cancer itself or with any of the exposure variables were considered as potential confounders. Age, family history of prostate cancer, educational level, intakes of B-cryptoxanthin and energy at baseline, marital status, and height were considered as confounders because they were associated with the exposure variables. All analyses were carried out using GLIM software [25]. Data were analyzed using the case-cohort approach, calculating age-adjusted rate ratios (RR) for prostate cancer and $95 \%$ confidence intervals $(\mathrm{Cl})$. Test for trend were based on likelihood ratio tests. In multivariate analyses. adjustment for covariates was carried out. To assess whether the effect of energy restriction on prostate cancer risk was modified by the timing at which dietary restriction took place. prostate cancer rate ratios for energy restriction in each of the three study periods were calculated within strata of the adolescent growth spurt. RR's were also computed in subgroups of localized, advanced, and latent prostate tumors. The classification into localized tumors (T0-2. MO) and advanced tumors (T3-4, M0: TO-4, M1) was based on the tumor-node-metastasis (TNM) staging system [26]. On the basis of information from the pathology reports, which we obtained from PALGA, prostate cancer cases detected during transurethral prostate resections were coded as latent. Cases detected during surgical procedures related to suspected cancer (biopsy. radical prostatectomy) were coded as nonlatent [24]. Cases were excluded from these subgroup analyses when this additional information was unknown or unclear (38.1percent).

\section{Results}

Table 1 shows the distributions of the exposure variables among prostate cancer cases and the male subcohort. Table 2 presents overall means for continuous variables and the distributions of categorical variables in relation to the exposure categories among subcohort men.

Table 1 Distribution of the food restricted exposure variables for the male subcohort and prostate cancer cases in the Netherlands Cohort Study (Sept 1986-Dec 1993)

\begin{tabular}{|c|c|c|c|c|}
\hline \multirow[b]{2}{*}{ Exposure variables } & \multicolumn{2}{|c|}{ Subcohort $(n=1630)^{\circ}$} & \multicolumn{2}{|c|}{ Cases $(n=903)^{\circ}$} \\
\hline & & $\%$ & $n$ & $\%$ \\
\hline \multicolumn{5}{|l|}{ Hunger winter 1944-1945 } \\
\hline non-western & 794 & 59.8 & 396 & 56.3 \\
\hline rural western & 199 & 150 & 126 & 17.9 \\
\hline western city & 334 & 252 & 181 & 25.8 \\
\hline \multicolumn{5}{|l|}{ War years $1940-1944$} \\
\hline rural area & 576 & 498 & 306 & 45.7 \\
\hline city & 581 & 502 & 346 & 54.3 \\
\hline \multicolumn{5}{|c|}{ Economic Depression 1932-1940 } \\
\hline father had a job & 1343 & 87.9 & 749 & 886 \\
\hline father had no job & 185 & 121 & 196 & 11.4 \\
\hline
\end{tabular}

- due to missing data numbers may not add up to 1630 and 903 
Table 2 Means and standard deviations (s d. ) of selected continuous and categorical variables by food restriction exposure category in male subcohort members ( $n=1630$ ). Netherlands Cohort Study 1986-1993

\section{Hunger winter 1944-1945}

\begin{tabular}{lll}
\hline Non-West & Rural West & City West \\
mean (sd) & mean (sd) & mean $(s d)$.
\end{tabular}

Characteristics

Age

Height $(\mathrm{cm})$ in 1986

Weight $(\mathrm{kg})$ in 1986

Weight at age 20

Body mass index $\left(\mathrm{kg} / \mathrm{m}^{2}\right)$

Alcohol intake $1986(\mathrm{~g} /$ day $)$

Energy intake 1986

(kcal/day)

B-cryptoxanthin

( $\mu g /$ day)

father with prostate cancer

rother with prostate cancer no

yes

level of education

$$
\begin{aligned}
& \text { low } \\
& \text { medium } \\
& \text { high }
\end{aligned}
$$

marital status

single

divorced

married

widower

$\begin{array}{ccc}61.0(4.2) & 60.7(4.2) & 61.2(4.4) \\ 176.1(6.7) & 178.9(7.0) & 177.0(6.6)^{*} \\ 78.5(9.7) & 78.0(9.7) & 77.8(9.5) \\ 68.3(8.1) & 68.0(9.2) & 67.1(8.1) \\ 253(2.7) & 24.4(2.6) & 24.8(2.6)^{*} \\ 14.8(16.9) & 14.0(15.0) & 13.8(16.7) \\ 2161(543) & 2180(517) & 2071(472)^{*} \\ 134(140) & 141(150) & 163(175)^{*}\end{array}$

$134(140)$

$\%$

\section{0}

2.0

100.0

53.2

30.9

15.9

4.4

3.8

86.4

5.4

0.6

$37.5^{\mathrm{c}}$

38.7

23.7

32.2

17.1

4.1

0.5

93.4

93.4
2.0

\section{War years 1940-1944}

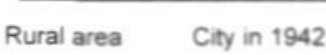

mean (s.d.) mean (s.d)

$61.1(4.2) \quad 61.6(42)$

$176.6(7.0) \quad 176.2(6.7)$

$79.0(9.9) \quad 77.0(9.0)^{\circ}$

$68.4(8.1) \quad 67.4(8.6)$

$25.3(2.7) \quad 24.8(2.6)^{\circ}$

$13.7(149) \quad 13.8(16.2)$

2173 (537) 2091(494)

128 (143) $162(159)^{b}$
$\%$

$\%$

98.3

97.2

28

99.7

0.3

97.7

\section{Economic Depression 1932-1940}

father a job father no job

mean (s.d.) mean (s.d.)

$61.3(4.2) \quad 61.5(4.3)$

$1768(6.7) \quad 176.6(7.4)$

$78.2(9.7) \quad 77.9(9.9)^{\circ}$
$67.8(8.3)$

$67.8(8.3) \quad 68.0(9.8)$

$250(26) \quad 249(2.8)$

$14.7(16.9) \quad 13.4(14.5)$

$2152(519) \quad 2083(509)$

$148(159) \quad 146(158)$

315

58.3

10.2

$433^{\mathrm{e}}$

40.3

16.4

4.0

4. 8

860

anova $(p<0.05)$

t-test $(p<0.05)$

chi square $(p<0.05)$ 
For the Hunger winter period, height, intakes of energy and B-cryptoxanthin, having a brother with prostate cancer, educational level, and marital status differed between the three exposure categories. Men who had lived in a western rural area during the winter of 1944 1945 were taller and had the highest energy intake in 1986 compared with men who had lived in a western city or in some other part of the Netherlands in that winter. Men who had lived in a western city during the Hunger winter had the highest level of B-cryptoxanthin intake compared with men living in other parts of the Netherlands. For the World War II years (19401944), weight, energy intake, B-cryptoxanthin intake, and educational level were significantly different between the exposure categories. Men who had lived in a city during the war years were less heavy than men who had lived in a rural part of the country during the war. Baseline energy intake was significantly lower and intake of B- cryptoxanthin was significantly higher for men who were living in a city in 1942 as compared with a rural area. Men whose fathers had had no job during the Economic Depression years were considerably less educated than men whose fathers had had a job during the depression.

Table 3 shows results from the age-adjusted and multivariate analyses of exposure in the three periods and prostate cancer risk. For the Hunger winter, multivariate analyses showed an increased risk ( $R R=1.30,95 \% \mathrm{Cl} 0.97-1.73)$ for men living in a Western rural area compared with in other parts of the Netherlands. A small elevated risk was also seen for men living in a western city (RR=1.15, $95 \% \mathrm{Cl} 0.80-1.31)$ compared with other parts of the Netherlands. For exposure during the remaining war years, a risk of 1.12 (95\% Cl 0.90-1.40) was seen for men who had lived in a city in 1942 as compared with a rural area. With respect to the Economic Depression years, age-adjusted and multivariate analyses showed the same results. A small decrease in risk was seen for men whose fathers had been unemployed during the Depression years (age-adjusted: $R R=0.9395 \%$ Cl 0.70-1.22; multivariate: $R=0.95,95 \% \mathrm{Cl}$ $0.71-1.27$ ). We conducted several subgroup analyses to evaluate possible effects of the timing of energy restriction (see table 4). As a consequence of our definition of the adolescent growth spurt, (ages 12-15 years), the subgroup 'exposure before growth spurt in the Hunger winter' contained no cohort members. All the men had been older than 12 years at the time of the Hunger winter

Table 3 Age-adjusted and multivariate rate ratios (RR) of prostate cancer, according to food restriction exposure in three time periods. 1944-1945, 1940-1944 and 1932-1940, Netherlands Cohort Study 1986-1993 (7.3 yrs follow-up)

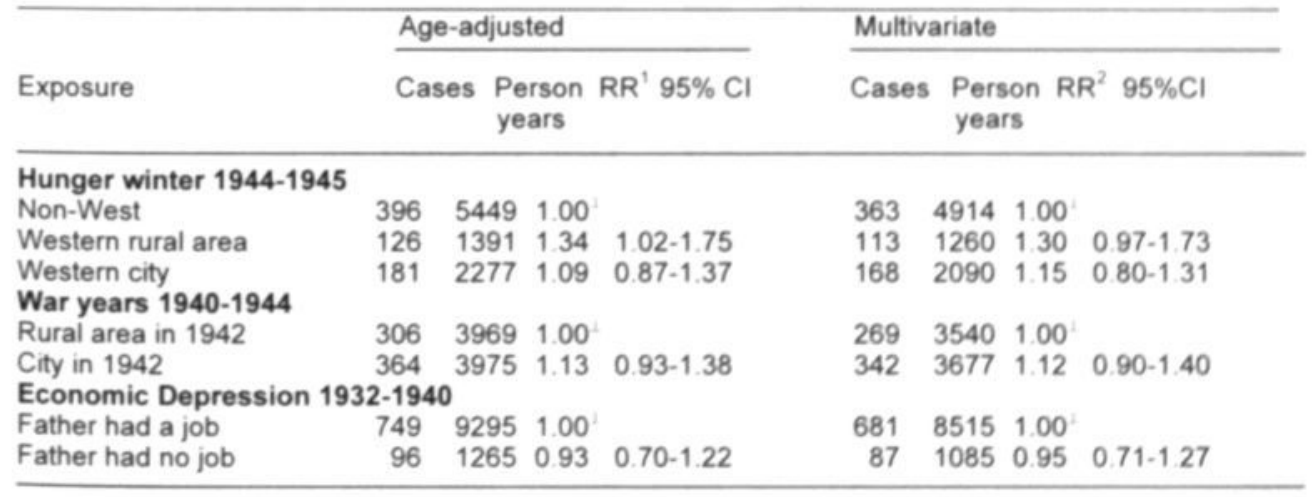

\footnotetext{
Reference category

Age in three categories: 55-59 yr, 60-64 yr, 65-69 y

${ }^{2}$ Rate ratio after adjustment for: age, prostate cancer in family, energy intake in 1986 (kcal/day). education, marital status, height, B-cryptoxanthin ( $\mu \mathrm{g} /$ day)
} 
Table 4 Rate ratios (RR) of prostate cancer for men exposed to energy restriction before, during and after their adolescent growth spurt (12-15 years) in the time period 1944-1945, 1942-43 and 1933-34, Netherlands Cohort Study 1986-1993 (7.3 yrs of follow-up)

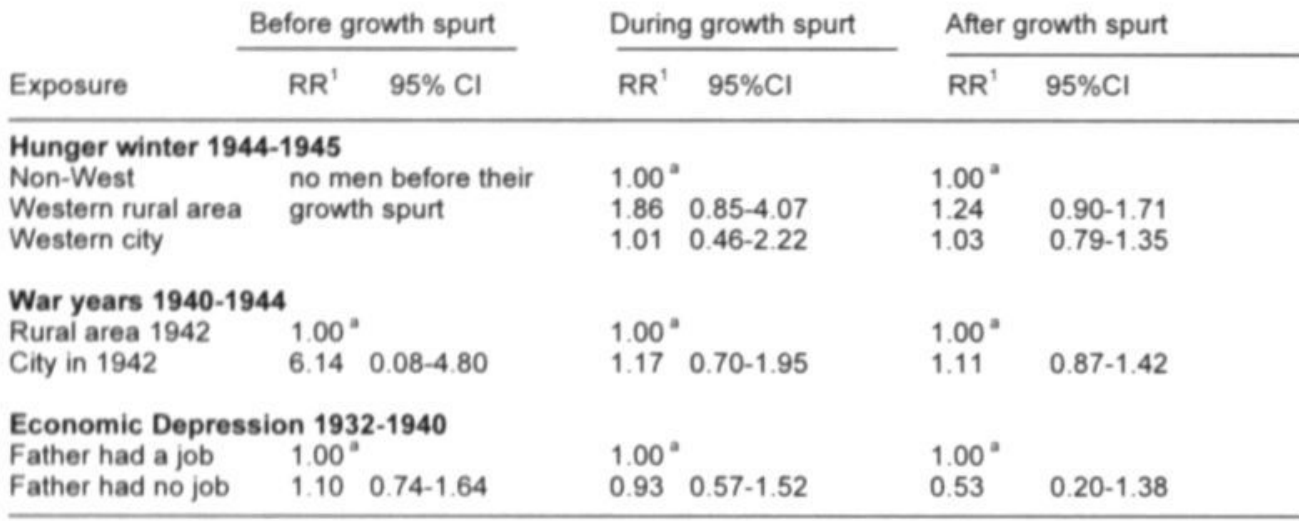

"Reference category

'Rate ratio after adjustment for: age, prostate cancer in family, energy intake in 1986 (kcal/day), education, marital status, height, B-cryptoxanthin ( $\mu \mathrm{g} /$ day)

Exposure to energy restriction during the adolescent growth spurt showed no decreased risk ( $R R=1.01,95 \% \mathrm{Cl} 0.46-2.22$ ) for men who had lived in a western city during the Hunger winter as compared with non-western parts of the Netherlands. For men living in a western rural area during the Hunger winter, a slightly increased risk ( $R R=1.86,95 \% \mathrm{Cl}$ 0.85-4.07) was seen in comparison with living in a nonwestern parts of the Netherlands during that winter, but the number of cases was very small and the $95 \%$ confidence interval was accordingly large. During the war years a slightly increased risk of prostate cancer ( $R R=1.17$. $95 \% \mathrm{Cl} 0.70-1.95$ ) was seen for men living in a city in 1942 during their adolescent growth spurt in comparison with men who were living in a rural area in 1942. The RR for men whose fathers had had no job in 1933-1934 and who were in their adolescent growth spurt at that time showed a slight decrease in prostate cancer risk ( $R R=0.93,95 \% \mathrm{Cl} 0.57-1.52)$. The subgroup exposed after the adolescent growth spurt showed a decreased risk $(R R=0.53,95 \%$ $\mathrm{Cl}$ 0.20-1.38) for men whose fathers were unemployed during the Depression years, but the number of cases was small. For men exposed before their adolescent growth spurt and whose fathers were unemployed during the Depression years a small increased risk was seen $(R R=1.10,95 \%$ Cl 0.74-1.64).
We also conducted multivariate analyses for energy restriction in the three time periods separately for localized, advanced, latent, and non-latent tumors. In the subgroup with localized prostate tumors, men living in a western city showed a decreased risk (RR=0.84, $95 \% \mathrm{Cl}$ $0.58-1.21)$ compared with men living in other parts of the country. The other subgroup analyses for the other exposure periods showed no pattern that differed from the overall results (data not shown). The energy restriction measures showed no consistent association with any specific subgroup of prostate cancer tumors.

\section{Discussion}

In this study we found no evidence for the hypothesis that energy restriction during adolescence is related to a decrease in prostate cancer risk. The results showed a slightly elevated prostate cancer risk among men who had lived in the presumably food restricted regions such as western cities $(R R=1.15)$ and western rural areas $(R R=1.30)$ during the Hunger winter 1944-1945, compared with controls living in northern and southern parts of the Netherlands who had almost no exposure to energy restriction. No association was seen with respect to the other War years (1940-1944) $(R R=1.12)$ or the Economic Depression years $(R R=0.95)$. In the subgroup analyses, in which 
subjects' exposure before, during, and after the adolescent growth spurt was evaluated, the results again showed no support for the hypothesis that energy restriction early in life plays a role in the development of prostate cancer.

Before we discuss these results in relation to those of other studies, we wish to make several relevant remarks about the Netherlands Cohort Study. Loss to follow-up is the primary source of potential selection bias in prospective cohort studies. Given the high completeness of followup for the cases and subcohort person years in the NLCS [20], selection bias is unlikely. Because we considered the most important potentially confounding factors reported in the literature and included in the multivariate model all factors associated with prostate cancer risk or the exposure variables (e.g., age, family history, energy intake), only unmeasured or still unknown other factors may have caused residual confounding.

A factor that could have influenced the results is misclassification of exposure to energy restriction. Three proxy measures of energy restriction were used in this study: the employment status of the men's fathers during the Economic Depression years (1932-1940). residence during World War II (1940-1944), and residence during the Hunger Winter (19441945). Whereas surveys have shown that energy intake was associated with father's employment status in 1932-1940 [16]. that the food supply in the cities deteriorated much faster than that in rural areas during 1940-1944 [12. 13]. and that starvation in the western of the country in 1944-1945 was mostly confined to cities [9-11, 13], we are aware that these ecologic measures are only a proxy measure of individual exposures. However, other studies used the same proxy measure we did for energy restriction during the Hunger winter, and their results also indicated that our proxy measure for energy restriction in the Hunger winter is reasonably adequate $[27,28]$. The finding of no association in our study could be due to a lack of variability in exposure

In our study, the period of severe energy restriction during the Hunger winter was relatively short $(7$ months of severe deprivation at less than $40 \%$ of normal energy-intake) [9] The short duration of energy restriction could be an explanation for our not finding an effect on prostate cancer risk. With respect to the war years (1940-1944) no association was found between living in a city and prostate cancer risk. During World War II, the food situation leveled off for everyone, people living in the city as well as people living in rural areas [29]. Therefore, the contrast in energy intakes between the exposure categories could not have been sufficient to detect an effect of energy restriction in 1940-1944. Furthermore, the cohort could have been too old at the time of exposure, since during exposure in the Hunger winter no men were under 12 years of age.

Only a few studies have examined the relation between adolescent diet and prostate cancer risk. Two studies were case-control studies $[6,8]$, and one study was the cohort study of 14.000 Seventh Day Adventist men [7]. The results of these studies are consistent with our findings. The case-control studies suggested that adolescent diet is not an important risk factor for prostate cancer but that perhaps other pubertal events affect prostate cancer risk (e.g. physical activity during childhood). Men who had diets high in saturated fatty acids as adolescents were not at increased risk for prostate cancer. It might be true that no association exits between energy restriction in adolescence and prostate cancer risk later in life.

In our study, data on physical activity in childhood were not available. Energy restriction during childhood and adolescence did have an impact on attained height and weight. Height was not a risk factor for prostate cancer in the NLCS-cohort but for body mass index (BMI) at age 20 years a significant positive trend in risk was observed [23]. This positive association is somewhat unexpected. In general, obesity has been reported to be inversely associated with plasma testosterone levels [30-33]. and lower testosterone levels may be related to lower prostate cancer risk [2]. However, obesity also shows an inverse relation with sex hormonebinding globuline (SHBG) and SHBG is hypothesized to have an inverse association with prostate cancer risk [4]. It might be plausible that different hormones or hormone levels are involved at different stages in prostate cancer development. Low energy intake during childhood and adolescence may be reflected in a lower height weight ratio at age 20 years. Our data show that weight at age 20 is related to the exposure variables, and height at baseline was 
also related to exposure during the Hunger winter period (men living in a western city were not as tall as men living in a western rural area). The subgroup analyses, with respect to different prostate cancer tumors or the timing of exposure, showed the same pattern as the overall results

In conclusion, we found no support for the hypothesis that energy restriction in childhood and adolescence leads to a decrease in prostate cancer risk among adults living in the Netherlands. In future studies, the effects of energy restriction on prostate cancer risk should be explored among populations who experienced energy restriction for longer periods of time and earlier in life. It would also be important that exposure for each subject be repeatedly assessed throughout life to promote insight into the relation of childhood nutritional patterns to cancer risk.

Acknowledgments: the Netherlands Cohort Study was supported by the Dutch Cancer Society and this project was financially supported by the American Cancer Society (grant no CCE-86051) and National Cancer Institute (grant no RO1CA81281-02) (L.H.Lumey, PI).

\section{References}

1. Visser O, Coebergh JWW. Schouten LJ, Dijck van JAAM Incidence of cancer in the Netherlands. Utrecht: Comprehensive Cancer Centers and their national Association, 1997

2. Ross RK. Henderson BE: Do diet and androgens alter prostatecancer risk via a common etiologic pathway? JNCI 1994, $86: 252-4$ (editorial)

3. Diamandis EP. Yu H Does prostate cancer start at puberty??? (letter to the editor). J.Clin Laboratory Analysis 1996: 10: 468-9

4. Gann PH. Hennekens $\mathrm{CH}$, Ma J, Longcope C. Stampfer MJ: Prospective study of sex hormone levels and risk of prostate cancer. J Natl Cancer Inst 1996, 88(16): $1118-1126$

5. Dorgan JF, Albanes D. Virtamo J, et al Relationships of serum androgens and estrogens to prostate cancer risk: results from a prospective study in Finland. Cancer Epidemiol Biomarker Prev 1998 . 7. 1069-1074

6. Slattery ML, Schumacher MC. West DW. Robison AM. French TK: Food-consumption trends between adolescent and adult years and subsequent risk of prostate cancer. Am J Clin Nutr 1990; 52: 752-7

7. Mills PK. Beeson WL. Phillips RL. Frase GE Cohort study of diet. lifestyle and prostate cancer in Adventist men. Cancer 1989, 64(3) 598-604
8. Andersson SO, Baron J, Wolk A, Lindgren C, Bergstrom R, Adami $\mathrm{HO}$ : Early life risk factors for prostate cancer: a population-based case-control study in Sweden. Cancer Epidemiol Biomarkers Prev 1995: 4(3): 187-92

9. Burger GCE, Sandstead HR, Drummond J Starvation in Western Holland: 1945. Lancet 1945; if: 282-3

10. Burger GCE, Drummond JC, Sandstead HR: Malnutrition and starvation in Western Netherlands, September 1944-July 1945. The Hague: The hague General State Printing Office, 1948.

11. Burger GCE, Drummond JC, Sandstead HR Appendices to malnutrition and starvation in Western Netherlands. September 1944- July 1945 (Part II).

The Hague: The Hague General Sate Printing Office. 1948.

12. Breunis J. The food supply. Ann Am Acad Pol Soc Sci 1946: $245: 87-92$

13. Dols MJL. Van Arcken A.JM De voedselvoorziening in Nederland tijdens en onmiddelijk na den tweeden wereldoorlog 1940-1945 Voeding 1946; 6: 193-207

14. Ten Bokkel Huinink SA: De voeding van de gezonde en zieke werkloozen, 1936

15. Tromp $\mathrm{MH}$ : De voeding in het gezin van den werklooze. Ned T Geneesk 1934; 78 : 5388-99.

16. Kastein GW: De voeding van 343 werkloozengezinnen in Rotterdam en Schiedam in de wintermaanden van 1934-1935. Ned T Geneesk 1935: 79: 5583-7

17. den Hartog AP: [Unemployed people and their nutrition in the depression years 1930-1939] Werklozen en hun voeding in de jaren 1930-1939. Voeding $1983 ; 44: 92-8$

18. Van den Brandt PA, Goldbohm RA, Van 't Veer P, Volovics A. Hermus, R.J.J., Sturmans F: A large scale prospective cohort study on diet and cancer in the Netherlands. J Clin Epidemiol 1990; 19: 285-95

19. Van den Brandt PA, Schouten LJ, Goldbohm RA, Dorant E. Hunen PMH: Development of a record linkage protocol for use in the Dutch cancer registry for epidemiological research. Int J Epidemiol 1990; 19: $553-8$

20. Goldbohm RA, Van den Brandt PA, Dorant E Estimation of the coverage of Dutch municipalities by cancer registries and PALGA based on hospital discharge data. Tijdschr Soc Gezondheidsz 1994, 72 80-4

21. Stein Z, Susser M. Saenger G, Marolla F: Famine and human development, the Dutch Hunger winter of 1944-1945. New York: Oxford University Press, 1975 22. Marshall WA, Tanner JM. Puberty, 2nd, ed. New York. Plenum Press, 1986. (Falkner F. Tanner JM. eds. Human growth, a comprehensive treatise)

23. Schuurman AG, Goldbohm RA, Dorant E, Van den Brandt PA Anthropometry in relation to prostate cancer risk in the Netherlands Cohort Study. Am J Epidemiol 2000, 151: 541-9

24. Schuurman AG Diet and other risk factors for prostate cancer. Thesis, Maastricht University: 1999 25. Baker J: GLIM 3.77 Reference Manual Oxford: Numerical Algorithms Group. 1985 
26. Balducci L, Friedland J: Prostate cancer. Clinics in geriatric medicine 1997; 13(2): 283-306.

27. Dirx MJM, van den Brandt PA, Goldbohm RA, Lumey LH: Diet in adolescence and the risk of breast cancer : results of the Netherlands Cohort Study. Cancer Causes Control 1999; 10(3): 189-99

28. Lumey LH, Stein AD: Offspring birth weights after maternal intrauterine undernutrition: a comparison within sibships. Am.J.Epidemiology 1997; 146(10): 810-9

29. Trienekens GMT: Between Us and starvation (Tussen ons volk en de honger, de voedselvoorziening 1940-1945). Wageningen Agriculter University; 1985.

30. Giovannucci E, Rimm EB, Stampfer MJ, Colditz GA. Willett WC: Height, body weight, and risk of prostate cancer. Cancer Epidemiol Biomarkers Prev 1997: 6: 557-563.
31. Dai WS, Kuller LH, LaPorte RE, Gutai JP, Falvo Gerard L, Caggiula A: The epidemiology of plasma testosterone levels in middle-aged men. Am J Epidemiol 1981; 114(6): 804-16.

32. Meikle AW, Bishop DT, Stringham JD, Ford MH, West DW: Relationship between body mass index. cigarette smoking. and plasma sex steroids in normal male twins. Genet Epidemiol 1989; 6(3): 399-412.

33. Wu AH, Whittemore AS, Kolonel LN, et al: Serum androgens and sex hormone-binding globulins in relation to lifestyle factors in older African-American, white, and Asian men in the United States and Canada. Cancer Epidemiol Biomarkers Prev 1995; 4(7): $735-41$ 

Energy restriction early in life and colon cancer risk: results of the Netherlands Cohort Study after 7.3 years of follow-up

Miranda J.M. Dirx ${ }^{1}$

Piet A. van den Brandt ${ }^{1}$

R.Alexandra Goldbohm ${ }^{2}$

L.H. Lumey ${ }^{3}$

\section{Affiliations}

${ }^{1}$ Maastricht University, Department of Epidemiology, Moastricht, The Netherlands

2 TNO Nutrition and Food Research Institute, Department of Epidemiology, Zeist, The Netherlands

${ }^{3}$ The Joseph L. Mailman School of Public Health, Columbia University, Division of Epidemiology, New York, NY10032 USA 


\section{Abstract}

Objective

The purpose of this study was to evaluate the effects of severe undernutrition during adolescence and subsequent colon cancer risk.

Methods

We examined the hypothesis in the Netherlands Cohort Study on Diet and Cancer (NLCS), among 62,573 women and 58,279 men aged 55-69 years at baseline. Information on diet and risk factors was collected by questionnaire in 1986. Additional information was collected on residence during the Hunger winter (1944-1945), the World War II years (1940-1944) and father's employment status during the economic depression of 1932-1940, used as indicators of exposure. After 7.3 years of follow-up, 807 colon cancer cases ( 388 females and 419 males) were available for analysis.

Results

Multivariate analysis showed that both men and women who had lived in a Western city in 1944-1945 had a decreased colon cancer risk (men: $R R=0.85,95 \% \mathrm{Cl} 0.62-1.16$; women $R R=0.80,95 \% \mathrm{Cl} 0.59$ 1.09). For the war years (1940-1944) we found no association between colon cancer risk and urban vs. rural residence. Having an unemployed father during the Economic Depression years 1932-1940 was associated with a small, but not significant decrease in colon cancer risk both for men ( $R R=0.90$, $95 \% \mathrm{Cl} 0.62-1.31$ ) and women ( $R R=0.75,95 \% \mathrm{Cl} 0.49-1.14)$. In subgroup analyses, a decreased colon cancer risk for men and women who were in their adolescent growth spurt and living in a Western city during the Hunger winter of $1944-1945$ was seen (men: $R R=0.72,95 \% \mathrm{Cl} 0.31-1.65$; women $R R=0.88$, $95 \% \mathrm{Cl} 0.40-1.96$ ).

\section{Conclusion}

We found in our study an inverse relation between energy restriction early in life and subsequent colon cancer risk, both for men and women.

(submitted for publication) 


\section{Introduction}

Colon cancer is the fourth most common cancer worldwide. For both sexes the incidence pattern is similar [1]. In the Netherlands the colon cancer incidence is approximately 50 per 100,000 in women and 60 per 100,000 in men [2]. In recent years the hypothesis that nutritional habits in childhood or adolescence (particularly caloric intake) may be associated with increased colon cancer risk - possibly mediated through hormone levels, body size or other components of energy balance- has attracted increased attention. In spite of the considerable literature from animal models suggesting that caloric restriction significantly reduces colon tumor risk [3-8], the results from epidemiologic studies in humans are conflicting $[9,10]$

Adult anthropometric measures (height, body mass index and sitting height) are often used as a proxy for the nutritional status during childhood and adolescence. Albanes et al. [11] demonstrated in their study of adult stature and colon cancer risk a stronger inverse association with the leg length component of stature than with sitting height. This finding agrees with early lifetime exposure hypotheses, because leg length is more sensitive to environmental influences during early life and adolescence than is sitting height $[12,13]$

To investigate early dietary exposures in relation to subsequent cancer risk, proxy measures are generally needed, as no individual data are available on diet early in life. In The Netherlands, a substantial part of the population experienced a severe famine during World War II. the so called Hunger winter (winter of 1944 45). especially in the Western part of the country. This unique setting provided the opportunity to study the effects of severe undernutrition during adolescence on the risk of colon cancer later in life [14-16]. In addition, a period of chronically impaired nutrition existed in The Netherlands during the earlier years of World War II (1940-44) and the Depression in the 1930 's. As a consequence of the poor availability of food products in the cities. nutritional differences developed between cities and rural areas during the war years [17, 18] The available amount of calories was greater in the rural areas. Also, the ratio between the dietary nutrients was different for cities and rural areas. In the cities carbohydrates contributed more to the total amount of energy (70 energy \%) compared to the rural areas (65 energy \%). The contribution of fat was also less in the cities compared to the rural areas ( 10 energy $\%$ vs. 15 energy $\%$ ).

During the Economic Depression a large proportion of people were unemployed. Several surveys showed that in the food pattern of the unemployed families there was little variation and the energy intake was not at the same level as for the employed people [19-21]. The total amount of energy available for unemployed families compared to employed families was 3000 vs. 3400 calories [22]. The daily menu of the unemployed people was very sober, consisting of boiled potatoes and some fat. Also the bread meals underwent changes, no longer including cheese, meat and confectionary. The energy restriction in these three periods. Economic Depression, the War years and the Hunger winter is subject of investigation in this study

We examined the association between diet in adolescence and colon cancer risk in the Netherlands Cohort Study (NLCS) on diet and cancer. Men and women who were passing their pubertal years during the Economic Depression, the War and the Hunger winter were included in this prospective cohort study. In this study we focused on the interaction with the age at which dietary restriction took place, with particular attention to men and women who were exposed during their adolescent growth spurt Our hypothesis is that energy restriction during childhood and adolescence will show a protective effect on colon cancer risk later in life.

\section{Materials and methods}

In September 1986, the Netherlands Cohort Study (NLCS), investigating various lifestyle variables. dietary habits and potential confounders of colon cancer was started. Also included were questions about the residences of the cohort members during their entire life, including the residence in the war years and the winter of 1944-45 and the father's employment status during the Economic Depression. A detailed description of the cohort study design has been reported elsewhere [23]. Briefly, the cohort included 62.573 women and 58.279 men 
aged 55 to 69 years at the beginning of the study. The study population originated from 204 municipal population registries throughout the country. Baseline exposure data were collected by means of a self-administered questionnaire. After the baseline exposure measurement, a subcohort was randomly sampled from the cohort and followed up biennially for vital status information. Incident cancer cases occurring in the entire cohort have been identified by record linkage to cancer registries and a national pathology register (PALGA). The method of record linkage has been described previously [24]

The collected data from subcohort and colon cancer cases were key-entered twice by a research assistant who was blinded with respect to subcohort/case status in order to minimize observer bias in coding and interpretation of the data. The present analysis is restricted to cancer incidence in the 7.3-year follow-up from September 1986 to December 1993. Completeness of cancer follow-up was estimated to exceed 96 percent. After these 7.3 years of follow-up, 807 colon cancer cases ( 388 females and 419 males) were available for analysis, after exclusion of prevalent cancer cases and cases with in situ carcinoma. Prevalent cancer cases other than skin cancer were also excluded from the subcohort, with the result that 3346 subjects (1630 men and 1716 women) remained in this group. For data analysis the case-cohort approach was used in which cases are derived from the entire cohort. while the person-years at risk are estimated from the subcohort.

\section{Assessment of energy restriction}

The exposure variables have to adequately represent the energy restriction of the subjects in the cohort for the Economic Depression years $(1932-40)$, the War years $(1940-44)$ and the Hunger winter (1944-45). Individual food intake data of the cohort members in these periods were not available; we therefore used proxy variables for the energy restriction in each of these periods. For the Economic Depression years (1932-40), the occupation of the father was the best available proxy variable for energy restriction. Contemporary studies observed that having an unemployed father indicated that the family had less energy to consume and less variation in their food pattern compared to families with an employed father [19-22]. The exposure variable for the Economic Depression years was dichotomous: subjects whose father had a job and subjects whose father had no job. For the other two periods, the War period (1940$44)$ and the Hunger winter (1944-45), the city of residence during these periods was used to approximate the exposure for energy restriction. Living in a city in 1942 (midpoint year 1940-44) with more than 40,000 inhabitants was considered as an indicator for energy restriction in the War period because of the documented nutritional differences between a city and a rural area. This exposure variable was dichotomous. cohort members living in a city in 1942 or living in a rural area in 1942.

With respect to the Hunger winter, three categories were defined, subjects who lived in a Western city, subjects who lived in a Western rural area and subjects who lived in a NonWestern part of The Netherlands. Living in a Western city in 1944-45 was considered as an indicator for severe energy restriction. The definition of a famine city ( $>40,000$ inhabitants) is based upon the definition of a famine city according to the study of Stein et al. [25]. The following western cities were determined as famine cities: Amsterdam, Rotterdam, The Hague, Utrecht, Zaandam, Hilversum, Amersfoort, Dordrecht, Vlaardingen/Schiedam, Delft and Leiden.

To assess whether the timing at which dietary restriction took place modified the effect of energy restriction on the risk of colon cancer, rate ratios of colon cancer for energy restriction in each of the three periods were calculated within strata of the adolescent growth spurt (subgroup analyses). In these analyses, subjects were divided into subgroups depending on exposure to energy restriction before, during or after the adolescent growth spurt. The analyses were conducted for men and women separately. For men adolescent growth spurt used in this study was taken to occur between the ages of 12 and 15 years. For women, the adolescent growth spurt in this study was defined as 2 years before the reported age at menarche until 1 year after the reported age at menarche [26]. Since the exposure periods are age-dependent and of varying duration it was decided to restrict the relevant time span in the long exposure periods $1932-40$ and $1940-44$ to the years in which the food situation was worst. For the Economic Depression period we selected the years 1933-34 because the 
literature regarding the Economic Depression showed a very poor food situation in the first years of the Economic Depression and some improvement in the later years. Thus, only men and women with the adolescent growth spurt in 1933-34 were included in the subgroup. For the War period we selected the years 1942-43 because the food situation deteriorated progressively during the World War II years and the years 1942-43 represent the worst years of the pre-famine period.

\section{Data analysis}

The distributions of the exposure variables were compared between the colon cancer cases and subcohort members, for men and women separately. For the continuous covariates age, body mass index $\left(\mathrm{kg} / \mathrm{m}^{2}\right)$, baseline alcohol and energy intake, vitamin C intake, beta-carotene, height and weight, mean values of these variables were compared between the exposure categories. Statistical significance of these associations was tested by t-tests and analysis of variance. Significance of the association between categorical covariates, such as large bowel cancer in the family (yes/no), baseline physical activity (< $30 \mathrm{~min} /$ day, 30-60 min/day. $60-90 \mathrm{~min} /$ day, > $90 \mathrm{~min} /$ day), education (low. medium, high), meat consumption ( $<1$ time a week, 1-4 times a week. >4 times a week) and smoking (never/ever) and the exposure categories, were tested by chi-square test.

Baseline recreational physical activity was used as the combination of the number of minutes spent per day on biking/walking, shopping. walking out the dog and the number of hours spent per week on the activities gardening/doing odd jobs, cycling/walking and sport/gymnastics.

The association between exposure variables and covariates was studied in the subcohort.

Covariates associated with colon cancer itself or with any of the exposure variables were considered as potential confounders. In the multivariate analysis adjustment was made for age, familial large bowel cancer, body mass. index, baseline alcohol and energy intake, recreational physical activity and education. Data were analyzed using the case-cohort approach $[27,28]$. The cases are derived from the entire cohort, while the person-years at risk of the entire cohort are estimated from a random sample of 3500 people (subcohort). Incidence rate ratios (RR) and corresponding 95\% confidence intervals $(\mathrm{CI})$ for colon cancer were estimated using exponentially distributed failure time regression models with the STATA statistical package. In multivariate analyses adjustment for covariates was carried out. All analyses were carried out with STATA [29]

Table 1 Distributions of the food restriction exposure variables for colon cancer cases and subcohort members. separately for men and women in the Netherlands Cohort Study. (Sept 1986-Dec 1993)

\begin{tabular}{|c|c|c|c|c|c|c|c|c|}
\hline \multirow[b]{2}{*}{ Exposure variables } & \multicolumn{4}{|l|}{ Men } & \multicolumn{4}{|l|}{ Women } \\
\hline & $\begin{array}{l}\text { subcohort } \\
(n=1630)\end{array}$ & $\%$ & $\begin{array}{l}\text { cases } \\
(n=419)\end{array}$ & $\%$ & $\begin{array}{l}\text { subcohort } \\
(n=1716)\end{array}$ & $\%$ & $\begin{array}{l}\text { cases } \\
(n=388)\end{array}$ & $\%$ \\
\hline \multicolumn{9}{|c|}{ Hunger Winter 1944-1945 } \\
\hline Non-West & 794 & 59.8 & 209 & 637 & 899 & 56.4 & 217 & 59.3 \\
\hline Rural Western area & 199 & 150 & 39 & 11.9 & 240 & 151 & 58 & 15.9 \\
\hline Western city & 334 & 252 & 80 & 244 & 454 & 285 & 91 & 248 \\
\hline \multicolumn{9}{|c|}{ War Years 1940-1944 } \\
\hline Rural area in 1942 & 576 & 497 & 131 & 452 & 598 & 489 & 162 & 51.7 \\
\hline City in 1942 & 582 & 50.3 & 159 & 548 & 624 & 51.1 & 151 & 48.3 \\
\hline \multicolumn{9}{|c|}{ Economic Depression } \\
\hline \multicolumn{9}{|c|}{$1932-40$} \\
\hline Father a job & 1349 & 878 & 357 & 89.0 & 1418 & 88.5 & 324 & 89.5 \\
\hline Father no job & 187 & 122 & 44 & 110 & 184 & 115 & 38 & 10.5 \\
\hline
\end{tabular}

- due to missing data numbers may not add up to $1630,419,1716$ and 388 , respectively 


\section{Results}

In table 1 the distributions of the exposure variables for colon cancer cases and subcohort members are presented, separately for men and women. Regarding the Hunger winter, there were proportionally more men and women from the case group living in the Non-Western region compared with the subcohort members. There were also proportionally more men from the cases living in a city in 1942 compared to the subcohort. For women, the distributions regarding the War years and the Economic Depression years were equal for cases and subcohort female members.

In the subcohort, men living in a Western rural area in 1944-45 were the tallest, had the highest energy intake at baseline and the lowest body mass index (BMI) compared to men living in a Western city in 1944-45 or men living in nonWestern region. Men living in a Western city in 1944-45 were more educated compared to men living in non-Western region or a Western rural

area. Men who lived in a city in 1942 had a lower weight and BMI, a lower energy intake at baseline and were more educated compared to men who lived in a rural area in 1942 (table 2a).

Table $2 b$ shows that women who lived in a Western city in 1944-45 had a lower BMI and a lower energy intake at baseline, a higher intake of alcohol at baseline and were more educated compared to women living in a Western rural area or in a non-Western region. Women who lived in a city in 1942 had a lower weight at age 20 , had a higher alcohol intake, a lower energy intake at baseline and were more educated compared to women who lived in a rural area in 1942. Women whose father had no job during the Economic Depression were younger, shorter, had a lower weight at age 20, had a lower energy intake at baseline and were less educated compared to women whose father had a job during the Depression.

Table 3 shows the results of the age-adjusted and multivariate analyses in which adjustment was made for age, familial large bowel cancer, BMI, baseline alcohol and energy intake, education and baseline recreational physical activity. The multivariate analyses showed a small but non-significant inverse relation between living in a Western city in 1944-45 and colon cancer risk for men and women together. The combined analyses for men and women together showed that men and women who lived in a western city had a RR of $0.81(95 \% \mathrm{Cl} 0.65$ 1.01, p-trend 0.02) compared to men and women living in a non-Western region (data not shown). The rate ratio for men living in a Western City in 1944-1945 was $0.85(95 \% \mathrm{Cl}$ $0.62-1.16)$ and for women $\mathrm{RR}=0.80(95 \% \mathrm{Cl}$ $0.59-1.09$ ) compared to the reference category. For men living in a Western rural area the rate ratio was $0.72(95 \% \mathrm{Cl} 0.48-1.09)$ and for women living in a Western rural area the rate ratio was $1.09(95 \% \mathrm{Cl} 0.77-1.55)$ compared to men and women living in a non-western area in 1944-45.

Living in a city in 1942 was not related to colon cancer risk. Having a father without a job during the Economic Depression years showed a small non-significant decrease in colon cancer risk. both for men and women. Men whose father had no job during the Economic Depression years had a rate ratio of $0.90(95 \% \mathrm{Cl} 0.62-1.31)$ and women whose father had no job had a rate ratio of $0.75(05 \% \mathrm{Cl} 0.49-1.14)$.

Furthermore, subgroup analyses were conducted to evaluate possible effects of the timing of energy restriction. As a consequence of the small number of cases in the subgroups "exposure before growth spurt in the Hunger winter" for women and "exposure before growth spurt in the War years" for men, the multivariate model did not converge. For these subgroups we only conducted an age-adjusted analysis. In our cohort there were no men who were exposed to the Hunger winter before their growth spurt. All the men were older than 12 years at the time of the Hunger winter. Exposure to energy restriction during the adolescent growth spurt (table $4 \mathrm{a}$ ) shows a decreased risk ( $R R=0.72,95 \% \mathrm{Cl} 0.31-1.65$ ) for men living in a Western city compared to men living in NonWestern parts of The Netherlands. For men living in the Western rural area also a decreased risk ( $R R=0.43,95 \% \mathrm{Cl} 0.14-1.33$ ) was seen compared to men living in Non-Western parts of The Netherlands during the Hunger winter, but the number of cases is very small. Exposure to energy restriction during the War years showed an increased risk for men living in a city in 1942 during their adolescent growth spurt ( $R R=1.28$, $95 \% \mathrm{Cl} 0.66-2.47$ ) compared to men living in a rural area. The RR for men whose father had no job in 1933-34 and who were in their growth spurt at that time showed a rate ratio of 0.91 (95\% Cl 0.46-1.82). 
Table 2a Means (s d) and distribution of potential confounders in the male subcohort $(n=1,630)$ by exposure category, the Netherlands Cohort Study $1986-1993$

\section{Hunger winter 1944-1945}

\begin{tabular}{|c|c|c|c|c|c|c|c|}
\hline Characteristics & $\begin{array}{l}\text { Non-West } \\
\text { mean (s d ) }\end{array}$ & $\begin{array}{l}\text { Rural West } \\
\text { mean (s.d.) }\end{array}$ & $\begin{array}{l}\text { City West } \\
\text { mean (s.d.) }\end{array}$ & \multicolumn{2}{|c|}{$\begin{array}{ll}\text { Rural area } & \text { City in } 1942 \\
\text { mean (s.d.) } & \text { mean (s d.) }\end{array}$} & $\begin{array}{l}\text { father a job } \\
\text { mean (s.d.) }\end{array}$ & $\begin{array}{l}\text { father no job } \\
\text { mean (s.d.) }\end{array}$ \\
\hline Age & $61.0 \quad(4.2)$ & $60.7 \quad(4.2)$ & $61.2(4.4)$ & $61.1 \quad(4.2)$ & $61.6(4.2)$ & $61.3(4.2)$ & $61.5 \quad(4.3)$ \\
\hline Height & $176.1(6.7)$ & $178.9(7.0)$ & $177.0(6.6)^{\circ}$ & $1766(7.0)$ & $176.2(6.7)$ & $176.8(6.7)$ & $176.6(7.4)$ \\
\hline Weight & $785(9.7)$ & $78.0(9.7)$ & $77.8 \quad(9.5)$ & $79.0 \quad(9.9)$ & $77.0(9.0)^{b}$ & $78.2 \quad(9.7)$ & $77.9(9.9)^{\circ}$ \\
\hline Weight at age 20 & $68.3(8.1)$ & $68.0(9.2)$ & $67.1(8.1)$ & $68.4(8.1)$ & $67.4(8.6)$ & $67.8(8.3)$ & $68.0(9.8)$ \\
\hline Body mass index $\left(\mathrm{kg} / \mathrm{m}^{2}\right)$ & $25.3(2.7)$ & $24.4(2.6)$ & $248(2.6)^{\circ}$ & $25.3(2.7)$ & $24.8(2.6)^{b}$ & $250 \quad(2.6)$ & $24.9(2.8)$ \\
\hline Alcohol intake $1986(g /$ day $) 1$ & 148 (169) & $14.0(150)$ & $13.8(16.7)$ & 13.7 (14.9) & $13.8(16.2)$ & 14.7 (16.9) & $13.4(14.5)$ \\
\hline \multirow{2}{*}{$\begin{array}{l}\text { Energy intake } 1986 \\
\text { (kcal/day) }\end{array}$} & $2181(529)$ & $2208(514)$ & $2090(460)^{2}$ & $2192(529)$ & $2113(485)^{b}$ & $2167(514)$ & $2116(498)$ \\
\hline & $\%$ & $\%$ & $\%$ & $\%$ & $\%$ & $\%$ & $\%$ \\
\hline \multicolumn{8}{|l|}{ Large bowel cancer in family } \\
\hline no & 955 & 950 & 94.9 & 95.5 & 947 & 94.4 & 96.2 \\
\hline yes & 45 & 5.0 & 51 & 4.5 & 53 & 56 & 3.8 \\
\hline \multicolumn{8}{|l|}{ Education } \\
\hline low & 53.2 & 508 & $37.5^{\circ}$ & 31.5 & $433^{c}$ & 45.9 & $641^{c}$ \\
\hline medium & 30.9 & 32.2 & 387 & 58.3 & 40.3 & 36.0 & 234 \\
\hline high & 15.9 & 170 & 237 & 10.2 & 16.4 & 18.1 & 12.5 \\
\hline \multicolumn{8}{|l|}{ Baseline physical activity } \\
\hline$<30 \mathrm{~min} / \mathrm{day}$ & 192 & 218 & 179 & 192 & 18.4 & 181 & 21.6 \\
\hline $30-60 \mathrm{~min} / \mathrm{day}$ & 31.9 & 34.5 & 273 & 335 & 281 & 31.2 & 28.1 \\
\hline $60-90 \mathrm{~min} / \mathrm{day}$ & 181 & 21.3 & 224 & 170 & 191 & 197 & 13.5 \\
\hline$>90 \mathrm{~min} / \mathrm{day}$ & 30.8 & 224 & 324 & 30.3 & 344 & 310 & 36.8 \\
\hline
\end{tabular}

anova $(p<0$ 05)

t-test $(p<0.05)$

chi square ( $p<0.05)$ 
Table 2b Means (s.d.) and distributions of potential confounders in the female subcohort ( $n=1,716$ ) by exposure category, the Netherlands Cohort Study 1986-1993

Hunger winter 1944-1945

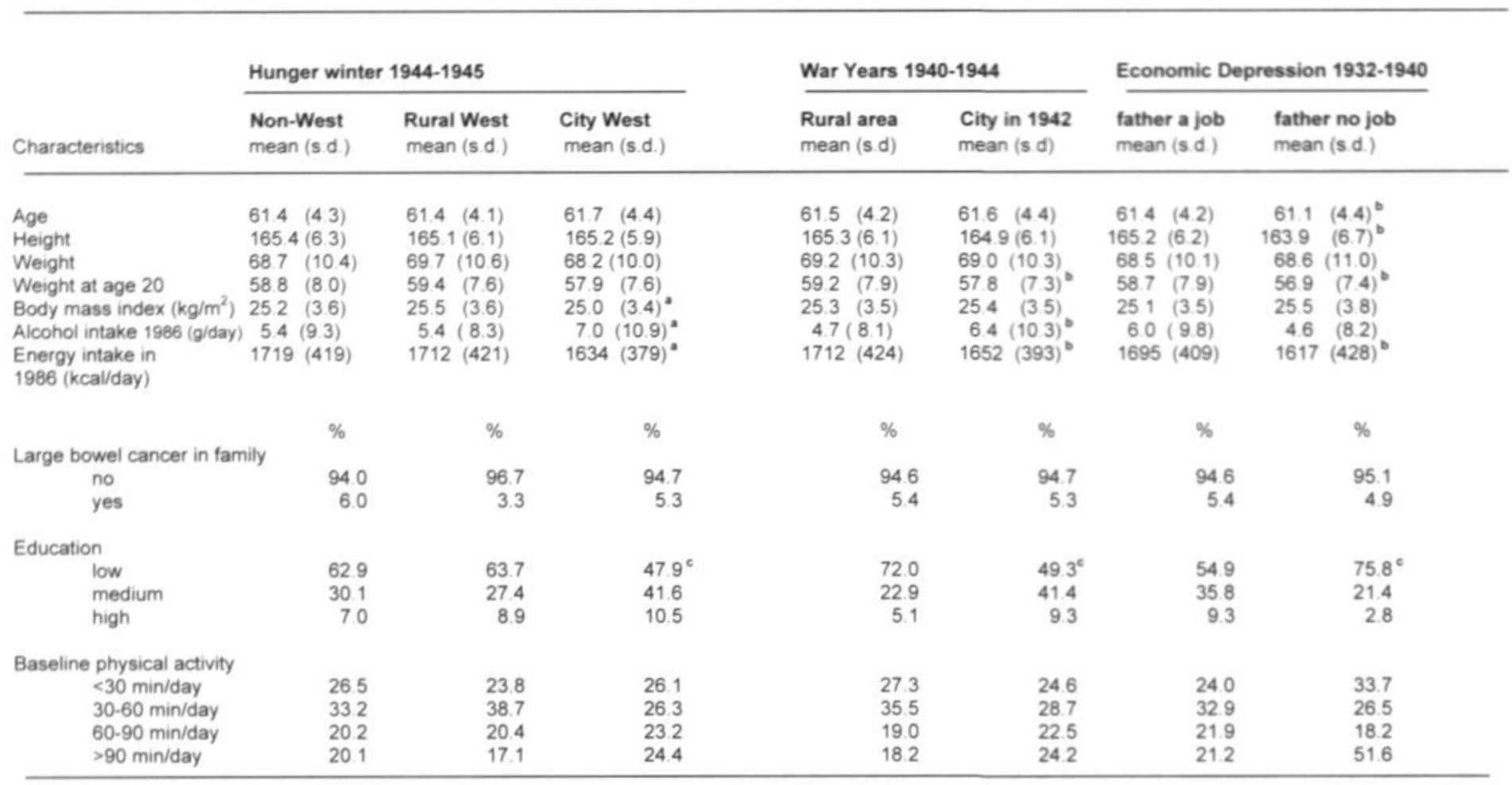

anova $(p<0.05)$

t-test $(p<0.05)$

chi square $(p<0.05)$ 
Table 3 Age adjusted and multivariate rate ratios for colon cancer according to three time periods of energy restriction in the Netherlands Cohort Study (1986-1993), separately for men and women

\begin{tabular}{|c|c|c|c|c|}
\hline & cases & prs.yrs & $\mathrm{RR}^{1}(95 \% \mathrm{Cl})$ & $\mathrm{RR}^{2}(95 \% \mathrm{Cl})$ \\
\hline \multicolumn{5}{|l|}{ Men } \\
\hline & 201 & 5115 & $1.00^{\star}$ & $1.00^{*}$ \\
\hline Rural West & 35 & 1332 & $0.74(0.53-1.12)$ & $0.72(0.48-1.09)$ \\
\hline City West & 76 & 2158 & $\begin{array}{l}0.90(0.74-1.23) \\
\text { p-trend } 0.23\end{array}$ & $\begin{array}{l}0.85(0.62-1.16) \\
p \text {-trend } 0.14\end{array}$ \\
\hline \multicolumn{5}{|l|}{ War years 1940-'44 } \\
\hline rural area in ' 42 & 123 & 3694 & $1.00^{\circ}$ & $1.00^{\circ}$ \\
\hline city in 42 & 151 & 3787 & $1.15(0.91-1.52)$ & $1.11(0.83-1.49)$ \\
\hline \multicolumn{5}{|c|}{ Economic Depression 1932-'40 } \\
\hline father had a job & 340 & 8767 & $1.00^{\circ}$ & $1.00^{\circ}$ \\
\hline \multirow[t]{2}{*}{ father had no job } & 41 & 1188 & $0.89(0.63-1.32)$ & $0.90(0.62-1.31)$ \\
\hline & cases & prs yrs & $\operatorname{RR}^{\prime}(95 \% \mathrm{Cl})$ & $\mathrm{RR}^{2}(95 \% \mathrm{Cl})$ \\
\hline \multicolumn{5}{|l|}{$\begin{array}{l}\text { Women } \\
\text { Hungerwinter 1944-'45 }\end{array}$} \\
\hline Non - West & 193 & 5601 & $1.00^{\circ}$ & $1.00^{\circ}$ \\
\hline Rural Area & 54 & 1507 & $1.01(0.81-1.57)$ & $1.09(0.77-1.55)$ \\
\hline \multirow[t]{2}{*}{ City west } & 81 & 2944 & $0.81(0.63-1.12)$ & $0.80(0.59-1.09)$ \\
\hline & & & p-trend 0.13 & p-trend 015 \\
\hline \multicolumn{5}{|l|}{ War years 1940-'44 } \\
\hline Rural area in 1942 & 141 & 3641 & $1.00^{*}$ & $100^{*}$ \\
\hline City in 1942 & 140 & 4092 & $0.88(0.73-1.12)$ & $088(0.67-1.19)$ \\
\hline \multicolumn{5}{|c|}{ Economic Depression 1932-'40 } \\
\hline Father had a job & 298 & 8985 & $1.00^{\circ}$ & $100^{\circ}$ \\
\hline Father had no job & 31 & 1108 & $0.86(0.64-1.21)$ & $0.75(0.49-114)$ \\
\hline
\end{tabular}

\footnotetext{
'only age-adjusted

${ }^{2}$ adjusted for age, familial large bowel cancer, body mass index, baseline alcohol and energy intake, education. baseline recreational physical activity

- reference category
}

The subgroups of men exposed after the growth spurt showed the same pattern as the group exposed during the growth spurt. Men who were exposed to the Hunger winter after their growth spurt showed a decreased risk, both for men living in a Western city or in the Western rural area $(R R=0.87, R R=0.77$, respectively).

Exposure during the adolescent growth spurt shows a small decreased risk $(R R=0.88,95 \% \mathrm{Cl}$ 0.40-1.96) for women living in a Western city during the Hunger winter, but not significant, compared to women living in non-western part of the country. For women living in a Western rural area during their growth spurt an increased risk was seen $(R R=1.55 .95 \% C l$ 0.68-3.53), but the number of cases is very small. For exposure during the war years there was no difference in risk between women living in a city during their adolescent growth spurt and women living in a rural area. The RR for the women whose father had no job in 1933-34 and who were in their growth spurt during the Economic Depression years showed a decrease in breast cancer risk
(RR=0.62, $95 \% \mathrm{Cl} \quad 0.29-1.31$ ) that was not statistically significant (table 4b). Again the number of cases is quite small.

The subgroup of women exposed after their adolescent growth spurt showed a decreased risk for women living in a Western city during the Hunger winter ( $R R=0.79,95 \% \mathrm{Cl} 0.56-1.11$ ) compared to women living in a non-Western region of the country in 1944-45. Women who lived in a city in 1942 and were exposed before their growth spurt during the War years also showed a decreased risk ( $R R=0.25,96 \% \mathrm{Cl}$ : $0.03-2.02$ ) compared to women who lived in a rural area in 1942, but the number of cases is very small. For women whose father had no job during the Economic Depression years and who were exposed before their growth spurt a decreased risk was shown ( $R R=0.68,95 \% \mathrm{Cl}$ : $0.37-1.26$ ) 
Table 4 Relative rate of colon cancer for men and women exposed to energy restriction before, during and after their adolescent growth spurt (men. 12-15 year, women $1 y r<$ menarche<2 yrs) in the time-period 1944-45, 1942-43 and 1933-34, the Netherlands Cohort Study 1986-1993

\begin{tabular}{|c|c|c|c|c|c|c|c|c|c|c|c|c|}
\hline \multirow[b]{2}{*}{ Exposure } & \multicolumn{4}{|c|}{ Before growth spurt } & \multicolumn{4}{|c|}{ During growth spurt } & \multicolumn{4}{|c|}{ After growth spurt } \\
\hline & \multicolumn{2}{|c|}{ Cases Person yrs } & $\mathrm{RR}^{+}$ & $(95 \% \mathrm{Cl})$ & Cases & Person yrs & $R^{*}$ & $(95 \% \mathrm{Cl})$ & Cases & Person yrs & $R^{*}$ & $(95 \% \mathrm{CI})$ \\
\hline \multicolumn{13}{|l|}{ Men } \\
\hline \multicolumn{13}{|l|}{ Hunger winter $1944-45$} \\
\hline Non-West & \multirow{3}{*}{\multicolumn{4}{|c|}{$\begin{array}{l}\text { no men exposed before } \\
\text { their growth spurt }\end{array}$}} & 34 & 1258 & $1.00^{\mathrm{a}}$ & & 167 & 3857 & $1.00^{\circ}$ & \\
\hline Western rural area & & & & & 4 & 359 & 0.43 & $(0.14-1.33)$ & 31 & 973 & 0.77 & $(0.50-1.22)$ \\
\hline Western city & & & & & 10 & 535 & 0.72 & $(0.31-1.65)$ & 66 & 1622 & 0.87 & $(0.62-1.23)$ \\
\hline \multicolumn{13}{|l|}{ War Years 1942-43 } \\
\hline Rural area in 1942 & 5 & 248 & $1.00^{a b}$ & & 23 & 1169 & $1.00^{\mathrm{a}}$ & & 95 & 2276 & $1.00^{\circ}$ & \\
\hline City in 1942 & 5 & 122 & 1.92 & $(0.49-7.52)$ & 31 & 1216 & 1.28 & $(0.66-2.47)$ & 115 & 2449 & 1.04 & $(0.74-1.47)$ \\
\hline \multicolumn{13}{|l|}{ Depression 1933-34 } \\
\hline Father had a job & 203 & 6356 & $1.00^{\circ}$ & & 111 & 1945 & $1.00^{\mathrm{a}}$ & & 26 & 465 & $1.00^{\circ}$ & \\
\hline Father had no job & 23 & 808 & 0.86 & $(0.52-1.43)$ & 13 & 285 & 0.91 & $(0.46-1.82)$ & 7 & 94 & 0.90 & $(0.18-4.58)$ \\
\hline \multicolumn{13}{|l|}{ Women } \\
\hline \multicolumn{13}{|l|}{ Hunger winter 1944-45 } \\
\hline Non-West & 4 & 116 & $1.00^{a b}$ & & 28 & 1531 & $1.00^{\circ}$ & & 161 & 3901 & $1.00^{\circ}$ & \\
\hline Western rural area & 1 & 21 & 1.27 & $(0.08-20.2)$ & 10 & 394 & 1.55 & $(0.68-3.53)$ & 43 & 1091 & 1.00 & $(0.68-1.49)$ \\
\hline Western city & 0 & 65 & 1.63 & $(3.76-7.03)$ & 13 & 736 & 0.88 & $(0.40-1.96)$ & 65 & 2113 & 0.79 & (0.56-1.11) \\
\hline \multicolumn{13}{|l|}{ War Years 1942-43 } \\
\hline Rural area in 1942 & 7 & 297 & $1.00^{\circ}$ & & 31 & 1141 & $1.00^{a}$ & & 103 & 2173 & $1.00^{\circ}$ & \\
\hline City in 1942 & 8 & 409 & 0.25 & $(0.03-2.02)$ & 35 & 1220 & 1.01 & $(0.54-1.89)$ & 95 & 2445 & 0.84 & $(0.59-1.20)$ \\
\hline \multicolumn{13}{|l|}{ Depression 1933-34 } \\
\hline Father had a job & 160 & 6179 & $1.00^{\circ}$ & & 115 & 2236 & $1.00^{\circ}$ & & 21 & 520 & $1.00^{\circ}$ & \\
\hline Father had no job & 13 & 708 & 0.68 & $(0.37-1.26)$ & 11 & 302 & 0.62 & $(0.29-1.31)$ & 6 & 97 & 1.52 & $(0.34-6.88)$ \\
\hline \multicolumn{13}{|c|}{$\begin{array}{l}\text { Relative rate after adjustment for: age, familial large bowel cancer, body mass index, baseline alcohol and energy intake, baseline recreational physical activity. } \\
\text { Reference category } \\
\text { 'Only age-adjusted }\end{array}$} \\
\hline
\end{tabular}




\section{Discussion}

This prospectieve cohort study found a nonsignificant inverse relation between energy restriction during adolescence and the risk of colon cancer, also after controlling for potential confounders. Compared to residents in the North and South of the Netherlands who served as controls with almost no exposure to energy restriction, the results showed a non-significant decreased colon cancer risk for men ( $R R=0.85$ ) and for women ( $R R=0.80)$ living in a Western city. For men living in a Western rural area in 1944-45 also a decreased risk was observed $(R R=0.72)$ and for women living in a Western rural area no difference was observed ( $R R=1.09$ ). With respect to exposure during the remaining years of World War II (1940-44) no differences in colon cancer risk were found for both men and women who lived in a city (food restricted area) in 1942 vs. men and women who lived in a rural area in 1942. Having an unemployed father during the Economic Depression years 1932-40 was associated with a small, but not significant, decrease in colon cancer risk both for men ( $R R=0.90)$ and women $(R R=0.75)$. Results of the subgroup analyses showed that men and women who were in their adolescent growth spurt and living in a Western city during the Hunger winter $1944-45$ or who were exposed after their adolescent growth spurt to the Hunger winter 1944-45, had a decreased colon cancer risk compared to men and women living in the non-Western parts of the Netherlands.

Before discussing the results of this study some weak points of the NLCS are addressed. A factor that could have influenced the results is misclassification of food restriction exposure

It has obviously been difficult to test the childhood nutrition hypothesis in Western populations for ethical and practical reasons Three proxy measures of energy restriction were used in this study: the father's employment status of the men and women during the Economic Depression years, residence during the World War II (1940-44), and residence during the Hunger winter (1944-45). Whereas surveys showed that energy intake was associated with father's employment status in $1932-40[19-21]$. that the food supply in the cities deteriorated much faster than in the rural area during $1940-44[17,18]$ and that starvation in the West in 1944-45 was mostly confined to Western cities [14-16], we are aware that these ecological measures are only a proxy measure of individual exposures. Other studies used the same proxy measure for energy restriction in the Hunger winter, however, and their results also indicated that the proxy measure for energy restriction in the Hunger winter is reasonably adequate [30, 31]. In a previous report on energy restriction and breast cancer risk in the NLCS-cohort, we asked the female subcohort members during follow-up, if they really had experienced hunger during the winter of 1944 45. Of the women who reported severe hunger during the Hunger winter $80 \%$ lived in a Western city during this winter. These results also indicated that the proxy measure for energy restriction in the Hunger winter is reasonably adequate [32]. If misclassification is present, it will be nondifferential because of the prospective design of the cohort.

The potential for selection bias in the NLCS is low considering the high completeness of cancer follow-up. Also, there were no reasons to assume that residual confounding was still present, because all known risk factors for colon cancer were measured and controlled for in multivariate analyses.

Energy intake is often related to a higher risk of colon cancer in case-control studies [33-35]. However, results from cohort studies that assessed total energy intake found, if anything. a slight inverse association between total energy intake and risk of colon cancer [36-39]. These studies were not able to analyze the adolescent diet in relation to subsequent colon cancer risk later in life. In the NLCS-cohort no association was found between baseline energy intake and colon cancer risk [40]. No other specific studies of early diet and colon cancer risk are conducted, to our knowledge

Adult anthropometric measures (height, body mass index and sitting height) are often used as a proxy for the nutritional status during childhood and adolescence. Russo et al. [41] conducted a case-control study to determine whether body size measurements at different ages were risk factors for cancer of the colon. Study subjects were asked to report their habitual height and weight, weight at 30 and at 50 years of age and perceived body size at 12 years of age. This study showed a positive association between BMI at various ages and 
colon cancer risk in men and women. Only in women, BMI at middle age was unrelated to colon cancer risk.

Other studies also found a positive association with excessive weight earlier in life, most notably at age 30 [42, 43]. Most of the studies found a positive association between colon cancer and weight in young adults [42, 44, 45].

Giovanucci et al [46] found a positive relation between adult height and colon cancer risk. Adult height might be a proxy of a positive energy balance during childhood, and is correlated with the total length of the colon. These observations agree with the association between body size and human cancer in the large population-based NHANES-study suggesting that higher levels of energy intake in childhood increase the risk of later development of cancer. These findings provide further evidence that the unfavorable trends in the incidence of colon cancer may have its origin in early life [47]. In the NLCS-cohort we found a positive association between height and colon cancer risk for women and positive associations between weight, BMI at age 20 and BMI-change from age 20 till baseline and colon cancer risk in men.

Energy intake and body mass are components of the energy balance, together with physical activity. Slattery et al. [48] conducted a casecontrol study which purpose was to determine how physical inactivity interacts with other components of energy balance (energy intake and body mass) in determining colon cancer risk. They concluded that those who had the most unfavorable energy balance in that they were physically inactive, had high energy intakes and had a large BMI were at greatest colon cancer risk. Energy balance as a whole seems to be associated with risk of colon cancer.

The role of energy intake, body mass and physical activity could operate at different levels in the etiology of colon cancer, but the most plausible explanation that unifies the three has to involve metabolic profiles rather than local influences on colonic epithelium. McKeownEyssen [49] has proposed that some factors that collectively characterize increased colon cancer risk (obesity and Western diet) may plausibly operate through influences upon serum triglycerids and insulin resistance. Giovannucci [50] also stated that elevated blood-insulin levels promote the growth of colon tumors. Recently, Bruce et al [51] described that an unfavorable energy balance, due to consumption of excess dietary energy or a sedentary lifestyle, may result in the development of insulin resistance with increased circulation levels of insulin, triglycerids and non-esterified fatty acids. This occurs when the increased dietary energy increases intravascular energy as carbohydrate and lipid in the bloodstream [52]. The result is that all cells, including colonic epithelial cells, are exposed to increased concentrations of insulin and energy substrates. Increased proliferation and mutation may result from insulin resistance $[53,54]$.

In conclusion, we found in our study an inverse relation between energy restriction early in life and subsequent colon cancer risk later in life, although not significant. To study interaction between physical activity, energy intake and BMI more cases are needed, thus longer followup is necessary for the NLCS-cohort. Future research should be concentrated on the interaction between the components of energy balance (physical activity, body mass and energy intake).

Acknowledgment: the Netherlands Cohort Study was supported by the Dutch Cancer Society.

\section{References}

1. Fund WCR Food, nutrition and the prevention of cancer: a global perspective American Institute for Cancer Research, 1997

2. Schouten LJ, De Rijke JM Huveneers JAM, Jager JJ, Van den Brandt PA. Cancer incidence in mid and south Limburg. the Netherlands Maastricht Maastricht Cancer Registry, 2000

3 Ross MH, Bras G Lasting influence of early caloric restriction on prevalence of neoplasmsm in the rat. $\mathrm{J}$ Natl Cancer Inst 1971, 47(5): 1095-1103

4. Tannenbaum A. The genesis and growth of tumors, effects of a high fat diet. Cancer Research 1942; 2 468-75.

5 Kritchevsky D. Klurfeld DM Influence of caloric intake on experimental carcinogenesis. a review. Adv Exp Med Biol 1986: 206 55-68

6 Albanes D, Salbe AD, Levander OA. Taylor PR, Nixon DW. Winick M. The effect of early caloric restriction on colonic cellular growth in rats. Nutr Cancer 1990, 13(1-2). 73-80

7. Kritchevsky D. Klurfeld DM Interaction of fiber and energy registration in experimental colon carcinogens Cancer letters 1997, 114(1-2): 51-2

8 Kritchevsky D Colorectal cancer the role of dietary fat and caloric restriction Mutat Res 1993: 290(1) 63-70

9. Slattery ML. Caan B. Potter JD, et al Dietary energy sources and colon cancer nsk Am J Epidemiol 1997. 145(3) $199-210$

10 Giovannucci E. Goldin B. The role of fat. fatty acids. and total energy intake in the etiology of human colon cancer Am J Clin Nutr 1997, 66(6 Suppl). 1564s-1571s 
11. Albanes D, Jones DY, Schatzkin A. Micozzi MS, Taylor PR. Adult stature and risk of cancer. Cancer Res 1988 , 48(6): $1658-62$

12. Gunnel DJ, Smith GD, Holly JMP. Frankel S: Leg length and risk of cancer in the Boyd Orr cohort BMJ 1998. 317 $1350-1$.

13. Tanner JM, Hayashi T. Preece MA, Cameron N Increase in length of leg relative to trunk in Japanese children and adults from 1957 to 1977 comparison with British and with Japanese Americans Ann Hum Biol 1982 9. 411-23

14. Burger GCE, Sandstead HR. Drummond $\mathrm{J}$ Starvation in Western Holland. 1945. Lancet 1945, ii 282-3

15. Burger GCE. Drummond JC. Sandstead HR Malnutrition and starvation in Western Netherlands. September 1944. July 1945 . The Hague: The hague General State Printing Office, 1948

16. Burger GCE. Drummond JC. Sandstead HR Appendices to mainutrition and starvation in Western Netherlands. September 1944- July 1945 (Part II). The Hague. The Hague General Sate Printing Office, 1948

17. Breunis J: The food supply. Ann Am Acad Pol Soc Sci 1946. 245 87-92

18. Dols MJL. Van Arcken A.JM. De voedselvoorziening in Nederland tijdens en onmiddelijk na den tweeden wereldoorlog 1940-1945 Voeding 1946; 6 : 193-207.

19 Ten Bokkel Huinink SA. De voeding van de gezonde en zieke werkloozen: 1936

20 Kastein GW De voeding van 343 werkloozengezinnen in Rotterdam en Schiedam in de wintermaanden van 1934. 1935 Ned T Geneesk 1935, 79 . 5583-7.

21. Tromp MH. De voeding in het gezin van den werklooze Ned T Geneesk 1934, 78 5388-99

22 Den Hartog AP Werklozen en hun voeding in de jaren 1930-39. Voeding 1983, 44 ,92-8

23 Van den Brandt PA Goldbohm RA. Van I Veer P Volovics A, Hermus, R J J. Sturmans F A large scale prospective cohort study on diet and cancer in the Netherlands J Clin Epidemiol 1990, 19 285-95

24 Van den Brandt PA. Schouten LJ. Goldbohm RA. Dorant E, Hunen PMH. Development of a record linkage protocol for use in the Dutch cancer registry for epidemiological research Int J Epidemiol 1990.19.553-8

25 Stein Z. Susser M. Saenger G. Marolla F. Famine and human development. the Dutch Hunger winter of 1944-1945 New York Oxford University Press, 1975

26 Marshall WA. Tanner JM Puberty. 2nd ed. New York Plenum Press, 1986 (Falkner F. Tanner JM. eds Human growth, a comprehensive treatise)

27 Volovics A. Van den Brandt PA. Methods for the analyses of case-cohort studies Biom J 1997. 39 195-214

28 Self SG. Prentice RL. Asymptotic distribution theory and efficiency results for case-cohort studies Ann Statistics 1988. 16 64-81

29 StataCorp Stata Statistical Software. Release 50 College Station. Texas Stata Corporation. 1997

30 Lumey LH. Stein $A D$ Offspring birth weights affer maternal intrauterine undernutrition a comparison within sibships Am J Epidemiology 1997, 146(10): 810-9

31 Noord van PA. Kaaks R. The effect of wartime conditions and the 1944-45 'Dutch famine' on recalled menarcheal age in participants of the DOM breast cancer screening project Ann Hum Biol 1991, 18(1) 57-70

32 Dirx M.MM van den Brandt PA Goldbohm RA, Lumey LH Diet in adolescence and the risk of breast cancer results of the Netherlands Cohort Study Cancer Causes Control 1999: 10(3) 189-99

33 Jain M. Cook GM. Davis FG. Grace MG. Howe GR Miller $A B$ A case-control study of diet and colo-rectal cancer Int J Cancer 1980. 26(6) 757-68

34 Bristol JB. Emmett PM. Heaton KW. Williamson RCN Sugar, fat and the risk of colorectal cancer BMJ 1985. 291 $1467-1470$
35. Peters RK, Pike MC, Garabrant D, Mack TM. Diet and colon cancer in Los Angeles County. California Cancer causes and control 1992: 3(5): 457.73

36. Bostick RM, Potter JD, Kushi LH, et al: Sugar, meat, and fat intake, and non-dietary risk factors for colon cancer incidence in lowas women (United States). CCC 1994; 8 649-67.

37. Willett WC. Stampfer MJ, Colditz GA. Rosner BA Speizer FE. Reiation of meat, fat, and fiber intake to the risk of colon cancer in a prospective study among women. New Engl J Med 1990, 323(24): 1664-72

38. Giovannucci E, Rimm EB, Stampfer MJ. Colditz GA. Ascherio A. Willett WC. Intake of fat meat and fiber in relation to risk of colon cancer in men. Cancer research 1994; 54(9): $2390-7$

39. Gaard M. Treti S. Loken EB. Dietary factors and risk of colon cancer: a prospective study of 50,535 young Nonwegian men and women. Eur J Cancer Prev 1996:5(6) 445-54

40. Goldbohm RA, Van den Brandt PA, Van 7 Veer P. et al A prospective cohort study on the relation between meat consumption and the risk of colon cancer. Cancer Res 1994. 54(3): $718-23$

41. Russo A, Franceschi S, La Vecchia C, et al. Body size and colorectal-cancer risk. Int J Cancer $1998,78(2)$; $161-5$

42. Lee IM. Paffenbarger RS. Jr. Quetelet's index and risk of colon cancer in college alumni. J Nati Cancer Inst 1992. 84(17): 1326-31

43. Le Marchand L. Wilkens LR, Mi MP Obesity in youth and middle age and risk of colorectal cancer in men Cancer causes and control 1992.3(4) 349-54

44. Martinez ME, Giovannucci E, Spiegelman D. Hunter DJ Willett WC. Colditz GA Leisure-time physical activity, body size, and colon cancer in women Nurses' Health Study Research Group J Nati Cancer Inst 1997. 89(13) 948-55 45 Nomura A. Heilbrun LK, Stemmermann GN Body mass index as a predictor of cancer in men $\mathrm{J}$ Natl Cancer Inst 1985. $74(2) 319-23$

46. Giovannuca E. Ascherio A. Rimm EB, Colditz GA Stampfer MJ. Willett WC Physical activity, obesity, and risk for colon cancer and adenoma in men Ann Intern Med 1995, 122(5) 327.34

47 Albanes D Height, early energy intake and cancer BM.J 1998, 317 1331-2

48 Slattery ML. Potter J. Caan B, et al Energy balance and colon cancer-beyond physical activity Cancer Res 1997 57(1) $75-80$

49 McKeown-Eyssen G Epidemiology of colerectal cancer revisited are serum triglycerides and/or plasma glucose associated with risk? Cancer Epidemiol Biom Prev 1994. 3 $687-95$

50 Giovannucci $\mathbf{E}$ Insulin and colon cancer Cancer causes and control 1995 .612) $164-79$

51 Bruce WR. Giacca A. Medline A Possible mechanisms relating diet and nsk of colon cancer Cancer Epidern Biomarkers Prevention 2000,9 1271-1279

52 Boden G. Chen X. Ruiz J. White IV. Rossett L Mechanisms of fatty acid-induced inhibition of glucose uptake J Clin Investig 1994, $93 \quad 2438-2446$

53 Bruce WR. Wolever TMS. Gacca A Mechanisms linking diet and colorectal cancer the possible role of insulin resistance Nutr Cancer 2000.37 19-26

$54 \mathrm{Yu} H$. Rohan T Role of the insulin-like growth factor family in cancer development and progression Journal Of The National Cancer Institute Sep 2000, 92(18) 1472-1489 

Baseline recreational physical activity, history of sports participation and postmenopausal breast cancer risk in the Netherlands Cohort Study.

Miranda J.M. Dirx ${ }^{1}$

Laura E. Voorrips ${ }^{2}$

R.Alexandra Goldbohm ${ }^{2}$

Piet $A$. van den Brandt ${ }^{1}$

Affiliations

'Maostricht University, Department of Epidemiology, Moastricht, The Netherlands

${ }^{2}$ TNO Nutrition and Food Research Institute, Department of Nutritional Epidemiology.

Zeist, The Netherlands 


\begin{abstract}
Background. The aim of the current study was to evaluate the relation between physical activity and breast cancer risk with specific emphasis on interaction with other aspects of energy balance.

Methods. The Netherlands Cohort Study on diet and cancer was conducted among 62,537 women aged 55-69 years at baseline. Information on baseline recreational physical activity, history of sports participation and occupational physical activity was collected with a questionnaire in 1986. After 7.3 years of follow-up 1208 incident breast cases were available for case-cohort analyses.

Results. A summed total of baseline recreational physical activity (including walking, cycling, gardening) showed an inverse association with breast cancer risk. Women who were active in above mentioned activities for more than 90 minutes a day had a rate ratio (RR) of $0.76(95 \% \mathrm{Cl} 0.58-0.99)$ compared to women who were active less than 30 minutes a day. Women who ever participated into sport before baseline had a RR of $1.13(95 \% \mathrm{Cl} 0.94-1.37)$ compared to women who never participated in sport. The relation between sports participation and breast cancer risk was not dependent on the time window of participation (before/after menarche, before/after birth of first child, before/after age 20). No interaction was found between baseline recreational physical activity, BMI $\left(\mathrm{kg} / \mathrm{m}^{2}\right)$ and energy intake in relation to breast cancer, although in the subgroup of women with a high $\mathrm{BMI}$ we found a stronger inverse relation between recreational physical activity and breast cancer risk independent of energy intake. Occupational physical activity was not related to breast cancer risk.

Conclusions. Our findings support the hypothesis that recreational physical activity is inversely associated with breast cancer.

(Dirx MJM, Voornips LE, Goldbohm RA, van den Brandt PA. Baseline recreational physical activity, history of sports participation and postmenopausal breast carcinoma risk in the Netherlands Cohort Study. Cancer 2001: 92: 1638-49)
\end{abstract}




\section{Introduction}

Many studies have examined the role of physical activity in breast cancer etiology. Decreased breast cancer risk associated with regular physical activity was first suggested by Frisch et al [1] when they reported a significantly greater prevalence of breast cancer among women who were not involved with athletics in college compared with athletes 1 to 56 years after graduation. Since then more than 20 epidemiological studies have been published from the US, Europe. Australia and Japan. These studies have investigated the relationship between breast cancer and occupational and/or recreational physical activity. The study designs, population samples, measures of physical activity and outcome varied widely. The populations studied ranged from occupation- or education-based cohorts to hospital-based case control studies. Some studies compared women according to participation in college sports, some looked at occupational physical activity only, several examined recreational physical activity only and others studied both occupational and recreational physical activity. Physical activity assessment methods used across studies have been quite heterogeneous. Most of the studies used questionnaires but the questions asked varied substantially. Often the studies relied on reported hours per week doing exercise, or persons had to classify themselves as light, moderate or strenuous physically active [2].

Four cohort studies [1, 3-5] reported that recreational exercise reduces the risk of developing breast cancer at least among certain subgroups of women. No association was reported in three other cohort studies [6-8] and an increased risk of breast cancer was associated with higher levels of physical activity in the Framingham cohort study [9]. Most of the population-based [10-15] and hospital-based case control[16-18] studies have reported an inverse association with recreational activity. One case-control study found an increased risk [19].

The studies concerning occupational physical activity showed inconclusive results. It is unclear yet whether occupational physical activity protects against breast cancer in premenopausal women [20]. postmenopausal women [21] or women of all ages [5, 16, 22].
Several possible biological mechanisms have been postulated as explanation for the observed protective effect of physical activity and the risk of breast cancer. These have focused on exercise and sex hormone interactions, exercise and immune function and exercise and energy balance [23].

There is some evidence to suggest that physical activity can influence at least some of the aspects of menstrual history, and it has been suggested that if physical activity does modify breast cancer risk, it might do so through a hormone-related pathway. Strenuous physical exercise before menarche is believed to delay the onset of menstruation and to increase the number of anovulatory cycles therefore reduces the cumulative (lifetime) estrogen exposure. Bernstein et al. reported that moderate physical exercise during adolescence reduces the number of ovulatory cycles and increases menstrual cycle length patterns [24].

It also has been suggested that exercise may influence breast cancer development through concurrent changes in immune function. Despite the evidence that training enhances natural immune function, the biological relevance for breast cancer risk is not known [23]. It also has been postulated that energy balance could have an influence on breast carcinogenesis. Energy balance is defined by a state in which energy intake is equal to energy expenditure, resulting in no net change of energy stores in the body The aspects of energy balance that have been linked to the etiology of breast cancer include low physical activity and an excess accumulation of body weight. The relation between these two risk factors is complex and the mechanism relating them to increased breast cancer risk is unknown [23]

To our knowledge, it is yet not known what the magnitude of the effect is, what intensity. duration and frequency of activity are required for a reduction in breast cancer risk and what time period(s) in a woman's life are important in such a risk reduction. Therefore, we conducted this study to evaluate the relation between physical activity and breast cancer risk in postmenopausal women in an ongoing cohort study. Furthermore we were interested in the modification by the different time windows in which women are physically active and studied the possible interaction with other indicators of energy balance regarding breast cancer risk. 


\section{Materials and methods}

This study was conducted in an ongoing prospective cohort study on diet and cancer, the Netherlands Cohort Study (NLCS) among 62.573 women aged $55-69$ years at baseline. Baseline exposure data were collected by means of a self-administered questionnaire in 1986. The questionnaire referred to dietary habits and potential confounders such as reproductive history, reported height and weight, education and family history of cancer. Also included were questions about baseline recreational physical activity, the history of sports participation and occupational history. A detailed description of the cohort study design has been reported elsewhere [25]. After the baseline exposure measurement, a subcohort was randomly sampled from the cohort and followed up biennially for vital status information. Incident cancer cases occurring in the entire cohort have been identified by record linkage to cancer registries and a national pathology register (PALGA). The method of record linkage has been described previously [26]

The collected data from subcohort and breast cancer cases were key-entered twice by research assistants who were blinded with respect to subcohort/case status in order to minimize observer bias in coding and interpretation of the data. After 7.3 years of follow-up 1208 breast cancer cases were available for analysis, after exclusion of prevalent cancer cases and cases with in situ breast carcinoma. Prevalent cancer cases other than skin cancer also were excluded from the subcohort, after which 1716 women remained. For data-analysis the case-cohort approach was used in which cases were derived from the entire cohort, while the person-years at risk were estimated from the subcohort.

\section{Baseline recreational physical activity}

Assessment of baseline recreational physical activity was based on two questions. The first question was: "how many minutes do you spend on average per day walking or cycling to your work, to go shopping or to take out your dog?" The subjects could fill in the number of minutes spent per day on these activities. The minutes spent per day on these activities were categorized (less than 30 minutes a day, 30-60 minutes a day, 60-90 minutes a day and more than 90 minutes a day).
The second question was: " how many hours of your leisure time do you spend on average per week on the following activities: gardening/doing odd jobs, cycling/walking (other than in first question), and sports/gymnastics". Possible answers were never, less than 1 hour, 1-2 hours or more than 2 hours per week. We added the time spent on these activities up to an overall measure (minutes per day). Baseline recreational physical activity was used as the combination of the number of minutes spent per day biking/walking, shopping, and walking the dog and the number of hours spent per week on the activities gardening/doing odd jobs. cycling/walking and sport/gymnastics. Women who participated in sports at baseline could also fill in the type of sport.

\section{History of sports participation}

Physical activity that took place earlier in time was estimated by asking about the history of sports participation of the women. For each sport separately, we recorded the type of sport, the number of hours per week spent in that sport, and the years in which the participant engaged in that sport. A total of three sports could be mentioned. First a dichotomization was made in never/ever playing a sport. Total duration of sport activities in years was calculated by summing up the duration of all episodes of playing a sport (accounting for the overlap between sports). The number of total hours per week that they participated in each sport was also added.

We used the Compendium of Ainsworth et al [27] to assign a MET-score to each type of sport activity, as an indicator for intensity. This method was also used in other studies [12, 13, 15, 22]. A MET score is defined as the ratio of the associated metabolic rate for the specific activity divided by the resting metabolic rate. A total MET score was calculated for the various sports activities, weighted by the duration (in years) of each activity. For example, being active for 10 years in tennis (MET sore of 7 ) and being active for 5 years in recreative swimming (MET score of 8 ) gives a weighted MET score of $((7 \times 10)+(8 \times 5)) /(10+5)=7.3$. For the type of sport at baseline, we assigned a MET-score, as an indicator for intensity. which was not weighted by duration. Sport was defined as an activity with a MET-score higher than 2.5 . 


\section{Occupational physical activity}

Subjects were asked for their lifetime occupational history, with regard to job title and duration. A total of five jobs could be mentioned. We used information about the longest job ever held as well as information about the last occupation as indicators for the lifetime physical activity at work. Assessment of physical activity at work was based on job title. Two different measures of occupational physical activity have been used: sitting time (hours/day) and energy expenditure $(\mathrm{kJ} / \mathrm{min})$. The sitting time scale was divided into three groups: low activity (more than 6 working hours per day spent sitting), moderate activity (2-6 hours per day) and high activity (less than 2 working hours per day sitting). The total energy expenditure was based on a rating system developed by Hettinger et al. [28]. Low activity included work with an energy expenditure less than $8 \mathrm{~kJ} / \mathrm{min}$; moderate activity was defined as an energy expenditure between 8 and $12 \mathrm{~kJ} / \mathrm{min}$ and high activity corresponded to an activity level higher than 12 $\mathrm{kJ} / \mathrm{min}$. Housewives were categorized into the moderate groups

\section{Data analysis}

The distribution of the activity variables was compared between breast cancer cases and subcohort members. The association between exposure variables and covariates were studied in the subcohort. For the continuous variates age, age at menarche, age at menopause, age at first birth, height, weight at age 20, BMI $\left(\mathrm{kg} / \mathrm{m}^{2}\right)$, alcohol intake and energy intake, mean values of these variables were compared (ANOVA) between the categories of baseline recreational physical activity, history of sports participation and occupational physical activity. Covariates associated with breast cancer itself or with the exposure variables were considered as potential confounders. Data were analyzed using the case-cohort approach [29]. Incidence rate ratios (RR) and corresponding 95\% confidence intervals $(\mathrm{Cl})$ for breast cancer were estimated using exponentially distributed failure time regression models [29] with the Stata statistical software package [30]. We conducted several analyses to obtain insight into the periods of life that may be important in breast cancer etiology. We defined three time windows based on the sports participation before and after age 20 (categories: before/after/before and after age 20), sports participation before and after birth of the first child (categories: before/after/before and after birth of first child) and sports participation before and after the menarche (categories: before/after/before and after menarche). Women who never participated in sports were used as the reference category for each subgroup in the analyses.

We conducted several subgroup analyses to assess whether the effect of physical activity on the risk of breast cancer was modified by baseline BMI, weight gain/loss during life, baseline energy intake and modification by different time windows in which women were physically active. BMI was categorized according to the standardized categories of the $\mathrm{NIH} \mathrm{[31].} \mathrm{As} \mathrm{a} \mathrm{consequence} \mathrm{of} \mathrm{the} \mathrm{small} \mathrm{number}$ of cases in the subgroups we recoded BMI into three categories (BMI <25 normal weight, BMI 25-30 overweight, $B M \mid>=30$ obese). Energy intake was calculated from the food frequency questionnaire using the computerized Dutch Food Composition table [32, 33]

\section{Results}

Table 1 represents the distribution of the baseline recreational physical activity, history of sports participation and occupational physical activity (only longest held job is presented) among breast cancer cases and subcohort members. The distributions of the variables did not differ to a large extent between cases and subcohort members.

The means of potential confounders according to baseline recreational physical activity, history of sports participation and occupational physical activity among subcohort members is summarized in table 2. Women who reported being active more than 90 minutes per day at baseline were younger, had a later age at menopause, had a lower BMI and had a higher energy intake at baseline compared to women who were active less than 30 minutes per day 
Table 1 Distribution of the baseline recreational physical activity, the history of sports participation and occupational physical activity in breast cancer cases $(n=1208)$ and subcohort women $(n=1716)$, The Netherlands Cohort Study (1986-1993)

\begin{tabular}{llll}
\hline & Cases $^{\prime}$ & & \multicolumn{2}{l}{ Subcohort' } \\
Exposure variables & $n$ & n & \\
\hline
\end{tabular}

Baseline recreational physical activity

total recreational physical activity

$\begin{array}{lllll}<30 \mathrm{~min} / \text { day } & 347 & 29.2 & 442 & 26.3 \\ 30-60 \mathrm{~min} / \text { day } & 383 & 32.3 & 532 & 31.7 \\ 61-90 \mathrm{~min} / \text { day } & 226 & 19.0 & 355 & 21.1 \\ >90 \mathrm{~min} / \text { day } & 231 & 19.5 & 350 & 20.9\end{array}$

daily biking/walking

$$
<10 \mathrm{~min} / \text { day }
$$

10-30 min/day

$\begin{array}{llll}118 & 9.9 & 157 & 9.3\end{array}$

$31-60 \mathrm{~min} / \mathrm{day}$

$279 \quad 23.5$

$\begin{array}{ll}416 & 24.7\end{array}$

$>60 \mathrm{~min} / \mathrm{day}$

$405 \quad 34.1$

$539 \quad 32.1$

gardening/doing odd jobs

$\begin{array}{llll}387 & 32.5 & 570 & 33.9\end{array}$

$\begin{array}{llllll}\text { no gardening/doing odd jobs } & 471 & 39.6 & 677 & 40.3\end{array}$

$<1$ hour per week

20.2

$305 \quad 18.1$

1-2 hours per week

241

$>2$ hours per week

229

19.3

$334 \quad 19.9$

sports/gymnastics

248

20.9

$\begin{array}{ll}366 & 21.7\end{array}$

no sports activity

823

69.2

1126

66.9

$131 \quad 11.0$

$212 \quad 12.6$

1-2 hours per week

13.7

$247 \quad 14.7$

$>2$ hours per week

163

6.1

$\begin{array}{ll}97 & 5.8\end{array}$

History of sports participation

never
ever

634

53.4

962

57.3

553

46.6

717

42.7

duration of sports participation (years)

$$
\begin{aligned}
& 1-10 \text { years } \\
& 11-20 \text { years } \\
& 21-30 \text { years } \\
& 31-40 \text { years } \\
& >40 \text { years }
\end{aligned}
$$

271

54.5

346

53.4

22.5

137

21.1

39

7.9

64

9.9

5.2

47

7.3

49

54

8.3

number of hours sport per week
$<1 \mathrm{hr}$ pw
1-2 hr pw
2-3 hr pw
3-5 hr pw
$>5 \mathrm{hr} \mathrm{pw}$

$\begin{array}{rrrr}111 & 21.1 & 146 & 20.9 \\ 129 & 24.5 & 160 & 22.9 \\ 65 & 12.4 & 87 & 12.4 \\ 75 & 14.2 & 121 & 17.3 \\ 146 & 27.8 & 185 & 26.5\end{array}$

Occupational physical activity

longest held job

energy expenditure

$$
\begin{aligned}
& <8 \mathrm{~kJ} / \mathrm{min} \\
& 8-12 \mathrm{~kJ} / \mathrm{min}
\end{aligned}
$$

$>12 \mathrm{~kJ} / \mathrm{min}$

sitting time per day

6-8 hours sitting

2-6 hours sitting

$<2$ hours sitting

$\begin{array}{rrrr}540 & 59.2 & 700 & 58.3 \\ 328 & 35.9 & 426 & 35.5 \\ 45 & 4.9 & 75 & 6.2 \\ & & & \\ 290 & 31.7 & 394 & 32.8 \\ 209 & 22.9 & 283 & 23.5 \\ 414 & 45.4 & 525 & 43.7\end{array}$

\footnotetext{
'due to missing values numbers may not add up till 1208 (cases) and 1716 (subcohort)
} 
Table 2 Means of potential confounders according to levels of total baseline recreational physical activity. history of sports participation and occupational physical activity in the Netherlands Cohort Study, 1986-1993 (subcohort women $n=1.716$ )

\begin{tabular}{|c|c|c|c|c|c|c|c|c|c|}
\hline & \multicolumn{4}{|c|}{ Baseline recreational physical activity } & \multicolumn{2}{|c|}{ History of sports participation } & \multicolumn{3}{|c|}{ Occupational physical activity (longest held job) } \\
\hline & $<30$ min pd & $30-60 \mathrm{~min}$ pd & $60-90 \mathrm{~min}$ pd & $>90 \mathrm{~min}$ pd & no & yes & 6-8 hrs sitting & $2-6 \mathrm{hrs}$ sitting & $<2$ hrs sitting \\
\hline \multicolumn{10}{|l|}{ Characteristics } \\
\hline Age in 1986 (year) & 61.9 & 61.6 & 61.3 & $60.9^{\circ}$ & 61.7 & 61.2 & 61.0 & 61.4 & 61.3 \\
\hline Age at menarche (year) & 13.6 & 138 & 13.7 & 13.7 & 13.7 & 13.6 & 13.5 & 13.8 & 13.8 \\
\hline Age at menopause (year) & 48.2 & 48.9 & 48.8 & $49.1^{*}$ & 48.6 & 49.0 & 48.6 & 49.1 & 48.6 \\
\hline Baseline height $(\mathrm{cm})$ & 1647 & 165.3 & 165.3 & 165.0 & 164.8 & 165.4 & 164.9 & 165.9 & 164.9 \\
\hline Baseline weight ( $\mathrm{kg}$ ) & 69.2 & 68.4 & 68.4 & 67.8 & 68.8 & 68.2 & 67.1 & 68.6 & 68.8 \\
\hline Weight at age $20(\mathrm{~kg})$ & 58.1 & 58.5 & 59.3 & 57.9 & 58.4 & 58.5 & 57.5 & 58.5 & 58.8 \\
\hline Weight gain/oss (kg) & 119 & 110 & 10.1 & 10.4 & 112 & 10.7 & 10.6 & 110.7 & 10.7 \\
\hline Body mass index (kgm) & 256 & 250 & 250 & 24.9 & 254 & 249 & 24.7 & 249 & 25.3 \\
\hline Energy -ntake (Rcaliday) in 1966 & 1638 & 1716 & 1676 & 1722 & 1671 & 1712 & 1678 & 1687 & 1725 \\
\hline Alcohol (guday) in 1986 & 50 & 60 & 6.3 & 58 & 48 & 6.9 & 6.8 & 7.5 & 49 \\
\hline Age at first birth (year) & 21.7 & 221 & 224 & 224 & 219 & 224 & 21.6 & 19.2 & 22.7 \\
\hline
\end{tabular}

pe0 05 (anova) 
Women who had ever engaged in sports activities had a higher energy and alcohol intake at baseline and a lower BMI compared to women who never participated in sports. Women who had a longest held job with a high level of physical activity level (less than 2 working hours sitting) were heavier at baseline and at age 20, had a higher BMI, they had their first child at a later age and drank less alcohol compared to women in more sedentary jobs.

\section{Baseline recreational physical activity}

Baseline recreational physical activity (daily walking. biking combined with gardening/doing odd jobs, sports) showed an inverse association with breast cancer risk. In multivariate analysis, women who were active for more than 90 minutes a day had a $R R=0.76,(95 \% \mathrm{Cl} 0.58$ 0.99 , p-trend 0.003 ) compared to women who were active less than half an hour a day. The several aspects of baseline recreational physical activity showed the following relations: daily walking/biking showed a significant inverse association with breast cancer risk. Women who did these activities for more than 1 hour a day had a $R R=0.81, \quad(95 \% \mathrm{Cl} \quad 0.60-1.09$, p-trend $0.001)$ compared to women who did these activities less than 10 minutes a day. Gardening and doing odd jobs were not related to breast cancer risk. (see table 3).

Table 3 Age-adjusted and multivariate rate ratios of postmenopausal breast cancer according to baseline recreational physical activity (including sports) and intensity scores (MET-score) regarding baseline sports activity, the Netherlands Cohort Study (1986-1993)

\begin{tabular}{lllll}
\hline cases & prs.yrs $R^{1}$ & $R^{2}$ & $95 \% \mathrm{Cl}$ & p-trend \\
\hline
\end{tabular}

\section{Baseline recreational physical activity}

total recreational physical activity

$\begin{array}{llllll}<30 \mathrm{~min} / \text { day } & 246 & 2095 & 1.00 & 1.00 & \\ 30-60 \mathrm{~min} / \text { day } & 307 & 3084 & 0.90 & 0.84 & 0.67-1.07 \\ 61-90 \mathrm{~min} / \text { day } & 195 & 2131 & 0.81 & 0.78 & 0.60-1.00 \\ >90 \mathrm{~min} / \text { day } & 193 & 2113 & 0.84 & 0.76 & 0.58-0.99\end{array}$

daily biking/walking

$<10 \mathrm{~min} /$ day
$10-30 \mathrm{~min} /$ day
$31-60 \mathrm{~min} /$ day
$>60 \mathrm{~min} /$ day

313

276

235

117

2657
2818
2738
1211

1.00

1.00

$0.92 \quad 0.81$

$0.76 \quad 0.71$

$0.91 \quad 0.81$

$0.65-1.02$

$0.56-0.89$

0.60-1.09

0.001

gardening/doing odd jobs

$\begin{array}{llllll}\text { no gardening/ odd jobs } & 367 & 3520 & 1.00^{1} & 1.00^{1} & \\ <1 \text { hour per week } & 186 & 1814 & 1.12 & 1.02 & 0.80-1.31 \\ 1-2 \text { hours per week } & 186 & 1987 & 0.98 & 0.88 & 0.69-1.13 \\ >2 \text { hours per week } & 204 & 2124 & 0.97 & 0.93 & 0.73-1.17\end{array}$

0.003

$0.73-1.17 \quad 0.23$

sports/gymnastics

no sports activity

$<1$ hour per week

1.2 hours per week

$>2$ hours per week

$\begin{array}{rrrr}632 & 6107 & 1.00 & 1.00 \\ 111 & 1290 & 0.85 & 0.81 \\ 138 & 1439 & 0.89 & 0.90 \\ 62 & 608 & 1.00 & 0.98\end{array}$

$0.61-1.06$

$0.70-1.17$

0.68-1.42

\section{MET-scores}

Baseline type of sport in 1986

$<4$ METs
$4.01-6.00$ METs
$>6.00$ METs

$\begin{array}{rrrr}66 & 831 & 1.00 & 1.00 \\ 82 & 915 & 0.75 & 0.73 \\ 158 & 1514 & 0.81 & 0.84\end{array}$

0.45-1.17

$0.55-1.29$

0.43

'reference category, ' age-adjusted analysis

${ }^{2}$ multivariate analysis adjusted for age, age at menarche, age at menopause, benign breast disease, parity, age at first birth, maternal breast cancer, breast cancer in sister(s), education, height, baseline alcohol use and energy intake 
Baseline sports participation also showed no relation ( $\mathrm{RR}=0.98,95 \% \mathrm{Cl} 0.68-1.42$ ) (table 3 ). Baseline intensity score for sports showed a small decreased breast cancer risk, although not significant. Women who participated in a sport with a high intensity ( $>6.00$ METs) had a rate ratio of $0.84(95 \% \mathrm{Cl} 0.55-1.29)$ compared to women who participated in a sport with a low intensity ( $<4$ METs) at baseline. Exclusion of cases detected during the first two years of follow-up did not change the results presented here.

\section{History of sports participation}

Women who reported ever to have engaged in a sport had no reduction in breast cancer risk compared to women who never participated in a sport. The rate ratio for women who had ever engaged in sports was $1.13(95 \% \mathrm{Cl} 0.94$ 1.37)(see table 4) compared to women who never engaged in sports. The total duration of sports in years showed no relation with breast cancer. Women who participated in sports longer than 40 years had a RR of $0.99(95 \% \mathrm{Cl}$ 0.58-1.67) compared to women who participated less than 10 years in a sport. The frequency (hours sport per week) showed a weak inverse relation with breast cancer risk. Women who participated 1-2 hours per week, 2-3 hours per week, 3-5 hours per week and more than 5 hours per week into sports had rate ratios of $0.98,0.88,0.76,0.87(95 \% \mathrm{Cl} 0.57-1.32$, p-trend 0.1 ). respectively, compared to women participating into sports less than 1 hour per week (see table 4). The mean intensity score based upon history of sports participation and duration in years showed no association with breast cancer risk. Women who had a mean intensity score of more than 6 METs had a rate ratio of $1.07(95 \% \mathrm{Cl} 0.71-1.60)$ compared to women with a mean sport intensity of less than 4 METs (see table 4).

Table 4 Age-adjusted and multivariate rate ratios of postmenopausal breast cancer according to history of sports participation, intensity scores (MET-scores) regarding history of sports participation and occupational physical activity, the Netherlands Cohort Study (1986-1993)

$$
\text { cases prs.yrs RR' } \mathrm{RR}^{2} \quad 95 \% \mathrm{Cl} \quad \text { p-trend }
$$

\section{History of sports participation}

never participated in sport ever participated in sport number of hours sport per week

$<1 \mathrm{hr}$ per week

2-3 hr per week

3-5 hr per week

$>5 \mathrm{hr}$ per week

sports duration in years

$$
\begin{aligned}
& 1-10 \text { years } \\
& 11-20 \text { years } \\
& 21-30 \text { years } \\
& 31-40 \text { years } \\
& >40 \text { years }
\end{aligned}
$$

Mean MET-score per year

$$
\begin{aligned}
& \text { < } 4 \text { METs } \\
& 4.01-6.00 \text { METs } \\
& >6.00 \mathrm{METs}
\end{aligned}
$$

$\begin{array}{rrrrr}478 & 5202 & 1.00 & 1.00 & \\ 471 & 4339 & 1.17 & 1.13 & 0.94-1.37 \\ & & & & \\ 91 & 862 & 1.00 & 1.00 & \\ 107 & 962 & 1.07 & 0.98 & 0.65-1.47 \\ 54 & 530 & 0.97 & 0.88 & 0.55-1.40 \\ 66 & 716 & 0.84 & 0.76 & 0.49-1.19 \\ 127 & 1117 & 1.06 & 0.87 & 0.57-1.32 \\ & & & & \\ 231 & 2140 & 1.00 & 1.00 & \\ 97 & 816 & 1.06 & 0.97 & 0.68-1.38 \\ 33 & 360 & 0.79 & 0.83 & 0.50-1.37 \\ 23 & 296 & 0.69 & 0.66 & 0.37-1.19 \\ 42 & 324 & 1.20 & 0.99 & 0.58-1.67 \\ & & & & \\ 63 & 652 & 1.00 & 1.00 & \\ 178 & 1583 & 1.09 & 1.11 & 0.74-1.66 \\ 187 & 1690 & 1.12 & 1.07 & 0.71-1.60\end{array}$

Occupational physical activity

longest held job

energy expenditure

$$
\begin{aligned}
& <8 \mathrm{~kJ} / \mathrm{min} \\
& 8-12 \mathrm{~kJ} / \mathrm{min} \\
& >12 \mathrm{~kJ} / \mathrm{min}
\end{aligned}
$$


table 4, continued

\section{Cases prs.yrs $\mathrm{RR}^{1} \quad \mathrm{RR}^{2} \quad 95 \% \mathrm{Cl} \quad$ p-trend}

sitting time per day

6-8 hours sitting

2-6 hours sitting

$<2$ hours sitting

2430
1632
3045

2430

3045

$\begin{array}{ll}1.00^{1} & 1.00^{\prime} \\ 1.00 & 1.19 \\ 1.07 & 1.21\end{array}$

1.21

$0.88-1.60$

$0.94-1.56$
0.54

last held job

energy expenditure

$$
\begin{aligned}
& <8 \mathrm{~kJ} / \mathrm{min} \\
& 8-12 \mathrm{~kJ} / \mathrm{min} \\
& >12 \mathrm{~kJ} / \mathrm{min}
\end{aligned}
$$

sitting time per day

$6-8$ hours sitting
$2-6$ hours sitting
$<2$ hours sitting

475
256
40

260
197
314

$\begin{array}{rrrr}4373 & 1.00 & 1.00 & \\ 2444 & 0.97 & 1.07 & 0.84-1.37 \\ 433 & 0.88 & 0.98 & 0.62-1.55 \\ & & & \\ 2474 & 1.00 & 1.00 & \\ 1729 & 1.04 & 1.24 & 0.92-1.65 \\ 3047 & 1.03 & 1.10 & 0.85-1.42\end{array}$

0.68

\footnotetext{
'reference category, ' age-adjusted analysis, ${ }^{2}$ multivariate analysis adjusted for age, age at menarche, age at menopause, benign breast disease, parity, age at first birth, maternal breast cancer. breast cancer in sister(s), education, height, baseline alcohol use and energy intake
}

\section{Occupational physical activity}

No relation was found between occupational physical activity and breast cancer risk. Women with a high energy expenditure $(>12 \mathrm{~kJ} / \mathrm{min})$ in the longest held job showed a nonsignificantly decreased risk ( $R R=0.83,95 \% \mathrm{Cl} 0.51-1.34$ ) compared to women with a longest held jobs with low energy expenditure ( $<8 \mathrm{~kJ} / \mathrm{min})$. No relation was found between energy expenditure in last held job and breast cancer risk $(R R=0.98)$. Also, no relation was found between total number of sitting hours per day in longest or last held job and breast cancer risk (see table 4).

\section{Time windows}

When we examined sports participation in different time windows we found no particular subgroups showing reductions in risk associated with sports participation. Women who engaged in sports only after the age of 20 had a $R R=1.03$ $(95 \% \mathrm{Cl} 0.76-1.40)$ (see table 5) compared to women who never participated in a sport. Women who participated in a sport only before, only after and before and after the birth of the first child had rate ratios of 1.18, 1.04, 1.22 $(95 \% \mathrm{Cl} 0.89-1.67)$, respectively, compared to women who never participated into sports. Another subgroup consisted of women who were physically active only before, only after and before and after their menarche.
The subgroup women who were physically active only before menarche was too small to include in the analysis. The results showed a slight increased breast cancer risk for women who were physically active before and after the menarche ( $R R=1.25,95 \% \mathrm{Cl} \quad 0.98-1.59$ ) compared to women who never participated in a sport (see table 5).

We stratified the data according to baseline BMI, baseline energy intake and weight gain/loss during adult life. In every BMI category we found a reduction in risk associated with baseline recreational physical activity, although none of them were statistical significant. However, in the overweight category (BMI 25-30) we found a somewhat stronger association ( $R R=0.6795 \%$ $\mathrm{Cl}$ 0.42-1.08, p-trend 0.01)(table 6) between baseline recreational physical activity and breast cancer risk.

According to baseline energy intake the results also showed nonsignificant reductions in risk associated with baseline recreational physical activity and with borderline significant trends, except for the lowest quintile. Women in the second quintile of energy intake and being active for more than 90 minutes a day showed a decreased breast cancer risk of $R R=0.66$ $(95 \% \mathrm{Cl} 0.34-1.27$, p-trend 0.05). Even women in the highest quintile of energy intake and being active for more than 90 minutes a day had a $R R=0.85(95 \% \mathrm{Cl}$ 0.42-1.71, p-trend 0.07$)$. 
Table 5 Multivariate rate ratios of postmenopausal breast cancer according to sports participation in different time periods in a woman's life, the Netherlands Cohort Study (1986-1993)

\begin{tabular}{|c|c|c|c|c|c|}
\hline & cases & prs.yrs & $\mathbf{R R}^{\prime}$ & $95 \% \mathrm{Cl}$ & p-trend \\
\hline \multicolumn{6}{|l|}{ Time windows } \\
\hline \multicolumn{6}{|l|}{ Age 20} \\
\hline never participated in sport & 478 & 5205 & $1.00^{t}$ & & \\
\hline participated in sport only before age 20 & 81 & 742 & 1.22 & $0.87-1.69$ & \\
\hline participated in sport only after age 20 & 107 & 1026 & 1.03 & $0.76-1.40$ & \\
\hline participated in sport before and after age 20 & 240 & 2142 & 1.16 & $0.92-1.45$ & 0.17 \\
\hline \multicolumn{6}{|l|}{ Birth of first child } \\
\hline never participated in sport & 478 & 5205 & 1.00 & & \\
\hline participated in sport only before birth $1^{\text {st }}$ child & 172 & 1688 & 1.18 & $0.91-1.52$ & \\
\hline participated in sport only after birth $1^{\text {st }}$ child & 56 & 589 & 1.04 & $0.69-1.55$ & \\
\hline participated in sport before and after birth $1^{\text {st }}$ child & 109 & 994 & 1.22 & $0.89-1.67$ & 0.09 \\
\hline \multicolumn{6}{|l|}{ Age at menarche ${ }^{\circ}$} \\
\hline never participated in sport & 478 & 5202 & $1.00^{1}$ & & \\
\hline participated in sport only after menarche & 224 & 2085 & 1.04 & $0.83-1.32$ & \\
\hline participated in sport before and after menarche & 190 & 1717 & 1.25 & $0.98-1.59$ & 0.03 \\
\hline
\end{tabular}

\footnotetext{
reference category

1 multivariate analysis adjusted for age, age at menarche, age at menopause, benign breast disease. parity, age at first birth, maternal breast cancer, breast cancer in sister(s), education, height, baseline alcohol use and energy intake

the category 'participated in sport only before menarche' was too small $(n=14)$ to include in the analysis
}

According to weight gain/loss during adult life the results showed also reduction in breast cancer risk associated with baseline recreational physical activity. Women who had a weight gain of $10-17 \mathrm{~kg}$ during adult life (from age 20 till baseline) showed a $R R=0.55$ $(95 \% \mathrm{Cl} 0.29-1.04)$ with a significant trend $(\mathrm{p}$ trend 0.004 ). For women who had a weight gain of more than $17 \mathrm{~kg}$ still a reduction in breast cancer risk was observed, associated with baseline recreational physical activity (RR=0.86, 95\% Cl 0.44-1.67, p-trend 0.42). We found no significant tests of interaction between baseline recreational physical activity. baseline BMI, baseline energy intake and weight gain/loss during adult life.

We also studied the interaction between baseline recreational physical activity, baseline energy intake and baseline BMI together (see table 7 ). In the category obese women $(>30)$ the number of cases was too small to conduct a multivariate analysis. So, only age-adjusted analyses are shown for this category. The greatest reduction in risk is seen in the second category of BMI (25-30), independent of energy intake. In the subgroup women with overweight and a high baseline energy intake. baseline recreational physical activity is inversely related to breast cancer risk ( $R R=0.35,95 \% \mathrm{Cl} 0.1-1.23 \mathrm{p}$-trend 0.002 ).

Even in the lowest category of BMI (<25) a reduction in risk is seen and energy intake is intermediate $(R R=0.59,95 \% \mathrm{Cl} 0.29-1.19$, $\mathrm{p}$ trend 0.05 ).

\section{Discussion}

The results of the present study support the hypothesis that physical activity protects against breast cancer in postmenopausal women. Baseline recreational physical activity showed an inverse association with breast cancer risk. Especially daily walking and biking more than an hour a day show a protective effect ( $R R=0.81$ ). Women who were ever engaged in sports before baseline did not have a lower breast cancer risk. No relation was found for duration of the sport activity in years and breast cancer risk. A weak inverse relation was found for the number of hours sports per week. Women who spent more than 5 hours per week participating in a sport had a reduction in breast cancer risk of $13 \%$ ( $R R=0.87$ ) compared to women who spent less than 1 hour per week on sports. 
Table 6 Multivariate rate ratios of postmenopausal breast cancer according to categories of baseline recreational physical activity, stratified by baseline BMI $\left(\mathrm{kg} / \mathrm{m}^{2}\right.$, according to WHO/NIH standardized categories), baseline energy intake (in quintiles) and weight gain/loss during life (in quartiles), the Netherlands Cohort Study (1986-1993)

cases prs.yrs $\mathrm{RR}^{1} \quad 95 \% \mathrm{Cl} \quad$ p-trend

\section{Baseline BMI $\left(\mathrm{kg} / \mathrm{m}^{2}\right)$ baseline recreational physical activity} normal $(<25)$ $<30 \mathrm{~min} /$ day $30-60 \mathrm{~min} /$ day $61-90 \mathrm{~min} /$ day $>90 \mathrm{~min} /$ day

\begin{tabular}{|c|c|}
\hline $\begin{array}{l}\text { overweight } \\
(25-30)\end{array}$ & $\begin{array}{l}<30 \mathrm{~min} / \text { day } \\
30-60 \mathrm{~min} / \text { day } \\
61-90 \mathrm{~min} / \text { day } \\
>90 \mathrm{~min} / \text { day }\end{array}$ \\
\hline $\begin{array}{l}\text { obese } \\
(>30)\end{array}$ & $\begin{array}{l}<30 \mathrm{~min} / \text { day } \\
30-60 \mathrm{~min} / \text { day } \\
61-90 \mathrm{~min} / \text { day } \\
>90 \mathrm{~min} / \text { day }\end{array}$ \\
\hline
\end{tabular}

Baseline energy intake (quintiles) ${ }^{a}$ baseline recreational physical activity

Q1 (low) $\quad \begin{array}{ll}<0 \mathrm{~min} / \text { day } \\ & 30-60 \mathrm{~min} / \text { day } \\ & 61-90 \mathrm{~min} / \text { day } \\ & >90 \mathrm{~min} / \text { day } \\ & \\ & <30 \mathrm{~min} / \text { day } \\ & 30-60 \mathrm{~min} / \text { day } \\ & 61-90 \mathrm{~min} / \text { day } \\ & >90 \mathrm{~min} / \text { day } \\ & <30 \mathrm{~min} / \text { day } \\ & 30-60 \mathrm{~min} / \text { day } \\ & 61-90 \mathrm{~min} / \text { day } \\ & >90 \mathrm{~min} / \text { day }\end{array}$

Q4

$$
\begin{aligned}
& <30 \mathrm{~min} / \text { day } \\
& 30-60 \mathrm{~min} / \text { day } \\
& 61-90 \mathrm{~min} / \text { day } \\
& >90 \mathrm{~min} / \text { day }
\end{aligned}
$$

Q5 (high) $\quad \begin{aligned} &<0 \mathrm{~min} / \mathrm{day} \\ & 30-60 \mathrm{~min} / \text { day } \\ & 61-90 \mathrm{~min} / \text { day } \\ &>90 \mathrm{~min} / \text { day }\end{aligned}$

\section{Weight gain/loss (in quartiles)}

baseline recreational physical activity

$$
\begin{aligned}
(-35 \mathrm{~kg}-+5 \mathrm{~kg}) & 30-60 \mathrm{~min} / \mathrm{day} \\
& 60-90 \mathrm{~min} / \mathrm{day} \\
& >90 \mathrm{~min} / \mathrm{day}
\end{aligned}
$$

$\begin{array}{rrrr}118 & 1035 & 1.00 & \\ 160 & 1732 & 0.86 & 0.62-1.20 \\ 113 & 1242 & 1.88 & 0.61-1.25 \\ 97 & 1212 & 0.74 & 0.52-1.08\end{array}$

0.05

$\begin{array}{rrrr}97 & 774 & 1.00 & \\ 121 & 1119 & 0.76 & 0.51-1.13 \\ 70 & 694 & 0.66 & 0.41-1.06 \\ 79 & 741 & 0.67 & 0.42-1.08\end{array}$

0.01

$\begin{array}{lll}30 & 277 & 1.00\end{array}$

$\begin{array}{lll}25 & 225 & 1.30\end{array}$

$\begin{array}{lll}12 & 186 & 0.77\end{array}$

$\begin{array}{lll}17 & 153 & 0.94\end{array}$

$0.48-3.52$

$0.27-2.22$

$0.27-3.32$

0.55

$\begin{array}{lll}48 & 446 & 1.00\end{array}$

$\begin{array}{lll}53 & 580 & 0.81\end{array}$

$\begin{array}{lll}43 & 416 & 0.97\end{array}$

$\begin{array}{lll}32 & 402 & 0.77\end{array}$

0.45-1.45

$0.52-1.79$

0.40-1.46

0.53

$49 \quad 505 \quad 1.00^{1}$

$\begin{array}{lll}62 & 554 & 1.17\end{array}$

$\begin{array}{lll}32 & 349 & 0.95\end{array}$

$\begin{array}{lll}31 & 472 & 0.66\end{array}$

$0.66-2.07$

$0.47-1.92$

$0.34-1.27$

0.05

$\begin{array}{lll}58 & 334 & 1.00\end{array}$

$\begin{array}{lll}70 & 654 & 0.64\end{array}$

$\begin{array}{lll}51 & 475 & 0.60\end{array}$

$\begin{array}{lll}45 & 379 & 0.67\end{array}$

$0.37-1.10$

$0.33-1.08$

$0.35-1.28$

0.06

$53 \quad 425 \quad 1.00^{\prime}$

$\begin{array}{lll}60 & 633 & 0.72\end{array}$

$\begin{array}{lll}40 & 453 & 0.63\end{array}$

$0.39-1.31$

$0.34-1.19$

$0.70 \quad 0.36-1.36$

0.08

$38 \quad 363$

1.00

0.82

$435 \quad 0.68$

$0.45-1.51$

$0.36-1.30$

0.85

$0.42-1.71$

0.07 
table 6, continued

\begin{tabular}{lllllll}
\hline & & cases & prs.yrs & RR & $95 \% \mathrm{Cl}$ & p-trend \\
\hline 2 & $<30 \mathrm{~min} /$ day & 39 & 353 & 1.00 & & \\
$(5-10 \mathrm{~kg})$ & $30-60 \mathrm{~min} /$ day & 61 & 684 & 0.71 & $0.38-1.34$ & \\
& $61-90 \mathrm{~min} /$ day & 48 & 406 & 1.15 & $0.60-2.18$ & \\
& $>90 \mathrm{~min} /$ day & 42 & 399 & 0.95 & $0.49-1.87$ & 0.52 \\
3 & & & & & & \\
$(10-17 \mathrm{~kg})$ & $30-60 \mathrm{~min} /$ day & 60 & 558 & 1.00 & & \\
& $61-90 \mathrm{~min} /$ day & 86 & 798 & 0.85 & $0.52-1.38$ & \\
& $>90 \mathrm{~min} /$ day & 46 & 448 & 0.72 & $0.39-1.32$ & \\
4 & & 46 & 508 & 0.55 & $0.29-1.04$ & 0.004 \\
$(>17 \mathrm{~kg})$ & $30-60 \mathrm{~min} /$ day & 72 & 590 & 1.00 & & \\
& $61-90 \mathrm{~min} /$ day & 46 & 455 & 0.72 & $0.53-1.52$ & \\
& $>90 \mathrm{~min} /$ day & 51 & 439 & 0.70 & $0.44-1.67$ & 0.42 \\
\hline
\end{tabular}

reference category. 'multivariate analysis adjusted for age, age at menarche, age at menopause, benign breast disease, parity, age at first birth, maternal breast cancer, breast cancer in sister(s), education, height. baseline alcohol use and energy intake, " multivariate model without baseline energy intake

We found no association between occupational physical activity and breast cancer risk. We could not distinguish a specific period in life in which the association between sports activity and breast cancer risk was more pronounced. thus the age at which women participating into sports is not related to breast cancer risk. Furthermore, in the subgroup of women with overweight (BMI 25-30), we found a decreased breast cancer risk independent of baseline energy intake. Before discussing the results in relation with other studies, some remarks concerning the NLCS are relevant. Loss to follow-up is the primary source of potential selection bias in prospective cohort studies. The prospective nature of a cohort study together with completeness of follow-up as has been achieved in this study, reduces the potential for selection bias to a minimum [34]. As we considered the most important potential confounding factors reported in the literature and included all factors associated with breast cancer risk or the exposure variables in our study in the multivariate model (e.g. age. reproductive factors. dietary factors), only unmeasured or still unknown other factors may have caused residual confounding

Measuring physical activity in epidemiologic studies is difficult, and different methods have been used, which may explain in part the inconsistent results across studies [2]. Studies have differed with regard to the following parameters: the period for which physical activity was assessed (i.e. childhood/ adolescence, lifetime etc.). the sources of physical activity (i.e. recreational, occupational or both), and the various parameters of activity (i.e. frequency, intensity, duration). In this study the baseline recreational physical activity was measured by several aspects including gardening/doing odd jobs, biking/walking during leisure time, daily walking and biking (leaving out the dog. go shopping) and participating in sports/gymnastics. We made use of the history of sports participation as indicator for physical activity in the past. We were not able to achieve a complete overview of all the elements of past physical activity (e.g. gardening and house keeping activities were not included).

Misclassification and recall bias might play a role in determining the exposure status of the participants early in life. Because such misclassification would be unrelated to disease status (nondifferential), it should underestimate any true association between lifetime recreational physical activity and breast cancer risk.

Especially for the women in our Dutch cohort (55-69 years old) it was not so common to participate in a sport during adolescence and adulthood as it is nowadays. Therefore, many cases and subcohort members had never participated in sport. Nowadays. $40 \%$ of the persons older than 55 year are engaged in one sport in the Netherlands [35]. Almost $35 \%$ of the subcohort members did participate in a sport at baseline. Thus, at baseline our cohort is more or less comparable to the general Dutch population regarding sports activities 
Table 7 Multivariate rate ratios of postmenopausal breast cancer according to categories of baseline recreational physical activity, stratified by energy intake (in tertiles) and BMI ( $\mathrm{kg} / \mathrm{m}^{2}$, according to WHO/NIH standardized categories), the Netherlands Cohort Study (1986-1993)

Baseline recreational physical activity

$<30$ minutes per day $\quad 30-60$ minutes per day $60-90$ minutes per day $>90$ minutes per day p-trend

\begin{tabular}{|c|c|c|c|c|c|c|}
\hline BMI $\left(\mathrm{kg} / \mathrm{m}^{2}\right)$ & $\begin{array}{l}\text { Energy intake } \\
\text { (kcal)(tertiles) }\end{array}$ & RR & $\mathrm{RR}^{\prime}(95 \% \mathrm{Cl})$ & $\mathrm{RR}^{\prime}(95 \% \mathrm{Cl})$ & $\mathrm{RR}^{\prime}(95 \% \mathrm{Cl})$ & \\
\hline normal & low & 1.00 & $1.07(0.50-2.30)$ & $1.25(0.57-2.78)$ & $0.63(0.27-1.46)$ & 0.28 \\
\hline \multirow[t]{2}{*}{$(<25)$} & intermediate & 1.00 & $0.67(0.37-1.21)$ & $0.73(0.38-1.40)$ & $0.59(0.29-1.19)$ & 0.05 \\
\hline & high & 1.00 & $0.86(0.48-1.54)$ & $0.77(0.42-1.40)$ & $0.83(0.45-1.53)$ & 0.36 \\
\hline overweight & low & 1.00 & $0.83(0.36-1.91)$ & $1.13(0.43-3.02)$ & $0.90(0.36-2.23)$ & 0.97 \\
\hline \multirow[t]{2}{*}{$(25-30)$} & intermediate & 1.00 & $0.78(0.40-1.54)$ & $0.73(0.32-1.65)$ & $0.61(0.27-1.38)$ & 0.25 \\
\hline & high & $1.00^{-}$ & $0.49(0.19-1.07)$ & $0.37(0.14-1.00)$ & $0.35(0.10-1.23)$ & 0.002 \\
\hline obese ${ }^{\circ}$ & low & 1.00 & $1.08(0.67-1.73)$ & $0.83(0.50-1.39)$ & $0.91(0.54-1.52)$ & 0.35 \\
\hline \multirow[t]{2}{*}{$(>30)$} & intermediate & 1.00 & $0.75(0.42-1.33)$ & $0.49(0.24-1.01)$ & $0.71(0.37-1.36)$ & 0.07 \\
\hline & high & 1.00 & $0.88(0.27-2.89)$ & $0.48(0.11-2.09)$ & $0.56(0.11-2.79)$ & 0.18 \\
\hline
\end{tabular}

reference category

' multivariate analysis, adjusted for age, age at menarche, age at menopause, benign breast disease, parity, age at first birth, maternal breast cancer, breast cancer

in sister(s). education, height and baseline alcohol use intake

categories of energy intake low <1455 kcal, intermediate $1455-1789 \mathrm{kcal}$, high $>1789 \mathrm{kcal}$, BMI based on stardardized categories according to WHO/NIH

Donly age-adjusted analysis because the numbers of cases in the subgroups were too small 
The main aim of the NLCS was to investigate the relationship between diet and the risk of cancer and with no specifical emphasis on physical activity. An advantage of this largescale prospective cohort study is the possibility to study interactions between the different indicators of energy balance (physical activity. energy intake and BMI). As the results showed, no interaction was found between baseline recreational physical activity and BMI or baseline energy intake or weight gain/loss during adult life, although in the subgroup women with a high BMI an inverse relation was seen between baseline recreational physical activity and breast cancer risk, independent of baseline energy intake. Thus, heavy women appear to have a lower breast cancer risk if they exercise daily for $>90$ minutes, regardless their energy intake. A recent case-control study [36] suggested that frequent episodes of strenuous physical activity during young adulthood might have the greatest benefits for reducing postmenopausal breast cancer risk only in women who avoid weight gain during adult life. If women gain substantive weight during adulthood, the benefits of frequent and strenuous early life physical activity appear to be lost. In our cohort the results showed that women who gained weight (more than $17 \mathrm{~kg}$ ) still had a reduction in breast cancer risk associated with baseline recreational physical activity. However, the relation between body size, energy intake en physical activity requires further research. BMI is only a gross measurement of body composition and does not provide information regarding the percentages of lean and fat masses, nor concerning the distribution of body mass.

For some aspects of past physical (sport) activity (hours sport per week) the results showed a possible $U$-shaped relation with breast cancer risk. Moderate physical activity may enhance the immune system by elevating the number of natural killer cells whereas exhaustive physical exercise may depress immunologic function [23]. Others stated that the relation between physical exercise and immune functions follows a " $J$-shaped curve. with the lowest risk observed among women who undertake regular moderate exercise [37].

Sports participation during specific periods in life was not related to breast cancer risk in our cohort. Some of the studies that assessed physical activity during adolescence and/or young adulthood observed reduction in subsequent breast cancer risk [7, 14, 16], while others found no association [8, 15, 38].

Our results showed no association between occupational physical activity and breast cancer risk. This is in agreement with another study. Coogan et al. showed that holding a job of medium/heavy activity did not reduce breast cancer risk [39]. The assessment of occupational activity was based on job title and the coding system was based on the Dutch situation; however, there may be large variations in physical activity within one job. This variation could not be included in the assessment of occupational physical activity. Women who had one job for a very short period (less than 5 years) and a long time ago (e.g. in the age of 20-25 years) were categorized into physical activity scores according to this job (for longest as well as latest job). Their physical activity pattern during the rest of their life is perhaps not in comparison with the period in which they worked

In conclusion, our study supports the hypothesis that physical activity is inversely related to breast cancer risk in postmenopausal women. However, we could not distinguish a certain period in life at which it was important to be physically active. The frequency, duration and intensity of sports activities were not strongly related to breast cancer risk in our cohort. Baseline BMI and energy intake together showed a somewhat stronger reduction in breast cancer risk associated with baseline recreational physical activity in women with overweight (BMI between 25-30), independent of baseline energy intake.

Further research should be concentrated on the assessment of lifetime physical activity to gain insight into different aspects of physical activity and their relation to breast cancer risk.

Physical activity is one of the few modifiable, protective factors for breast cancer and there are many other important health-related reasons to promote regular exercise.

\section{References}

1 Frisch RE, Wyshak G. Albright NL. et al Lower prevalence of breast cancer and cancers of the reproductive system among former college athletes compared to non-athletes $\mathrm{Br} J$ Cancer 1985. 52885 . 91 
2. Ainsworth BE, Sternfeld B, Slattery ML, Daguise V Zahm SH. Physical activity and breast cancer evaluation of physical activity assessment methods. Cancer 1998: 83(3 Suppl): 611-20

3. Rockhill B. Willett WC. Hunter DJ. Manson JE Hankinson SE. Colditz GA: A prospective study of recreational physical activity and breast cancer risk. Archives of internal medicine 1999, 159(19): 2290-6 4. Cerhan JR, Torner JC, Lynch CF, et al Association of smoking. body mass, and physical activity with risk of prostate cancer in the lowa 65+ Rural Health Study (United States) Cancer Causes Control 1997: 8(2): 229-38

5. Thune I: Physical activity and energy balance. modifiable lifestyle factors for breast cancer? Irish Medical Journal 1997. 90 : 168-70

6 Albanes D. Blair A. Taylor PR Physical activity and risk of cancer in the NHANES I population. Am $J$ Public Health 1989, 79(6) 744-50.

7 . Paffenbarger RS. Hyde RT. Wing AL. Physical activity and incidence of cancer in diverse populations a preliminary report Am J Clin Nutr $1987: 45 \quad 312.7$

8. Rockhill B. Willett WC. Hunter DJ, et al Physical activity and breast cancer risk in a cohort of young women [see comments] J Natl Cancer Inst 1998 90(15): 1155-60

9. Dorgan JF, Brown C. Barrett M. et al: Physical activity and risk of breast cancer in the Framingham Heart Study. Am J Epidemiol 1994, 139(7). 662-9

10 . Bernstein L. Henderson BE. Hanisch R. Sullivan Halley J. Ross RK Physical exercise and reduced risk of breast cancer in young women [see comments]. J Natl Cancer Inst 1994: 86(18) 1403-8

11. Friedenreich $C M$, Rohan TE: Physical activity and risk of breast cancer. Eur J Cancer Prev 1995: 4(2) 145-51

12. McTiernan A, Stanford JL, Weiss NS. Daling JR, Voigt LF: Occurrence of breast cancer in relation to recreational exercise in women age 50-64 years Epidemiology 1996, 7(6): 598-604

13. Mittendorf R. Longnecker MP. Newcomb PA ef al: Strenuous physical activity in young adulthood and risk of breast cancer (United States) Cancer Causes Control 1995: 6(4): 347-53

14. Marcus PM. Newman B. Moorman PG. et al Physical activity at age 12 and adult breast cancer risk (United States). Cancer Causes Control 1999 10(4) :293-302

15. Verloop J, Rookus MA van der Kooy $\mathrm{K}$. van Leeuwen FE: Physical activity and breast cancer risk in women aged 20-54 years. J Natl Cancer Inst 2000 . 92(2) $128-35$

16. D'Avanzo B. Nanni O, LaVecchia C. et al Physical activity and breast cancer risk Cancer Epidemiol Biomarkers Prev 1996: $5: 155-60$

17. Hu YH. Nagata C. Shimizu H. Kaneda N. Kashiki $Y$ : Association of body mass index. physical activity and reproductive histories with breast cancer a casecontrol study in Gifu. Japan. Breast Cancer Res Treat 1997, 43(1) 65-72

18. Taioli E. Barone J. Wynder EL A case-control study on breast cancer and body mass. The American Health Foundation--Division of Epidemiology. Eur J Cancer 1995, 31a(5) 723-8

19. Dosemeci M. Hayes RB, Vetter R. et al. Occupational physical activity, socioeconomic status. and risks of 15 cancer sites in Turkey. Cancer Causes Control 1993:4(4): 313-21

20. Pukkala E. Poskiparta M. Apter D. Vihko V. Lifelong physical activity and cancer risk among Finnish female teachers. Eur J Cancer Prev 1993: 2(5): 369 76.

21. Steenland K. Nowlin S. Palu S: Cancer incidence in the National Health and Nutrition Survey I. Followup data diabetes. cholesterol. pulse and physical activity. Cancer Epidemiol Biomarkers Prev 1995 4(8): $807-11$

22. Coogan PF, Newcomb PA, Clapp RW. Trentham Dietz A, Baron JA, Longnecker MP. Physical activity in usual occupation and risk of breast cancer (United States). Cancer Causes Control 1997, 8(4): 626-31

23 Hoffman Goetz L. Apter D. Demark Wahnefried W. Goran MI. McTiernan A, Reichman ME: Possible mechanisms mediating an association between physical activity and breast cancer. Cancer 1998 83(3 Suppl) $621-8$

24 Bernstein L. Ross RK, Lobo RA, Krailo MD Henderson BE The effects of moderate physical activity on menstrual cycle patterns in adoiscence implications for breast cancer prevention. $\mathrm{Br}$.J. Cancer 198755681.5

25 Van den Brandt PA. Goldbohm RA. Van T Veer P Volovics A. Hermus, R.J J., Sturmans F: A large scale prospective cohort study on diet and cancer in the Netherlands. J Clin Epidemiol 1990: 19: 285-95

26. Van den Brandt PA. Schouten LJ, Goldbohm RA. Dorant E. Hunen PMH Development of a record linkage protocol for use in the Dutch cancer registry for epidemiological research. Int J Epidemiol 1990 19. $553-8$

27. Ainsworth BE, Haskell WL, Leon AS, et al Compendium of physical activities classification of energy costs of human physical activities. Med Sc Sports Exerc 1993: 25(1): 71-80.

28. Hettinger $\mathrm{TH}$. Mueller $\mathrm{BH}$, Gebhard $\mathrm{H}$. Ermittlung des Arbeitsenergieumsatzes bei Dynamisch Muskulaerer Arbeit. Dortmund, 1989 Schriftenreihe der Bundesarbeit fur Arbeitsschutz)

29. Volovics A. Van den Brandt PA: Methods for the analyses of case-cohort studies Biom J 1997: 39 195-214

30. StataCorp Stata Statistical Software, Release 50 . College Station. Texas. Stata Corporation, 1997 31. NCI/NHLBJ, Obesity, Education, Members ITF Clinical guidelines on the identification, evaluation. and treatment of overweight and obesity in adults NHLBI. $1998,1-137$

32. Goldbohm RA, Van 't Veer P. Van den Brandt PA. et al Reproducibility of a food frequency questionnaire and stability of dietary habits determined from five annually repeated measurements Eur J Clin Nutr 1995: 49(6) 420-429. 33. Goldbohm RA, Van den Brandt PA. Brants HA, et al: Validation of a dietary questionnaire used in a large-scale prospective cohort study on diet and cancer. Eur J Clin Nutrition 1994, 48 253-65

34 Goldbohm RA. Van den Brandt PA. Dorant E Estimation of the coverage of Dutch municipalities by cancer registries and PALGA based on hospital discharge data Tijdschr Soc Gezondheidsz 199472 80-84

35 Centraal Buro voor de Statistiek CBS Sociaal culturele berichten. 1995 
36. Shoff SM, Newcomb PA, Ytentham-Dietz A, et al: Early life physical activity and postmenopausal breast cancer: effect of body size and weight change. Cancer Epidemiol Biomarkers Prev 2000, 9: 591-5. 37. Calabrese LH: Exercise, immunity, cancer and infection. In: Bouchard C. Shepherd RH. Stephens T. et al., eds. Exercise, fitness, and health: a consensus of current knowdledge, 1990; 567-79.
38. McTiernan A, Ulrich C, Slate S, Potter J: Physical activity and cancer etiology: associations and mechanisms. Cancer Causes Control 1998; 9: 487 . 509.

39. Coogan PF, Aschengrau A: Occupational physical activity and breast cancer risk in the upper Cape Cod cancer incidence study. American journal of industria medicine 1999; 36(2):279-85. 



\section{General discussion}


Chapter 7 


\section{General Discussion}

In the prospective cohort study described in this thesis the association between energy restriction in childhood and adolescence, physical activity and the risk of breast, prostate and colon cancer was investigated. Many of the limitations and strengths of the specific investigations as well as the implications of the specific results have been discussed in the previous chapters. In this chapter, the main findings of the separate studies of this thesis are summarized and compared with results of other studies and we will elaborate on the implications of our findings for the energy restriction hypothesis, also in relation to energy balance. Furthermore, methodological shortcomings of our studies will be discussed and we will discuss the role of insulin-like growth factor-I (IGF-1). which may be a common biological mechanism relevant for breast, prostate and colon carcinogenesis. Finally, overall public health implications are considered and recommendations for future research will be made.

\section{Main findings and comparison with other studies}

In the meta-analysis on energy restriction and the risk of spontaneous mammary tumors we confirmed that energy restriction in itself consistently protects against the development of spontaneous mammary tumor in mice. irrespective of the type of restricted nutrient or other study characteristics. The energyrestricted (range 23-50\%) animal groups developed $55 \%$ less mammary tumors than the ad libitum control groups (chapter 2). These animal results still await confirmation in human studies. In our epidemiological study, the energy restriction in childhood or adolescence was not associated with breast cancer and prostate cancer risk. Men and women living in a famine area during the Hunger winter 1944-1945 had no decreased breast and prostate cancer risk respectively. compared to men and women living in a Non-western region of the country during the Hunger winter 1944-1945 (chapter 3 and 4). Regarding early energy restriction and breast cancer the results are in contradiction with what was expected Vatten et al [1, 2] suggested that in populations where variation in height reflects variation in nutritional living conditions during childhood and adolescence, there might be a positive association between height and risk of breast cancer. They found different associations between body height and breast cancer risk for women in different birth cohorts. There was a strong linear trend for height among women who were born between 1929-1936. These women had experienced a reduction in dietary fat and restricted caloric intake in World War II (1940-1945) before their adolescent growth spurt. In Norway an ecological study was conducted in which [3] the hypothesis that lifestyle changes during World War II decreased the risk of breast cancer, was examined. The results indicated that one or more environmental factors changed during the war that influenced the risk of breast cancer. The major factor, which changed during World War II in Norway, was diet. One important dietary change was a decrease in daily energy intake by $22 \%$ during the war. In the NLCS. cohort a positive association was found between height and breast cancer [4]. Hislop et al. [5] conducted a case-control study to examine the relationship between childhood and current eating practices and the risk of breast cancer. No elevated risks of breast cancer for the childhood consumption of foods with high fat content were found, except possibly for animal fat.

With regard to prostate cancer, our results are consistent with the few studies conducted on the relation between energy restriction in adolescence and prostate cancer risk. Only a few studies have concentrated on diet in adolescence and these studies also found no relation between early diet and prostate cancer risk. Slattery et al. (1990) conducted a casecontrol study of prostate cancer in which reported food consumption patterns for the adolescent and adult years were assessed. Men, who consumed a diet high in saturated fatty acids as adolescents. were not at increased risk of developing prostate cancer [6] Another study evaluated dietary and lifestyle characteristics to subsequent prostatic cancer risk in a cohort of 14,000 Seventh-day Adventist men. In this study, exposure to a vegetarian lifestyle during childhood was not associated with prostate cancer risk later in life [7]. Results of a case-control study in Sweden showed no 
clear association between dietary habits during childhood and adolescence and prostate cancer risk [8]

However, we found an inverse association both for men $(R R=0.85)$ and women $(R R=0.80)$ between living in a Western city during the Hunger winter 1944-1945 and colon cancer risk (chapter 5). Men and women who were living in a Western city (thus exposed to the Hunger winter) during their adolescent growth spurt had a decreased colon cancer risk later in life compared to men and women living in nonWestern parts of the Netherlands during that period of life. The relation between colon cancer and energy restriction in childhood or adolescence has never been investigated in humans, to our knowledge. Total energy intake has been related to a higher risk of colon cancer in case-control studies [9-12]. However, results from cohort studies that assessed total energy intake indicated, if anything. a slight inverse association between total energy intake and risk of colon cancer [13-16]. These studies were not able to analyze the adolescent diet in relation to subsequent colon cancer risk later in life. In the NLCS also an inverse, but statistically nonsignificant association was found between energy intake and colon cancer risk. [17].

Baseline recreational physical activity was inversely related to breast cancer risk. Women who were daily active in activities like walking. cycling. gardening for more than 90 minutes a day had a rate ratio of 0.76 compared to women who were active less than 30 minutes a day. In the subgroup of women with a high BMI we found a stronger inverse relation between baseline recreational physical activity and breast cancer risk independent of energy intake (chapter 6). With respect to baseline recreational physical activity and breast cancer risk, our conclusions contribute to the body of evidence suggesting that higher levels of recreational physical activity afford protection against breast cancer [18-21]

\section{Methodological shortcomings}

There are several methodological shortcomings that might play a role in interpreting the results. The potential for selection bias in the NLCS is low considering the high completeness of cancer follow-up. Also, there were no reasons to assume that residual confounding was still present, because all major risk factors for breast, prostate and colon cancer were measured and controlled for in multivariate analyses. A factor that could have influenced the results is misclassification of food restriction exposure and the misclassification of physical activity

\section{Exposure early diet}

It has obviously been difficult to test the childhood energy restriction hypothesis in Western populations for ethical and practical reasons. To assess energy restriction in the studies described in this thesis we used proxy measures. We used the residence during the War years (1940-1944) and the Hunger winter (1944-1945) and the father's employment status during the Economic Depression years (19321940) as proxy measures for the food situation of our cohort members in their youth. Other studies, which concentrated on the consequences of the famine in 1944-1945, used the same proxy measures [22-24]. These studies found relations between living in a Western city and perinatal mortality of the newborn, lower birth weight and delay in the onset of menarche. In our study, we tried to validate the proxy measures and asked the subcohort members during follow-up, if they really had experienced hunger during the winter of 1944-1945. Our results showed that $75 \%$ of the women living in a Western city reported that they experienced hunger during the winter of $1944-45$ of whom $35 \%$ experienced severe hunger. Of the women who reported severe hunger during the Hunger winter $80 \%$ lived in a Western city during this winter. These results also indicated that the proxy measure for energy restriction in the Hunger winter is reasonably adequate. If misclassification is present, it will be nondifferential because of the prospective design of the cohort

Other proxies that are often used as an indicator for the food situation during childhood and adolescence are anthropometric variables such as attained body height, weight and BMI. These variables are proxies for early nutrition (particularly of energy intake) and childhood growth and development, with taller and heavier people more likely to have been exposed to a greater surplus of dietary energy during maturation than shorter and less heavy ones. Attained height might be an indicator of childhood energy intake in situations where there is enough variation in energy intake [25] 
For colon and breast cancer, height can act as an intermediate factor between the relation of early energy restriction and the risk of colon and breast cancer. Energy restriction early in life may negatively affect attained height, which might itself lead to a reduction in breast cancer risk [26, 27]. In the NLCS-cohort a positive association was found between height and breast cancer [4] and between height and colon cancer risk in women [28]. Furthermore, if women experience a restricted energy intake during childhood their age at menarche might be delayed [29]. The data from the NLCS showed that a delayed age at menarche (15 yrs and older) reduces the risk of breast [30] and colon cancer [31]. . In addition, other studies confirm these results [32-38]. Berkey et al [39] evaluated the relation between childhood diet and age at menarche. They concluded that girls who were taller and who consumed more animal protein and less vegetable protein had an earlier menarche. Height and BMI were not related to prostate cancer in the NLCS-cohort [40]. although other studies found positive associations between height and prostate cancer risk [41-43]. Another anthropometric variable that might be important in relation to cancer risk is weight change during adulthood. In the NLCS-cohort information was also collected on the weight at age 20. This selfreported variable was used to define BMI at age 20 and the weight change during adulthood. For breast cancer no strong association was found with weight gain in the women with a low BMI at age 20 [4]. Regarding prostate cancer a significant inverse trend in risk was found with a gain in BMI from age 20 to cohort baseline age. [40]. And for colon cancer, men with BMI >25 $\mathrm{kg} / \mathrm{m}^{2}$ at age 20 had an increased subsequent colon cancer risk; for women no association was found [28]. All these self reported anthropometric measures might have led to some degree of non-differential misclassification. Despite errors in these selfreported variables we still found associations in the NLCS.

\section{Assessment of physical activity}

In chapter 6 we present a study on physical activity and breast cancer risk. An accurate measurement of lifetime patterns of physical activity is difficult to achieve. No single method is accurate enough to be called a 'golden standard' for physical activity [44, 45]. Furthermore, the NLCS was not specifically designed to explore the relation between physical activity and cancer risk. In our study we had only data available by questionnaire and no other physiological and biomechanical measurements. A woman's physical activity pattern is hard to assess because women without an occupation may have very different physical activity patterns depending on family care, home, and other responsibilities. At baseline in the NLCS, we asked several aspects of a lifetime pattern of physical activity such as daily walking/biking. gardening/doing odd jobs and participants had to recall their sports participation during their entire life. Regarding sports activities we used the Compendium of Ainsworth et al [46] to assign a MET-score to each type of sport activity, as an indicator for intensity. A total MET score was calculated for the various sports activities, weighted by the duration (in years) of each activity. The difficulty of this Compendium is that it is not specific for certain age groups. Few data are available on energy expenditure for specific activities in children and eiderly people. The development of tables with energy expenditure values for separate age groups would be of great use for research conducted in these groups [47]

Physical activity under free-living conditions is hard to measure. In the future, physical activity sensors, which are cheap, small and convenient for subjects and investigators, are needed to reliably monitor small changes in movements and grade as well as duration and intensity of typical physical activities during extended periods in free-living situations [45, 48, 49]

Furthermore, the assessment of occupational physical activity was based on job title and the coding system was based on the Dutch situation. However, there may be large variations in physical activity within one job. This variation could not be included in the assessment of occupational physical activity. Women who had one job for a very short period (less than 5 years) and a long time ago (e.g. in the age of 20-25 years) were categorized into physical activity scores according to this job (for longest as well as latest job). Their physical activity pattern during the rest of their life is perhaps not in comparison with the period in which they worked. Many women in the NLCScohort had one job for a few years and were housewife for the rest of their life. 


\section{Possible mechanisms of energy restriction in relation to possible cancer risk reduction}

A variety of physiologic, behavioral and genetic variables are altered when there is a reduction in energy intake [50]. For example body temperature decreases and as a consequence there is a corresponding decrease in the activity in cellular DNA and a more efficient metabolism is achieved. This means that in situations where less energy is available, the host will take precedence for utilization, and hence there is less energy available for tumor growth [51]. Reproductive capacity declines and as caloric intake declines, changes occur in the expression of a number of drug-metabolizing enzymes, with the most striking effect seen in sex-specific growth hormones.

Energy restriction enhances DNA repair and moderates oxidative damage to DNA [52]. Energy restriction might also reduce various aspects of oncogene expression [53-56]. Energy restriction might influence gene expression and energy restriction might have an impact on the (steroid) hormones levels. The overall consequences of energy restriction appear to be the up-regulation of cellular and molecular defense systems and down regulation of reproductive ageing [50, 57]. These observations might help us understand some of the basic mechanisms involved in establishment and proliferation of tumors, but also need further investigation. In addition, in the next paragraph we will discuss the role of insulin in cancer carcinogenesis because of its importance with regard to breast, prostate and colon cancer.

Insulin, insulin-like growth factor-1 (IGF-1) en IGF-binding proteins (IGFBP)

Nowadays, the role of insulin-like growth factor-1 (IGF-1), which may be a common biological mechanism relevant for breast, prostate and colon carcinogenesis, is topic of discussion. Life-style factors like being overweight, and sedentary (having a positive energy balance) are often associated with an increased risk of breast, prostate and colon cancer. Recent theories propose that the effects of these risk factors may be mediated by increases in circulating insulin levels and insulin-like growth factor (IGF-1). IGF-1 levels correlate with risk of premenopausal breast cancer in women [58]. prostate cancer $[59,60]$, and colorectal cancer [61-63]. Insulin and IGF-1 regulate the energy metabolism, stimulate cell proliferation and inhibit apoptosis [64]. Dunn conducted an animal study in which mice were fed a $20 \%$ energy restricted diet, or a $20 \%$ restricted diet plus IGF-1 supplement, and an ad libitum control group. Serum IGF-1 was lowered $24 \%$ by energy restriction but was completely restored in the IGF-1 treated energy-restricted group [64]. Restriction of energy intake in rats transplanted with human prostate cancer cells slows the growth of cancer and accelerates apoptosis (see figure 1). These effects are associated with a decrease in circulating IGF-1 [65]

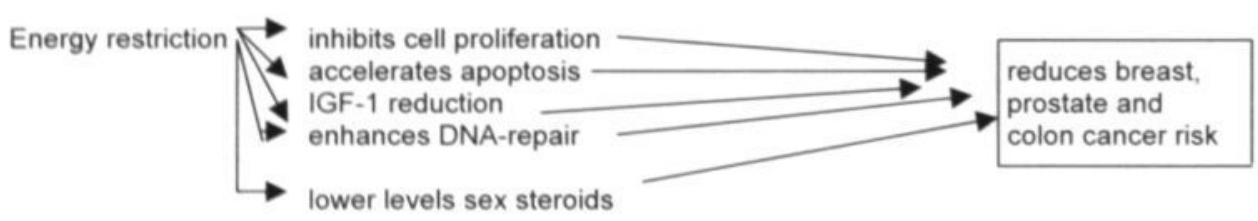

Figure 1 The impact of energy restriction

Energy restriction has been shown to reduce levels of serum insulin and insulin has been shown to be a growth factor for normal and malignant human mammary cells. The elevation of plasma IGF-1 levels might be a risk factor for different forms of cancer. There are possibilities that IGF-1 and corticoids may be effected by energy restriction and may in turn, influence tumorigenesis [66]. The role of IGFs in cancer is supported by epidemiologic studies, which have found that high levels of circulating IGF-1 and low levels of IGF binding protein-3 (IGFBP. 3) are associated with increased risk of several common cancers, including those of the breast, prostate and colon [67].

Stoll [68] has indicated that better nutrition accelerates growth hormone release, which, in turn, increases levels of IGF-1. Overeating, a lack of physical activity and obesity (particularly central obesity) may cause insulin resistance 
and, hence, tend to increase plasma insulin concentrations. A number of case-control studies have shown hyperinsulinemia to be a marker of increased breast cancer risk, particularly in obese postmenopausal women. Insulin, in turn can increase the bioactivity of IGF-1 by inhibiting the synthesis of certain IGFbinding proteins. On the other hand, plasma levels of both insulin and IGF-1 are decreased by energy restriction. The adolescent growth spurt involves stimulation by growth hormone, IGF and sex steroids, and Stoll hypothesizes that the combination of IGF and sex steroids results in mitogenic effect on developing tissue in adolescence and a concomitant increased risk of epithelial atypia and carcinogenesis [69, 70]. Serum IGF-1 level is low at birth and increases gradually until puberty. The rate of increase is very high at puberty, after which the concentration declines slowly with age [71, 72].
Height is positively related to IGF-1 concentration. Levels of IGF-1 in circulation are closely associated with body growth, especially at puberty. Children with short stature have low circulating IGF-1 levels [73]. The association between IGF-1 level and physical activity appears to be rather complex, and current evidence does not allow clear conclusions to be drawn. The hormonal changes and the pattern of energy consumption during exercise depend on the duration, type and intensity of exercise as well as on the person's level of physical training. The results are very inconsistent. Smith et al. [74] observed that vigorous exercise that was sustained for 1 week in exercise-conditioned persons produced decreased serum IGF-1 levels, despite intake of energy that was adequate for individuals with a normal level of activity. Suggestions have been

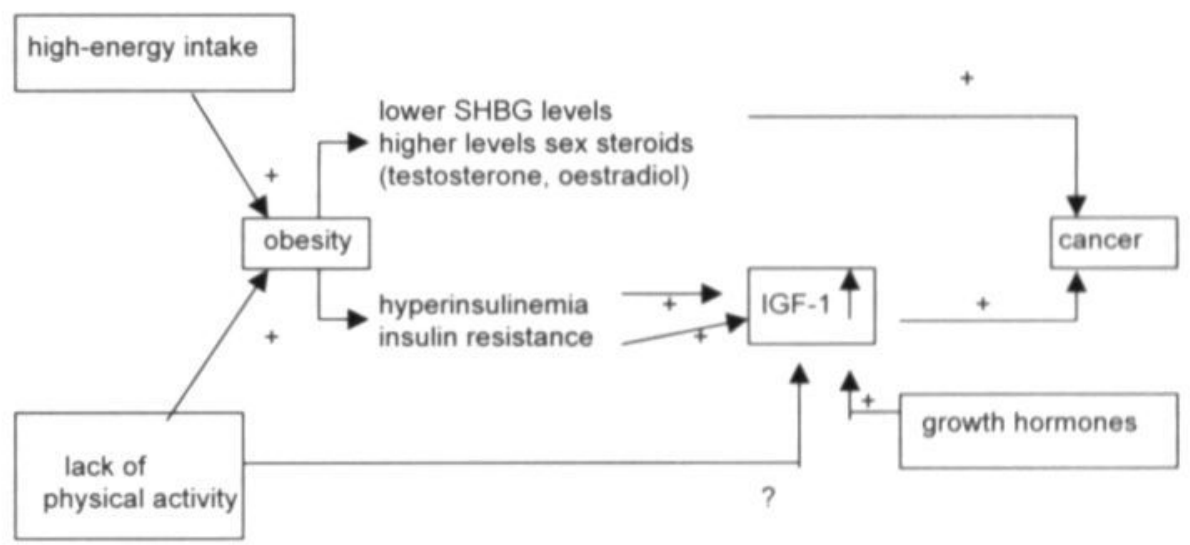

Figure 2 Possible relations between diet, physical activity and cancer risk

put forward that the age-related decline in serum IGF-1 is partially related to a decline in physical fitness and may have little to do with diet [75].

\section{Energy balance: interaction between energy intake, energy expenditure, and obesity}

Energy balance is defined by a state in which energy intake is equal to energy expenditure, resulting in no net change of energy stores in the body [76]. There are three main components of energy expenditure, firstly. the energy expended to maintain the basic physiologic function of the body (resting metabolic rate (RMR)). Second, the energy that is expended in order to digest, metabolize and store ingested macronutrients. The third component of energy expenditure is the increase in metabolic rate that occurs during body movement (exercise as well as other forms of physical activity) [77]. The aspects of the energy balance equation that have been linked to the etiology of breast. prostate and colon cancer include reduced physical activity and an excess accumulation of body fat. If energy consumption exceeds energy expenditure (overnutrition) a threat to health can occur. This hazard applies not only to the risk of cancer but also to cardiovascular diseases as well as other chronic illnesses (such as type 2 diabetes) [78]. In addition, there might be 
important interactions between obesity, weight change, hormone levels and risk of breast, prostate and colon cancer. Obesity is consistently associated with post-menopausal breast cancer and to a lesser extent with prostate and colon cancer. Abdominal obesity in women is associated with low sex hormone binding globulin (SHBG)levels [79] and thus with high levels of free oestradiol and androgens which might play a role in breast cancer carcinogenesis. With regard to prostate cancer, obesity is expected to lower SHBG levels in men and as a consequence thus high levels of free testosterone. Cell division in the prostate is controlled by testosterone and might play a role in the development of prostate cancer [80]. Obesity is also associated with hyperinsulinemia and insulin resistance, which are often related to colon cancer risk [76, 81] (see figure 2).

Also interactions between physical activity and other components of energy balance including energy intake and body size may exist. In a large case-control study of colon cancer in Utah. those at the highest risk for colon cancer had the most unfavorable energy balance: they had the least physical exercise, the highest energy intake and the largest BMI [82]. When physical activity was high, however, the risks of high energy intake and large body size were much less pronounced. Therefore, energy balance as a whole could be associated with colon cancer. In our study on physical activity and breast cancer risk, we found in the subgroup of women with a high BMI a stronger inverse relation between recreational physical activity and breast cancer risk independent of energy intake [83].

There are some indications that physical activity might interfere directly with hormonal metabolism in adolescence. It has been suggested that if physical activity modifies cancer risk, it might do so through a hormonerelated pathway. For example by reducing the cumulative exposure to ovarian hormones, by delaying menarche of by reducing the number of ovulatory cycles. Physical activity during reproductive life has been shown to alter the concentrations of sex hormones. Girls participating in vigorous sports such as ballet and running, experience a high incidence of primary and secondary amenorrhea, delayed menarche, and more irregular cycles, compared with non-athlete girls [29, 84-86]. Levels of estrogens and androgens may predict risk of developing prostate cancer. In the Physicians
Health Study a strong trend of increasing prostate cancer risk was observed with increasing levels of plasma testosterone and an inverse trend in risk with increasing levels of SHBG, which indicates that lower amounts of bioavailable testosterone were associated with decreased risk for prostate cancer [87]

Thus, physical activity might also play a part in the relationship between obesity and hormonedependent cancers through obesity, but on the other hand physical activity shows a direct relationship with breast [20, 21, 83, 88-91], colon [92-96] and to some lesser extent with prostate cancer [88, 97-100], independently from obesity [76].

\section{Implications for public health}

Despite intense research on etiological factors for breast, prostate and colon cancer, relatively few factors have emerged that are consistently associated with risk in different epidemiological study designs and that are modifiable. Physical activity and on the other hand reduction of weight gain during adult life are modifiable factors which show a relationship with the occurrence of breast and colon cancer. Also individuals who are overweight at a young age may be at a higher risk of (hormone related) cancers in later life. The current high prevalence of adolescent obesity suggests that cancer will remain a significant public health problem for future generations [101, 102]. Thus it is possible to prevent an appreciable proportion cancer cases by maintaining a healthy body weight. Any intervention to reduce excess weight would entail the modification of nutritional habits toward a different composition of the habitual diet to reduce energy intake and increase physical activity. An energy-restricted diet might be necessary for those children who are already obese, but on the other hand energy expenditure (physical activity) must exceed energy intake.

Weindruch and Walford [103] regard energy restriction as an ethical option for human use. under appropriate conditions. Others are less enthusiastic because of concerns about harmful effects in children, but animal studies have shown that energy restriction starting at early adulthood was effective in decreasing cancer risk in rodent as energy restriction started soon after weaning [104]. Many studies on energy restriction have been conducted in obese 
persons or in relation to the effects on the ageing process, but human trials in relation to subsequent cancer risk are not available. Research in an enclosed ecological space (Biosphere 2) demonstrated that energy restriction for two years reduced many risk factors for many diseases, including reduced levels of blood lipids, cholesterol, IGF-1, insulin. and testosterone. Overall the research findings on energy restriction showed that rodents. monkeys and humans reacted similarly to the beneficial effect. A reduction in oxidatieve stress, an increase in protein synthesis and DNA repair, and an improvement in endocrine homeostasis appeared to be the major antiageing and anti-disease effects of energy restriction $[50,105,106]$.

The level of energy restriction that will be appropriate in humans for the longer term is uncertain. In their semi starvation study Keys and colleagues showed that $50 \%$ energy restriction is not acceptable for the longer term as it appeared to introduce several negative health effects [107]. From studies described in a thesis on energy restriction and ageing it appeared that $30 \%$ energy restriction was also not an acceptable strategy for the longer term [108]. A level of $10 \%$ seemed to be more feasible for the longer term, but did not affect health parameters after 10 weeks. So further research is required to determine an appropriate level of energy restriction in the human situation.

\section{Implications for future research}

The evidence from the Netherlands Cohort Study on diet and cancer for a protective effect of early energy restriction on the risk of breast. prostate and colon cancer warrants further research. Energy restriction results in many alterations in biological processes in the human body and has an impact on or a relation with many variables. Interactions might also exist between (early) energy intake, physical activity. $\mathrm{BMI}$ and cancer risk. To study these interactions more cancer cases are needed for subgroup analyses, and will be investigated further in the Netherlands Cohort Study after a longer followup period.

Epidemiologic studies on the effect of energy restriction and subsequent cancer risk might concentrate on cancer biomarkers and intermediate endpoints. This is an attractive method for investigating the association between early diet and subsequent cancer risk. Studies with intermediate endpoints are easier and less expensive to conduct, compared with large-scale epidemiologic studies of early exposures and cancer endpoints. Examples of intermediate endpoints for breast, prostate and colon cancer include mammographic density (or atypical hyperplasia), psa-levels, and colon polyps, respectively. Measurable intermediate processes also include levels of endogenous hormones (levels of serum IGF-1, IGF binding proteins, estrogens), immunological processes and body fat distribution. However, for most cancer sites reliable and valid intermediate markers of disease have not yet been established.

Although controlled trials of early energy restriction are not feasible, natural experiments have occurred such as the Dutch famine during World War II. The circumstances of the Dutch famine provide a rare opportunity to investigate the relations in various nutritional exposures not normally seen in human populations [109]. It would be of great interest to see if energy restriction has associations with other cancer sites, and especially those with a presumed hormone-related etiology such as ovarium and endometrial cancer

Anorexia nervosa is also a kind of natural experiment in which the energy intake is very low. Mellemkjaer [110] investigated the energy restriction hypothesis for cancer in patients with anorexia nervosa, who had an extremely low intake of energy for prolonged periods of their lives. The standardized incidence rate (SIR) for cancer among women with anorexia nervosa was $0.80(95 \% \mathrm{Cl} 0.52-1.18)$. This means that the number of observed cases was smaller than the expected number of cancer cases. Most of the patients were under 50 years of age during the study period. The researchers intend to continue to follow the cohort of anorexia nervosa patients for cancer occurrence in the coming years, as more cohort members will probably develop cancer

The role of early nutrition and especially early energy restriction, is interesting in relation to subsequent cancer risk but perhaps also with regard to other diseases such as diabetes or coronary heart diseases. Especially, the role of obesity in the etiology of cancer and other diseases seems to be very important. So the 
effect of early energy restriction might be related to adolescent BMI and BMI at adult age and research should concentrate on the relation of obesity with biological mechanism like insulin production, levels of IGF-1 and hormones. Research should also concentrate on the determination of possible sensitive periods in a person's life in which energy restriction has the greatest impact on subsequent cancer risk. There are epidemiological findings that link birth weight and early childhood nutrition with cancer risk later in life [111]. Food intake is a strong determinant of IGF-1 concentration. Nutrition in early life may therefore have a "programming" effect, via IGF-1, that influences subsequent cancer risk [112].

To clarify the biological mechanisms, more systematic experimental research in rodents is needed to examine the effects of energy restriction on hormone levels. the insulin mechanism and the impact of energy restriction on the immune system.

Many intervention studies are conducted on the impact of energy restricted diet in obese persons. It would be very interesting to study the effects of energy restriction on hormone levels (p.e.IGF-1) and other biological mechanisms in normal weight persons. Also further research is necessary to gain insight in the acceptable energy restriction level in humans, because now it is still uncertain which level of energy restriction is appropriate in humans for the longer term.

The interrelationships of energy intake, and energy retention to energy expenditure and physical fitness need further investigation from the physiologic. metabolic, endocrine. epidemiologic and genetic aspects of cancer development, since obesity, energy expenditure and cancer have a familial predisposition. To study these interactions prospective cohort studies are necessary with a long follow-up period and many cancer cases. It would also be important in future studies that diet (especially energy intake) should be repeatedly assessed throughout life to gain insight into the relation between childhood nutritional patterns and subsequent cancer risk.

\section{References}

1. Vatten LJ, Kvikstad A, Nymoen EH: Incidence and mortality of breast cancer related to body height and living conditions dunng childhood and adolescence Eur J Cancer 1992; 28(1): 128-31
2. Vatten LJ, Kvinnsland S: Prospective study of height, body mass index and risk of breast cancer. Acta Oncol 1992; 31(2): 195-200.

3. Tretli S, Gaard M Lifestyle changes during adolescence and risk of breast cancer: an ecologic study of the effect of World War II in Norway. Cancer Causes Control 1996; 7(5): 507-12

4. Van den Brandt PA. Dirx M.JM. Ronckers CM. Van den Hoogen P. Goldbohm A Height, weight, weight change and postmenopausal breast cancer risk the Netherlands Cohort Study. Cancer Causes Control 1997, 8 . 39-47

5. Hislop TG, Coldman AJ, Elwood JM, Brauer G, Kan L. Childhood and recent eating patterns and risk of breast cancer Cancer Detect Prev 1986, 9(1-2): 47-58

6. Slattery ML. Schumacher MC. West DW. Robison AM, French TK Food-consumption trends between adolescent and adult years and subsequent risk of prostate cancer. Am J Clin Nutr 1990. 52: 752-7

7. Mills PK, Beeson WL. Phillips RL. Frase GE Cohort study of diet, lifestyle and prostate cancer in Adventist men. Cancer 1989, 64(3). 598-604

8. Andersson SO, Baron J, Wolk A, Lindgren C, Bergstrom R. Adami HO Early life risk factors for prostate cancer: a population-based case-control study in Sweden. Cancer Epidemiol Biomarkers Prev 1995: 4(3) 187-92

9. Jain M. Cook GM. Davis FG. Grace MG. Howe GR. Miller AB A case-control study of diet and colo-rectal cancer. Int J Cancer 1980; 26(6): 757-68

10. Bristol JB, Emmett PM, Heaton KW. Williamson RCN Sugar, fat, and the risk of colorectal cancer. BMJ 1985, 291: 1467-1470

11. Peters RK, Pike MC, Garabrant D. Mack TM: Diet and colon cancer in Los Angeles County. California Cancer causes and control 1992, 3(5): 457-73

12. Slattery ML, Caan BJ, Potter JD, et al: Dietary energy sources and colon cancer risk. Am J Epidemiol 1997; 145(3): 199-210

13. Bostick RM, Potter JD, Kushi LH, et al: Sugar. meat, and fat intake, and non-dietary risk factors for colon cancer incidence in lowas women (United States) CCC 1994, $8: 649-67$

14. Willett WC, Stampfer MJ, Colditz GA, Rosner BA Speizer FE: Relation of meat, fat, and fiber intake to the risk of colon cancer in a prospective study among women New Engl J Med 1990; 323(24): 1664-72

15 Giovannucci E. Rimm EB. Stampfer MJ. Colditz GA. Ascherio A. Willett WC: Intake of fat, meat, and fiber in relation to risk of colon cancer in men. Cancer research 1994, 54(9). 2390-7.

16. Gaard M. Tretli S. Loken EB. Dietary factors and risk of colon cancer. a prospective study of 50.535 young Norwegian men and women. Eur J Cancer Prev 1996: 5(6) 445-54

17 Goldbohm RA. Van den Brandt PA. Van 't Veer P. et al A prospective cohort study on the relation between meat consumption and the risk of colon cancer. Cancer Res 1994 . 54(3) .718-23 
18. Frisch RE, Wyshak G, Albright NL, et al: Lower prevalence of breast cancer and cancers of the reproductive system among former college athietes compared to non-athletes. $\mathrm{Br}$.J.Cancer 1985; 52 . 885. 91.

19. Rockhill B. Willett WC. Hunter DJ. Manson JE. Hankinson SE, Colditz GA: A prospective study of recreational physical activity and breast cancer risk. Archives of internal medicine 1999; 159(19): 2290-6

20. Thune I, Brenn T, Lund E, Gaard M: Physical activity and the risk of breast cancer New Engl.J.Med 1997: 336(18): 1269-75

21. Verloop J. Rookus MA, van der Kooy K, van Leeuwen FE: Physical activity and breast cancer risk in women aged 20-54 years. J Natl Cancer Inst 2000; 92(2): $128-35$

22. Stein Z, Susser M. Saenger G, Marolla F: Famine and human development, the Dutch Hunger winter of 1944-1945. New York: Oxford University Press. 1975. 23. Susser ES. Lin SP. Schizophrenia after prenatoal exposure to the Dutch Hunger Winter of 1944-45 Arch Gen Psychiatry 1992: 49: 983-988

24. Noord van PA. Kaaks R. The effect of wartime conditions and the 1944-45 'Dutch famine' on recalled menarcheal age in participants of the DOM breast cancer screening project. Ann Hum Biol 1991, 18(1): 57.70

25. Willett W Anthropometric measures and body composition In Willett W ed Nutritional epidemiology. 15 ed. New York. Oxford University Press. 1990, 217-44

26. Brinton LA, Swanson CA Height and weight at various ages and risk of breast cancer Ann Epidemiol 1992: 2(5): $597-609$

27. Le Marchand L. Kolonel LN. Earle ME. Mi MP Body size at different periods of life and breast cancer risk. Am J Epidemiol 1988, 128(1): $137-52$

28 Ariesen MJ. Dirx MJM. Van den Brandt PA. Voornips LE: Height, BMI, change in BMI and colon cancer risk the Netherlands Cohort Study. submitted

29. Merzenich $\mathrm{H}$. Boeing $\mathrm{H}$. Wahrendorf J. Dietary fat and sports activity as determinants for age at menarche. Am J Epidemiol 1993. 138(4): 217-24

30 Van den Brandt PA, Van 't Veer P. Goldbohm RA, et al : $A$ prospective cohort study on dietary fat and the risk of postmenopausal breast cancer Cancer Res 1993. 53(1) 75-82

31. Penders J. Weijenberg MP. Van den Brandt PA. A prospective cohort study on hormonal and reproductive factors and the risk of colon and rectum in women. submitted

32. Petridou E. Syrigou E. Toupadaki N. Zavitsanos $X$. Willett $W$. Trichopoulos D Determinants of age at menarche as early life predictors of breast cancer risk [see comments] Int J Cancer $1996.68(2)$ 193-8

33 Hsieh CC. Trichopoulos D. Katsouyanni K, Yuasa $\mathrm{S}$. Age at menarche, age at menopause, height and obesity as risk factores for breast cancer associations and interactions in an international casecontrol study Int J Cancer 1990 46(5) 796-800
34. Persky VW, Chatterton RT, Van HLV, Grant MD, Langenberg $P$. Marvin $\mathrm{J}$. Hormone levels in vegetarian and nonvegetarian teenage girls: potential implications for breast cancer risk. Cancer Res 1992; 52(3): $578-83$

35. Fioretti F, Tavani A, Bosetti C, et al : Risk factors for breast cancer in nulliparous women. $\mathrm{Br} \mathrm{J}$ Cancer 1999: 79(11-12): 1923-8

36. Gerhardsson de Verdier $M$, London $S$ : Reproductive factors, exogenous female hormones. and colorectal cancer by subsite. Cancer Causes Control 1992; 3(4): 355-60.

37. Kampman E, Potter JD, Slattery ML. Caan BJ, Edwards S: Hormone replacement therapy. reproductive history, and colon cancer: a multicenter. case-control study in the United States. Cancer causes and control 1997, 8(2): 146-58

38. Fernandez E, La Vecchia C. Braga C. et al: Hormone replacement therapy and risk of colon and rectal cancer. Cancer Epidemiol Biomarkers Prev 1998, 7(4): 329-33

39. Berkey CS, Gardner JD, Frazier AL, Colditz GA Relation of childhood diet and body size to menarche and adolescent growth in girls Am J Epid 2000, 152 446-52

40. Schuurman AG. Goldbohm RA, Dorant E, Van den Brandt PA. Anthropometry in relation to prostate cancer risk in the Netherlands Cohort Study. Am J Epidemiol 2000, 151 .541-9

41. Andersson S-O. Wolk A. Bergstrom R, et al Body size and prostate cancer a 20-year follow-up study among 135006 Swedish construction workers J Nati Cancer Inst 1997. 89(5) 385-389

42. Giovannucci E. Rimm EB. Stampfer MJ. Colditz GA. Willett WC Height body weight and risk of prostate cancer Cancer Epidemiol Biomarkers Prev 1997. 6 557.563

43 Le Marchand L. Kolonel LN. Wilkens LR Animal fat consumptions and prostate cancer a prospective study in Hawai Epidemiology 1994. 5 276-82

44. Ainsworth BE. Sternfeld B. Slattery ML. Daguise V. Zahm SH Physical activity and breast cancer evaluation of physical activity assessment methods Cancer 1998, 83(3 Suppl) 611-20

45 Schultz $Y$. Weinsier RL. Hunter GR Assessment of free-living physical activity in humans an overview of currently available and proposed new measures Obes Res 2001, 9 368-379

46. Ainsworth BE. Haskell WL. Leon AS. et al Compendium of physical activities classification of energy costs of human physical activities Med Sci Sports Exerc 1993. 25(1) 71-80

47 Pols MA. Peeters PH. Kemper HC. Grobbee DE Methodological aspects of physical activity assessment in epidemiological studies Eur $J$ Epidemiol 1998. 14(1) 63-70

48 Westerterp KR Assessment of physical activity level in relation to obesity current evidence and research issues Med Sa Sports Exerc 1999. 31(11) S522.\$525 
49. Friedenreich CM. Thune I, Brinton LA, Albanes D Epidemiologic issues related to the association between physical activity and breast cancer. Cancer 1998, 83(3 Suppl) $600-10$

50. Hart RW. Dixit R. Seng J, et al: Adaptive role of caloric intake on the degenerative disease processes. Toxicological sciences 1999, 52(2 Suppl): 3-12.

51. Kritchevsky D The effect of over- and undernutrition on cancer. European journal of cancer prevention 1995: 4(6): 445-51.

52. Loft S, Velthuis te Wierik EJ, van den Berg $H$, Poulsen HE Energy restriction and oxidative DNA damage in humans Cancer epidemiology. biomarkers and prevention 1995: 4(5): 515-9

53. Kritchevsky D Caloric restriction and experimental carcinogenesis. Toxicological sciences 1999, 52(2 Suppl) 13-6

54 Lipman JM. Turturro A. Hart RW. The influence of dietary restriction on DNA repair in rodents preliminary study Mech Aging Dev 1989, 48 , 135-43

55 Djuric Z. Depper JB. Uhley V, et al Oxidative DNA damage levels in blood from women at high risk for breast cancer are associated with dietary intakes of meats. vegetables. and fruits J Am Diet Assoc 1998, 98(5) 524-8

56. Djuric L. Lu MH, Lewis S Oxidatieve DNA damage in rats fed low fat. high fat or calonc. restricted diets Toxicol Appl Pharmacol 1992. 115 156-60

57. Hart RW. Turturro A Dietary restriction and cancer Environ Health Perspective 1997; 105(989992).

58. Hankinson SE. Willett WC. Colditz GA et al Circulating concentrations of insulin-like growth factor-1 and risk of breast cancer. The Lancet 1998 351: 1393-1396

59. Stattin P. Bylund A. Rinaldi S, et al: Plasma insulin-like growth factor-I, insulin-like growth factorbinding proteins, and prostate cancer risk: a prospective study. Journal of the National Cancer Institute 2000: 92(23): 1910-1917

60. Chan JM, Stampfer MJ, Giovannucci E, et al. Plasma insulin-like growth factor-l and prostate cancer risk a prospective study. Science 1998 . 279(5350): 563-566

61. Giovannucci $\mathrm{E}$ Insulin and colon cancer. Cancer causes and control 1995, 6(2): 164-79

62. Ma J, Pollak MN, Giovanucci E, Chan JM, Tao Y, Hennekens $\mathrm{CH}$. Prospective study of colorectal cancer risk in men and plasma levels of insulin-like growth factor (IGF-1) and IGF-binding protein-3. J Natl Cancer Inst 1999: 91: 620-625

63 Kaaks R. Toniolo P. Akhmedkhanov A, et al Serum C-peptide, insulin-like growth factor (IGF)-I. IGF-binding proteins, and colorectal cancer risk in women Journal of the National Cancer Institute 2000. 92(19) 1592-1600

64. Dunn SE. Kari FW. French J, et al Dietary restriction reduces insulin-like growth factor I levels. which modulates apoptosis, cell proliferation and tumor progression in p53-deficient mice. Cancer Research 1997: $57: 4667-4672$.

65. Mukherjee P, Sotnikov AV, Mangian HJ. Zhou JR. Visek WJ. Clinton SK. Energy intake and prostate tumor growth, angiogenesis, and vascular endothelial growth factor expression [see comments] J Natl Cancer Inst 1999: 91(6): 512-23

66. Kritchevsky D: Influence of caloric restriction and exercise on tumorigenesis in rats. Proceedings of the Society for Experimental Biology and Medicine 1990 . 193(1): 35-8

67. Yu H, Rohan T: Role of the insulin-like growth factor family in cancer development and progression. Journal Of The National Cancer Institute Sep 2000: 92(18): 1472-1489

68. Stoll BA. Does extra height justify a higher risk of breast cancer? Ann Oncol 1992, 3: 29-30

69. Stoll BA: Essential fatty acids, insulin resistance, and breast cancer risk. Nutr Cancer 1998: 31(1): 72 . 7

70 Stoll BA Western diet, early puberty, and breast cancer risk Breast Cancer Res Treat 1998: 49(3) $187-93$

71 Yu H. Mistry J. Nicar MJ, Khosravi MJ, Diamandis A. Van Doorn J Insulin-like growth factors and insulin-like binding proteins in blood circulation $\mathrm{J}$ Clin Lab Anal 1999, 13 166-72

72. Juul A, Bang P. Hertel NT, Main K, Dalgaard P Jorgensen $K$ : Serum insulin-like growth factor- 1 in 1030 healthy children, adolescents and adults relation to age, sex stage of puberty, testicular size and body mass index J Clin Endocrinol Metab 1994. 78(744-52)

73. Rosenfeld RG, Wilson DM. Lee PD. Hintz RL Insulin-like growth factors I and II in evaluation of growth retardation. J Pediatr 1986: 109:428-33

74. Smith AT, Clemmons DR. Underwood LE, Ben Ezra V. McMurray R. The effect of exercise on plasma somatomedin-C/insulinlike growth factor I concentrations. Metabolism clinical and experimental 1987; 36(6): $533-7$

75. Thissen JP, Ketelslegers JM, Underwood LE: Nutritional regulation of the insulin-like growth factors. Endocrine reviews 1994: 15(1): 80-101

76. Gerber M. Corpet D Energy balance and cancers. Eur J Cancer Prev 1999: $8: 77-89$

77. McArdle WD, Katch FI, Katch VL Exercise physiology, energy, nutrition and human performance. New York: Williams \& Wilkins, 1996

78. Albanes D Height. early energy intake and cancer. BMJ 1998, 317 , 1331-2

79. Bruning PF, Bonfrer JM. Hart AA, et al Body measurements. estrogen availability and the risk of human breast cancer a case-control study. Int J Cancer 1992: 51(1): 14-9

80 Ross RK. Henderson BE Do diet and androgens alter prostatecancer risk via a common etiologic pathway? JNCl 1994, 86 252-4 (editorial)

81 Hoffman Goetz L. Apter D. Demark Wahnefned W. Goran MI. McTiernan A. Reichman ME Possible mechanisms mediating an association between 
physical activity and breast cancer. Cancer 1998. 83(3 Suppl): $621-8$

82. Slattery ML, Potter J. Caan B, et al: Energy balance and colon cancer-beyond physical activity. Cancer Res 1997; 57(1): 75-80

83. Dirx MJM, Voorrips LE, Goldbohm RA, Van den Brandt PA. Baseline recreational physical activity, history of sports participation and postmenopausal breast cancer risk in the Netherlands Cohort Study Cancer 2001, 92 : 1638-49.

84 Bernstein L, Ross RK, Lobo RA, Krailo MD. Henderson BE The effects of moderate physical activity on menstrual cycle patterns in adolscence. implications for breast cancer prevention. Br.J Cancer 1987: $55: 681-5$

85. Frisch RE, Gotz Welbergen AV, McArthur JW, et al. Delayed menarche and amenorrhea of college athletes in relation to age of onset of training Jama 1981: 246(14): 1559-63

86. Moisan J. Meyer F. Gingras S Leisure physical activity and age at menarche. Med Sci Sports Exerc. 1991: 23(10) 1170-5

87 Gann PH. Hennekens CH. Ma J. Longcope C. Stampler MJ Prospective study of sex hormone levels and risk of prostate cancer J Natl Cancer inst 1996, $88(16)$. 1118-1126

88 Albanes D. Blair A. Taylor PR Physical activity and risk of cancer in the NHANES I population. Am J Public Health $1989,79(6) 744-50$

89 Francis K Physical activity breast and reproductive cancer. Compr Ther 1996, 22(2) 94-9

90. Marcus PM. Newman B. Moorman PG. et al Physical activity at age 12 and adult breast cancer risk (United States) Cancer Causes Control 1999; 10(4) 293-302

91. D'Avanzo B. Nanni O. LaVecchia C. et al Physical activity and breast cancer risk. Cancer Epidemiol Biomarkers Prev 1996: $5:$ 155-60

92. Giovannucci E, Ascherio A, Rimm EB, Colditz GA, Stampfer MJ. Willett WC Physical activity, obesity, and risk for colon cancer and adenoma in men. Ann Intern Med 1995; 122(5) 327-34

93 Paffenbarger RS. Jr. Lee IM. Wing AL. The influence of physical activity on the incidence of sitespecific cancers in college alumni. Adv Exp Med Biol 1992, $322,7-15$

94. Gerhardsson M. Floderus B. Norell SE Physical activity and colon cancer risk [see comments] Int J Epidemiol 1988, 17(4) 743-6

95. Martinez ME. Giovannucci E. Spiegeiman D. Hunter DJ. Willett WC Colditz GA Leisure-time physical activity, body size, and colon cancer in women Nurses' Health Study Research Group J Nat! Cancer Inst 1997. 89(13) 948-55

96 Slattery ML. Edwards SL. Ma KN. Friedman GD. Potter JD Physical activity and colon cancer a public health perspective Ann Epidemiol $1997.7(2)$ 137.45 97 Giovannucci E. Leitzmann M. Spiegeiman D, et al A prospective study of physical activity and prostate cancer in male health professionals Cancer Res 1998. 58(22) 5117-22
98. Hartman TJ, Albanes D, Rautalahti M, et al: Physical activity and prostate cancer in the AlphaTocopherol, Beta-Carotene (ATBC) Cancer Prevention Study (Finland). Cancer Causes Control 1998, $9(1): 11-8$

99. Le Marchand L. Kolonel LN Yoshizawa CN: Lifetime occupational physical activity and prostate cancer risk. Am J Epidemiol 1991; 133(2): 103-11

100. Thune I, Lund E Physical activity and the risk of prostate and testicular cancer: a cohort study of 53,000 Norwegian men. Cancer Causes Control $1994 ; 5(6): 549-56$

101. Okasha M, Smith Davey G. McCarron P. McEwen J Adolescent body mass index and cancer risk. European Conference on Nutrition and Cancer. Lyon, 2001

102. Bergstrom A, Pisani P. Tenet V, Wolk A, Adami $\mathrm{HO}$. Overweight as an avoidable cause of cancer in Europe International journal of cancer. Journal international du cancer 2001, 91(3): 421-30

103. Weindruch $R$, Walford $R$. The retardation of aging and disease by dietary restriction. Springfield: Charis C. Thomas, 1988. (Weindruch R, Waiford RL, eds

104 Engeiman RW, Day NK, Good RA Calorie intake during mammary development influences cancer risk. lasting inhibition of $\mathrm{C} 3 \mathrm{H} / \mathrm{HeOu}$ mammary tumorigenesis by peripubertal calorie restriction. Cancer Reserach 1994, $53,5724-30$

105 Walford RL. Mock D, MacCallum T. Laseter JL. Physiologic changes in humans subjected to severe. selective caiorie restriction for two years in biosphere 2 health, aging and toxicological perspectives Toxicological Sciences 1999. 52 (suppl) 61-65

106 Dixit $R$ The role of diet and caloric intake in aging. obesity and cancer Toxicological Sciences 1999. 52 (suppl) 1.2

107 Keys A. Brozek J. Henschel A. Michelsen O. Taylor $\mathrm{HL}$ The biology of human starvation. Vols 1 and 2 Minneapolis University of Minnesota Press. 1950

108 Velthuis-te Wierik EJM Energy restriction and ageing in man Maastricht University. 1995

109. Lumey LH Glucose tolerance in adults after prenatal exposure to famine - Reply Lancet Jun 2001. 357(9270) 1797-1798

110 Mellemkjaer L. Emborg C. Gridley G. et al Anorexia nervosa and cancer risk Cancer Causes Control 2001. 12(2) 173-177

111 Michels KB. Trichopoulos D. Robins JM, et al Birthweight as a risk factor for breast cancer Lancet 1996, 348(9041) 1542-6

112. Holly $J$ Insulin-like growth factor-I and new oppurtunities for cancer prevention The Lancet 1998. $351 \quad 1373-4$ 
100 


\section{Summary}

In the introduction (chapter 1) a description of the food situation during the Economic Depression years (1932-40) and World War II (1940-1945) is given, with specific emphasis on the so called Hunger winter of 1944-45. Energy restriction in childhood and adolescence and the risk of breast, prostate and colon cancer is the main topic of this thesis. The hypothesis relating energy restriction to the risk of cancer is supported by longstanding results from animal experiments documenting a reduced risk of cancer in rodents on an energy-restricted dietary regimen. To evaluate the hypothesis that early energy restriction protects against subsequent cancer development, several studies have been conducted.

First, a meta-analysis was conducted to review the results from animal studies regarding energy restriction and the development of mammary tumors. Three studies described in this thesis utilized the unique setting in the Netherlands, a Western population where a substantial part of the population experienced a severe famine during the last year of World War II (1944-45), the so called Hunger Winter. The Dutch famine can be considered as a unique natural 'experiment of history' to test the hypothesis that energy restriction early in life may be protective for breast, prostate and colon cancer risk later in life. The Netherlands Cohort Study on diet and cancer (NLCS) provided an opportunity to study the relation between early energy restriction and subsequent cancer risk. Furthermore, we evaluated the association between physical activity and breast cancer.

The purpose of the meta-analysis described in chapter 2 was to systematically review the animal literature on energy restriction and mammary tumors and to provide precise quantitative pooled estimates of the risk of mammary tumors. The meta-analysis had an emphasis on type and degree of restricted nutrient (fat, protein or carbohydrate) and duration of intervention period. The age at which the energy restriction took place had our special interest because energy restriction early in life may affect breast cancer risk. We performed a literature search and restricted the metaanalysis to experiments with mice and spontaneous mammary tumors because of the comparability. A criteria list was developed and the reviewers used this list to assess quality items (i.e. study characteristics). Potential factors for heterogeneity in results between studies were assessed. All publications were scored in a blind way. A total number of fourteen studies were included in the meta-analysis. The pooled risk difference for the 14 studies was $-0.55(95 \% \mathrm{Cl}-0.69 ;-0.41)$, implicating that the energy restricted animal groups developed $55 \%$ less mammary tumors than the control groups. irrespective of the type of restricted nutrient and/or other study characteristic. No significant heterogeneity in results between the animal studies was detected.

The Netherlands Cohort Study on diet and cancer (NLCS) started in 1986, when a cohort of 58,279 men and 62,573 women, aged 55-69 years. was recruited from 204 municipal population registries in the Netherlands. With the unique nutritional situation experienced by this cohort during World War $I I$ in mind, the NLCS also collected information on the food situation during childhood and adolescence of the cohort members. In the baseline questionnaire, information was collected about their residence during the Hunger winter (194445), their residence during the War years (194044) and if their father was employed during the Economic Depression years (1932-40) Residence history and father's employment status were used as proxy measures for the energy restriction to which the participants of the cohort were exposed during their childhood and adolescence. The exposure variable for the Economic Depression years was dichotomous men and women whose father had or had no job. For the other two periods, the War period (1940-1944) and the Hunger winter (19441945), the city of residence during these periods was used to approximate the exposure for energy restriction. For the war years, the exposure variable was dichotomous. men and women living in a city or living in a rural area in 1942. With respect to the Hunger winter, three categories were defined, living in a Western city. living in a Western rural area and living in a Non-Western part of The Netherlands. Living in a Western city in 1944-1945 was considered as an indicator for severe energy restriction In the NLCS. follow-up for incident cancer has been established by record linkage with the national cancer registry in the Netherlands and with a national pathology register (PALGA). In 
the studies described in this thesis we made use of 6.3 and 7.3 years of follow-up.

The results regarding energy restriction in childhood and cancer of breast, prostate and colon are described in chapters 3, 4 and 5. respectively. We found no association between breast cancer risk and energy restriction early in life after 6.3 years of follow-up. Women who had been living in a Western city during the Hunger winter of 1944-1945 had no decreased breast cancer risk. With respect to the war period (1940-1944) no differences in breast cancer risk were found for women who lived in a city (food restricted area) in 1942 vs. women who lived in a rural area. Having an unemployed father during the Economic Depression years 19321940 was associated with a small, but nonsignificant, decrease in breast cancer risk $(R R=0.9)$ (chapter 3). There are biological reasons to believe that the period between the beginning of breast development at puberty and the first full term pregnancy is a particular sensitive period in a woman's life regarding the development of breast cancer. We paid particular attention to those women who were exposed to energy restriction between menarche and delivery of their first child. No clear association was found between energy restriction during this sensitive period and breast cancer risk.

With regard to prostate cancer, the results showed a slightly elevated prostate cancer risk among men who had lived in the presumably food restricted regions such as western cities and western rural areas during the Hunger winter 1944-1945, compared with controls living in northern and southern parts of the Netherlands who had almost no exposure to energy restriction. No association was seen with respect to the other War years or the Economic Depression years (chapter 4). Exposure to energy restriction during the adolescent growth spurt showed no association for men who had lived in a Western city during the Hunger winter, after 7.3 years of follow-up.

An inverse association was found between colon cancer risk and energy restriction in adolescence for men and women. Men and women living in a Western city during the Hunger winter (1944-45) had a rate ratio of 0.85 and 0.80 , respectively. For men living in a Western rural area in 1944-1945 also a decreased risk was observed and for women living in a Western rural area no difference was observed. With respect to exposure during the remaining years of World War II (1940-44) no differences in colon cancer risk were found for both men and women who lived in a city (food restricted area) in 1942 vs. men and women who lived in a rural area in 1942. Having an unemployed father during the Economic Depression years $1932-40$ was associated with a small, but non-significant, decrease in colon cancer risk both for men and women. Results of the subgroup analyses showed that men and women who were in their adolescent growth spurt and living in a Western city during the Hunger winter 1944-45 or who were exposed after their adolescent growth spurt to the Hunger winter 1944-45, had a decreased colon cancer risk compared to men and women living in the non-Western parts of the Netherlands (chapter 5).

Energy balance results from the interaction between energy intake and energy expenses. Energy imbalance seems to be an important factor regarding the etiology of breast, prostate and colon cancer. Energy imbalance is characterized by obesity and sedentary life styles and is associated with increased morbidity and mortality from all causes of cancer. The interaction between energy restriction, physical activity and BMI may explain part of the observed inconsistencies between studies on physical activity and cancer.

In chapter 6 the association between breast cancer risk and physical activity was examined. Baseline recreational physical activity (1986) showed an inverse association with breast cancer risk after 6.3 years of follow-up. Especially daily walking and biking more than an hour a day showed a protective effect. Women who were ever engaged in sports before baseline did not have a lower breast cancer risk. No relation was found for duration of the sport activity (in years) and breast cancer risk. Women who spent more than 5 hours per week participating in a sport had a reduction in breast cancer risk compared to women who spent less than 1 hour per week on sports, irrespective of duration. We found no association between occupational physical activity and breast cancer risk. We could not distinguish a specific period in life in which the association between sports activity and breast cancer risk was more pronounced; thus the age at which women participate in sports seems not relevant 
Furthermore, in the subgroup of women with overweight (BMI 25-30), we found a decreased breast cancer risk with physical activity independent of baseline energy intake.

In the discussion (chapter 7) these results were evaluated and compared to other studies. The potential for selection bias in the NLCS is low. However, a factor that could have influenced the results is misclassification of food restriction exposure and the misclassification of physical activity. We used the residence during the War years (1940-1944) and the Hunger winter (19441945 ) and the father's employment status during the Economic Depression years (1932-1940) as proxy measures for the food situation of our cohort members in their youth. We attempted to validate the residence in the Hunger winter (1944-1945) among subcohort members. Of the women who reported severe hunger during the Hunger winter $80 \%$ lived in a Western city during this winter

The NLCS was not specifically designed to explore the relation between physical activity and cancer risk. In our study we had only data available on physical activity by questionnaire and no other physiological and biomechanical measurements. If misclassification is present, it will be nondifferential because of the prospective design of the cohort.
The role of insulin-like growth factor-1 (IGF-1), which may be a common biological mechanism relevant for breast, prostate and colon carcinogenesis was discussed. A variety of physiologic, behavioural and genetic variables are altered when there is a reduction in energy intake. Energy restriction inhibits cell proliferation, accelerates apoptosis, enhances DNA-repair and leads to a reduction in IGF-1. Insulin and IGF-1 regulate the energy metabolism and might be the common biological mechanism relevant for breast. prostate and colon cancer carcinogenesis. The possible interaction between energy intake, energy expenditure and obesity is discussed. Implications for public health and further research are stated. These recommendations concentrate on the level of energy restriction. cancer biomarkers and intermediate endpoints and on the role of early nutrition in the etiology of other diseases than cancer. 
104 


\section{Samenvatting}

In de inleiding van dit proefschrift wordt een beschrijving gegeven van de voedselvoorziening tijdens de crisisjaren (1932-40) en de oorlogsjaren (1940-45), met speciale aandacht voor de hongerwinter van 1944-45. In dit proefschrift wordt beschreven wat de invloed van energierestrictie in de jeugd is op het ontstaan van kanker op latere leeftijd. De hypothese dat energierestrictie in de jeugd en adolescentie beschermt tegen het ontstaan van kanker wordt sinds lange tijd ondersteund door resultaten uit dierexperimenteel onderzoek. Vele studies hebben aangetoond dat dieren die een energiebeperkt dieet kregen minder tumoren ontwikkelden in vergelijking met dieren die een normale voeding kregen. Om de hypothese te onderzoeken zijn een aantal onderzoeksprojecten uitgevoerd

Ten eerste is een literatuuronderzoek (metaanalyse) uitgevoerd om de resultaten van de verschillende dierexperimentele studies met elkaar te kunnen vergelijken. Deze dierstudies hadden als onderwerp de invloed van energierestrictie op het ontstaan van borsttumoren. Verder zijn 3 studies uitgevoerd die gebruik hebben gemaakt van de unieke situatie in Nederland, waarin de Hongerwinter 1944-1945 als een soort van natuurlijk experiment beschouwd kan worden. Tijdens deze periode leed een substantieel deel (vooral mensen die woonden in de Westerse provincies) van de Nederlandse bevolking aan ondervoeding. Door dit 'natuurlijke' experiment is het mogelijk geweest om de hypothese dat energierestrictie tijdens de jeugd beschermt tegen kanker op latere leeftijd te kunnen bestuderen. De Nederlandse Cohort Studie naar voeding en kanker (NLCS) bood de mogelijkheid om de relatie tussen energierestrictie en het latere kankerrisico te onderzoeken. Verder is onderzocht of lichamelijke activiteit een preventieve werking heeft in relatie tot het borstkankerrisico

In hoofdstuk 2 wordt de meta-analyse beschreven die als doel had om op een systematische manier de literatuur samen te vatten met betrekking tot energierestrictie en borsttumoren bij muizen. Verder bood deze meta-analyse een gepoolde kwantitatieve effectmaat en kon de invioed van verschillende studiekarakteristieken zoals duur van de interventie, type interventie (vet-, koolhydraat- of eiwitbeperkt dieet) en de mate van restrictie bekeken worden. De leeftijd waarop de muizen het energiebeperkte dieet kregen kreeg speciale aandacht aangezien energierestrictie tijdens de jeugd het latere borstkankerrisico mogelijk kan beinvloeden. De dierexperimentele literatuur is verzameld via de literatuurbestanden van Medline, Current Contents en door deskundigen in het veld te raadplegen. Daarnaast zijn de referentielijsten van relevante publicaties doorzocht. Om vergelijkbaarheid te verkrijgen heeft de meta-analyse zich uiteindelijk geconcentreerd op studies met alleen muizen en spontane (niet-geìnduceerde) mammae tumoren. $\mathrm{Er}$ is een criterialijst ontwikkeld om de kwaliteitskenmerken van elke publicatie te kunnen evalueren. Uiteindelijk zijn 14 studies opgenomen in de meta-analyse. De gepoolde effectmaat bedroeg -0.55 hetgeen betekent dat de groepen muizen die een energie beperkt dieet kregen $55 \%$ minder borsttumoren ontwikkelden dan de controlegroepen. onafhankelijk van welk nutrient beperkt was en van andere studiekarakteristieken. Verder kon geen heterogeniteit tussen de resultaten van de verschillende dierstudies aangetoond worden.

De Nederlandse Cohort Studie naar voeding en kanker (NLCS) bood de mogelijkheid om te onderzoeken of energierestrictie in de jeugd inderdaad een verband vertoont met het kankerrisico op latere leeftijd. Deze cohortstudie is gestart in september 1986. In dit cohort zitten ruim 120.000 Nederlanders (58.279 mannen en 62.573 vrouwen) uit 204 gemeentes verdeeld over heel Nederland. Deze mannen en vrouwen waren in 1986 tussen de 55 en 69 jaar oud. Dit cohort heeft dus die unieke voedingssituatie (hongerwinter 1944-1945) in hun jeugd meegemaakt Tijdens de baselinemeting in 1986 is dan ook specifiek gevraagd naar de woonplaats in 1944-45, de woonplaats tijdens de oorlogsjaren (1940-44) en of de vaders van de cohortdeeinemers wel of geen werk hadden tijdens de crisisjaren (1932. 1940). De woonplaats tijdens hongerwinter en oorlogsjaren en het wel of niet werkloos zijn van de vader in de crisisjaren zijn gebruikt als proxymaten voor energierestrictie in de jeugdjaren. Voor de economische crisisjaren is de expositievariabele gedichotomiseerd: de vaders hadden wel of geen werk tijdens deze periode. Voor de oorlogsjaren is de expositievariabele ook gedichotomiseerd cohortdeeinemers woonden 
in een stad of op het platteland in 1942. Met betrekking tot de hongerwinter 1944-45 zijn drie categorieên gedefinieerd, namelijk wonen in een stad in het Westen, wonen op het platteland in het Westen of niet in het Westen wonen. Het wonen in een stad in het Westen tijdens de hongerwinter 1944-45 wordt beschouwd als indicator voor blootstelling aan een erge mate van energierestrictie tijdens de jeugd.

De kanker follow-up vond plaats door jaarlijkse koppelingen met de regionale kankerregistraties in Nederland en met PALGA (Pathologisch Landelijk Geautomatiseerd Archief). In de studies is gebruikt gemaakt van gegevens over 6.3 jaar en 7.3 jaar follow-up.

In de hoofdstukken 3,4 en 5 worden achtereenvolgens de studies besproken die onderzocht hebben of energierestrictie in de jeugd een associatie vertoont met het latere borst-, prostaat- en colonkanker risico. Op basis van de resultaten uit hoofdstuk 3 kunnen we concluderen dat er geen relatie bestaat tussen energierestrictie in de jeugd en het latere borstkankerrisico. Vrouwen die tijdens de hongerwinter in een stad in het Westen hadden gewoond hadden geen verlaagd borstkankerrisico vergeleken met vrouwen die niet in het Westen hadden gewoond tijdens de hongerwinter 1944-45. We vonden geen verschil in borstkankerrisico tussen vrouwen die in 1942 in een stad of op het platteland woonden. Vrouwen waarvan de vader werkloos was tijdens de economische crisisjaren hadden een niet significante verlaging van het borstkankerrisico $(R R=0.9)$. Er wordt beweerd dat de periode tussen de eerste menstruatie (menarche) en de eerst-voldragen zwangerschap een gevoelige periode is voor wat betreft het borstkankerrisico. Extra analyses zijn verricht met speciale aandacht voor vrouwen die tijdens deze gevoelige periode (tussen menarche en geboorte eerste kind) blootgesteld waren aan de hongerwinter. Er werd geen verband gevonden tussen blootstelling gedurende deze gevoelige periode en het borstkankerrisico.

Met betrekking tot prostaatkanker tonen de resultaten een licht verhoogd prostaatkankerrisico voor mannen die tijdens de hongerwinter in een stad in het Westen woonden ten opzichte van mannen die in het Noorden en Zuiden woonden. Voor de andere twee periodes, oorlogsjaren en crisisjaren, werd geen verband gevonden met prostaatkankerrisico (hoofdstuk 4). Specifieke aandacht ging uit naar de mannen die tijdens hun groeispurt waren blootgesteld aan de hongerwinter. Er werd geen verband gevonden tussen blootstelling aan de hongerwinter tijdens deze groeispurt en het prostaatkankerrisico.

We hebben een negatief verband gevonden tussen colonkankerrisico en energierestrictie in de jeugd, zowel voor mannen als voor vrouwen. Mannen en vrouwen die tijdens de hongerwinter (1944-45) in een stad in het Westen woonden hebben een rate ratio van respectievelijk 0.85 en 0.80 . Voor mannen die op het platteland in het Westen woonden tijdens de hongerwinter werd ook een verlaagd risico op colonkanker gevonden. Voor vrouwen die op het platteland in het Westen woonden tijdens de hongerwinter werd er geen verband gevonden. Voor blootstelling tijdens de oorlogsjaren vonden we geen verband tussen energierestrictie en colonkankerrisico, zowel niet voor mannen als voor vrouwen. Mannen en vrouwen die een werkloze vader hadden in de crisisjaren 1932-40 hebben een klein, niet significant verlaagd risico op colonkanker ten opzichte van mannen en vrouwen waarvan de vader wel werk had tijdens de crisisjaren. Resultaten van de subgroepanalyses laten zien dat mannen en vrouwen die tijdens hun groeispurt de hongerwinter meemaakten en woonden in een stad in het westen een verlaagd colonkankerrisico hadden in vergelijking met mannen en vrouwen die niet in het Westen woonden tijdens de hongerwinter (hoofdstuk 5).

Energiebalans is de resultante van de interactie tussen energie-inname aan de ene kant en energiegebruik aan de andere kant. Het niet in balans zijn van de energie-inname en het energiegebruik zou wel eens een belangrijke factor kunnen zijn in het ontstaan van borst-, prostaat- en colonkanker. Overgewicht (of obesitas) en een zittende levensstijl zijn kenmerken van een energie-dysbalans en worden geassocieerd met verhoogde ziekte en sterfte aan allerlei kankersoorten. De interactie tussen energierestrictie, lichamelijke activiteit en body mass index (BMI) kan gedeeltelijk de inconsistenties verklaren tussen de studies naar lichamelijke activiteit en kanker.

In hoofdstuk 6 is de relatie tussen lichamelijke activiteit en het borstkankerrisico nader onderzocht in de NLCS. Hedendaagse (in 1986) recreatieve lichamelijke activiteit laat een daling zien in het borstkankerrisico na 6.3 jaar follow- 
up. Vooral het dagelijkse wandelen en fietsen van meer dan 1 uur laat een beschermend effect zien ( $R R=0.81$ ). Vrouwen die vroeger ooit een sport beoefend hadden, hebben geen lager borstkankerrisico vergeleken met vrouwen die nooit gesport hadden. We vonden geen relatie met het aantal jaren dat een sport beoefend werd en het borstkankerrisico. Vrouwen die meer dan 5 uur per week gesport hadden, hebben een reductie van het borstkankerrisico vergeleken met vrouwen die minder dan 1 uur sporten per week, onafhankelijk van het aantal jaren dat een sport beoefend werd. We konden geen specifieke periode in het leven van de vrouwen onderscheiden waarin de relatie tussen sportactiviteiten en het borstkankerrisico er anders uitzag. Met andere woorden het lijkt erop dat de leeftijd waarop er gesport is niet van belang is met betrekking tot borstkanker. Verder hebben we speciale aandacht gericht op vrouwen met overgewicht (BMI 25-30) en vonden we voor deze vrouwen een verlaagd borstkankerrisico in relatie tot lichamelijke activiteit, onafhankelijk van de baseline energie inname

Het laatste hoofdstuk (hoofdstuk 7) geeft een beschouwing van de resultaten van de afzonderlijke studies en vergelijkt deze met andere studies. De mogelijkheid van selectie bias is klein in de NLCS. Maar een factor die de resultaten heeft kunnen beïnvloeden is de misclassificatie van de blootstelling aan de hongerwinter en missclassificatie van lichamelijke activiteitenpatroon van de cohortdeelnemers. We hebben de woonplaats tijdens de hongerwinter en oorlogsjaren gebruikt en de werkeloosheidsstatus van de vaders in de crisisjaren (1932-40) als indicator voor de voedingstoestand tijdens de jeugd van de cohortdeeinemers. De woonplaats in 1944-45 hebben we getracht om te valideren in het subcohort. Hieruit bleek dat $80 \%$ van de vrouwen die erge honger rapporteerden, in een stad in het Westen woonden tijdens de hongerwinter (1944-45).

De NLCS is destijds opgezet om specifiek onderzoek te doen naar de relatie voeding en kanker. Het onderzoeken van de relatie lichamelijke activiteit en kankerrisico was geen expliciete doelstelling. Dit betekende dat we alleen beschikbare data uit de vragenlijst hadden over lichamelijke activiteit en geen extra fysieke of biomechanische data. Maar mocht er misclassificatie zijn opgetreden dan zal dit nondifferentieel zijn omdat het een prospectieve cohort studie betreft.

De mogelijke rol van insuline groeifactor I (IGF1), die een mogelijke biologische rol speelt in het ontstaan van borst-, prostaat-, en colonkanker, is bediscussieerd. Beperking van de energie-inneming (energierestrictie) zorgt ervoor dat een aantal variabelen veranderd worden. Energierestrictie leidt tot remming van celdeling, versnelt de celdood, stimuleert DNAherstel en kan leiden tot een reductie van IGF-1. Insuline en IGF-1 reguleren het energiemetabolisme en kunnen dan ook mogelijkerwijs een rol spelen in het ontstaan van borst-, prostaat- en colonkanker. De mogelijke interacties tussen energie inname, energiegebruik en obesitas wordt bediscussieerd. Verder worden er aanbevelingen voor de volksgezondheid gedaan en worden suggesties voor verder onderzoek uitgewerkt. Dit verdere onderzoek zou zich moeten concentreren op welk niveau van energierestrictie voor de humane situatie geschikt is, op biomarkers voor kanker en intermediaire eindpunten en zou verder de rol van vroege voeding moeten bekijken in relatie tot het ontstaan van andere ziektebeeiden. 
108 


\section{Dankwoord}

Een dankwoord schrijven na 10 jaar gewerkt te hebben bil de vakgroep Epidemiologie is geen gemakkelijke klus. 10 jaar Epidemiologie!!!

Wat een tijd, zullen veel mensen zeggen, maar voor mezelf lijkt het niet eens de helft van de tijd. Er gebeurt in die jaren heel veel op je werkplek, heel veel leuke dingen en at en toe ook minder leuke dingen. Collega's vertrekken maar er komen ook weer nieuwe mensen bil. It's all part of living and working. In dit dankwoord wil ik een aantal mensen graag apart bedanken, daarbij wetende dat ik wellicht een aantal mensen zal vergeten.

Ten allereerste het thuisfront. Bert, bedankt voor alle ondersteuning die je maar kon geven. Het laatste jaar was voor jou een ommekeer in je werk en dit betekende voor mij dat elke dag het eten klaar stond en de kinderen opgehaald waren als ik thuiskwam. Wat een relaxte omgeving om je proefschrift af te schrijven zonder te hoeven nadenken over de organisatie van je privé-leven. Ik zal zelf in de toekomst weer vaker het keukenshort aantrekken.

Tim en Luka zorgden voor de nodige relativering van de arbeidsstress. Tevens hadden en hebben we de beschikking over een geweldig oppasgezin. Marie-Louise (oppasmoeder) hartstikke bedankt!!

In 1986 is de Nederlandse Cohort Studie naar voeding en kanker (NLCS) gestart en nog steeds ben ik blij dat ruim 120.000 Nederlanders toen die behoorlijk lange vragenlijst hebben ingevuld. Zonder hun bijdrage aan dit grote onderzoek was dit proefschrift er nooit gekomen. Nogmaals dank aan al die mensen!!

Mijn promotietraject was een weg met vallen en opstaan. En zeker in het begin was ik dagelijks de weg kwijt en heb zelfs gedroomd over de NLCS, SPSS, GLIM, stroomschema's, alpha's en allerlei andere ingewikkelde zaken. Mijn promoter en co-promotoren hebben me vooral in deze fase steeds weer op het rechte pad gezet.

Piet (van den Brandt), als promotor en projectleider van de NLCS, je was steeds zeer betrokken bij mijn problemen. En ik heb je dan ook als een grote stimulator steeds beschouwt achter mijn projecten. Inhoudelijke besprekingen met jou leverden altijd wel weer nieuwe ideeên en vragen op, zodat ik weer met volle moed naar mijn kamer terugliep.
Bertie (Lumey), als co-promoter zeer betrokken bij de projecten over de hongerwinter. Bertie, je was vanaf het begin zeer begaan met de projecten en ik heb je leren kennen als iemand waarmee het op een plezierige manier samen werken is (ook al is dat op een afstand). Ik hoop dat in de toekomst deze samenwerking gecontinueerd gaat worden.

Sandra (Bausch), als co-promoter en projectleider van de NLCS, steeds meer aanwezig op de achtergrond. Jouw inhoudelijke bijdragen in het begin van dit promotie-traject waren zeer waardevol.

De directe (ex)-collega's binnen de NLCS zorgden er steeds voor dat het spreekwoord. gedeelde smart is halve smart, echt klopte. Elisabeth Dorant, Jeanne van Loon, Agnes Schuurman, Anita Botterweck, Matty Weijenberg. Mirian Brink, Margreet Lochtenborg. Boukje van Dijk, als dames van het NLCS-cohort, bedankt voor alle leuke gesprekken over werk, andere zaken en alle gezellige etentjes

Sacha van de Crommert heeft me wegwijs gemaakt in de data-structuur van de NLCS. En geen enkele vraag was haar teveel, Sacha bedankt!

De heren van het cohort Leo Schouten. Ton van Moergastel en Harry van Montfort wil ik hierbif ook bedanken voor de plezierige sfeer binnen de NLCS. Maurice Zeegers, is de drijvende kracht achter hoofdstuk 2 van dit proefschrift Maurice, bedankt voor je jeugdig enthousiasme en hopelijk blijft dit in de toekomst ook zo, ook al word jij natuurlijk ook ouder

Conny de Zwart, Marijke Moll, Patricia Florax en Jolanda Nelissen wil ik bedanken voor al die vragenlijsten die ingevoerd werden en voor al die uurtjes in die vochtige en niet al te schone kelder. Zonder jullie invoer had ik geen databestanden om te analyseren En de rode pen van Jolanda verricht wonderen

TNO-voeding in Zeist draagt ook het nodige bij aan de NLCS zowel wat betreft de invoer van vragenlijsten als inhoudelijke bijdragen. Willy van Dijk, Henny Brants, Linda van de Bosch. Laura Voorrips en alle anderen, bedankt hiervoor

Tevens wil ik de andere (ex)-collega's van de vakgroep ook bedanken voor de plezierige samenwerking en gezellige werksfeer die op de 
vakgroep heerst. Met velen heb ik afgelopen jaren wel op de een of andere manier samengewerkt.

Erik (van Rossum), vanaf de eerste dag dat ik bij Epidemiologie kwam werken, maakte jij me al duidelijk dat het vooral belangrijk was om een goede pot koffie te kunnen zetten. Ik hoop dat we nog vele jaren onze gezamenlijke liefde voor Volvo Amazones mogen delen.

Mijn (ex)-kamergenoten, Myriam Draad, Gerrie Bours, Arianne Verhagen en Ludovic van Amelsvoort maakten het altijd weer aangenaam om op het werk te komen.

Sandra Beurskens, Marielle Kroese, Nicole Janssen, Danielle Mohren, Veron Schrijnemakers. IJmert Kant, bedankt voor steeds weer jullie belangstelling zowel voor het wel en wee van het onderzoek, maar ook voor andere aspecten van het leven.

De drie-eenheid, Raymond (Ostelo), Marcus (Huibers) en Edwin (Wagena), wil ik graag bedanken voor hun opbeurende woorden. inspirerende gespekken en hun kijk op de wetenschap en het leven. Ik hoop dat we nog vele dineetjes samen kunnen nuttigen, toneelstukken bezoeken en glaasjes wijn samen kunnen drinken.
Ute (Bültmann), jou wil ik hier graag speciaal bedanken, vooral voor de laatste fase van mijn proefschrift. We hadden al een band door ons gezamenlijk handbalverleden en dit is het afgelopen jaar alleen maar sterker geworden omdat we ook beiden in het afrondingsjaar van onze promotie zaten. Ik ben blij dat ik jou heb leren kennen niet alleen als collega maar ook als vriendin. En ik vind het dan ook erg leuk dat jii vandaag hier naast me staat als paranimf. En met de ander paranimf, mijn zus, is het handbaltrio compleet. Verder wil ik al mijn familie en vrienden bedanken die bij tijd en wijle echt geïnteresseerd waren in het reilen en zeilen van mijn onderzoek en aan mij vroegen hoever het "boekje" al klaar was. Bedankt voor jullie steun en luisterende oren.

Als laatste maar natuurlijk niet de minst belangrijke, wil ik toch mijn ouders, pap en mam, bedanken. Jullie hebben mij de mogelijkheden gegeven om te gaan studeren en jullie stonden altijd achter mijn keuzes, ook al waren jullie het er niet altijd mee eens. 


\section{Curriculum Vitae}

Miranda Dirx werd geboren op 4 april 1967 in Beek. Na het behalen van het atheneum $A$. diploma aan de Scholengemeenschap St. Michiel te Geleen (1985) volgde zij de studie Gezondheidswetenschappen met als afstudeerrichting Gezondheidsvoorlichting en Opvoeding aan de Universiteit Maastricht. Zij behaalde haar doctoraal diploma in 1989. Tijdens haar afstudeeronderzoek specialiseerde zij zich in de epidemiologie en voerde een patiênt-controle onderzoek uit naar de etiologie van handbalblessures bij de Stichting Consument en Veiligheid te Amsterdam. Zij werkte vervolgens van augustus 1989 tot en met juni 1990 bij de Stichting Consument en Veiligheid te Amsterdam aan het opzetten van een grote landelijke voorlichtingscampagne: "Blessures, blijf ze de baas". In augustus 1990 startte zij als docente communicatie en voorlichtingskunde aan de toenmalige THW/Diêtetiek opleiding te Heerlen (nu Facilitaire Dienstverlening) tot en met augustus 1993.
Vanaf augustus 1991 combineerde zij deze baan met een baan bij de vakgroep Epidemiologie aan de Universiteit Maastricht als toegevoegd docent. Sinds 1995 is zij werkzaam als universitair docent bij dezelfde vakgroep en sindsdien is ze ook betrokken bij de Nederlandse Cohort Studie naar voeding en kanker. Zii voerde binnen deze Cohort Studie enkele onderzoeksprojecten uit zoals beschreven in dit proefschrift. In juni 2000 behaalde zij de posterprijs van het jaarlijkse wetenschappelijke epidemiologie congres in Nederland (WEON) met als onderwerp "Energy restriction in childhood and adolescence and the risk of prostate cancer: results of the Netherlands Cohort Study". Haar postacademische opleiding bestond uit het volgen van verschillende epidemiologische cursussen. Tevens voert zij de nodige onderwijstaken uit binnen de faculteit Gezondheidswetenschappen. 
Energy restriction in childhood, physical activity and the risk of breast, prostate and colon cancer

\section{Miranda J.M. Dirx}

Energy restriction in childhood may have an impact on cancer risk later in life. The Dutch famine 1944-45, though a historical disaster, provided a unique setting to study effects of energy restriction in childhood and adolescence on subsequent cancer risk. In this thesis we investigated the hypotheses regarding energy restriction and the risk of breast, prostate and colon cancer, in the Netherlands Cohort Study on diet and cancer. Furthermore, physical activity might have a protective effect on breast cancer risk. Our findings suggest that energy restriction in childhood do not affect breast and prostate cancer risk later in life. For colon cancer we found a protective effect of early energy restriction. Physical activity is inversely associated with breast cancer in postmenopausal women.

Energierestrictie in de jeugd kan leiden tot een verminderd kankerrisico op latere leeftijd. De Hongerwinter van 1944-45 bood een unieke kans om de effecten van energierestrictie in de jeugd op het latere kankerrisico te kunnen onderzoeken. In dit proefschrift hebben we de hypothesen met betrekking tot energierestrictie en het risico op borst-, prostaat- en dikke darmkanker onderzocht in de Nederlandse Cohort Studie naar voeding en kanker. Verder hadden we ook nog het vermoeden dat lichamelijke activiteit beschermt tegen het krijgen van borstkanker. Onze resultaten laten zien dat we geen relatie konden vinden tussen energierestrictie in de jeugdjaren en het risico op borst- en prostaatkanker. Voor het risico op dikke darmkanker vonden we een beschermende werking van energierestrictie in de jeugd. Lichamelijke activiteit laat een verlaging van het borstkankerrisico zien. 